\title{
Anisotropic conduction and ventricular tachycardia
}

Citation for published version (APA):

Schalij, M. J. (1988). Anisotropic conduction and ventricular tachycardia. [Doctoral Thesis, Maastricht University]. Rijksuniversiteit Limburg. https://doi.org/10.26481/dis.19880527ms

Document status and date:

Published: 01/01/1988

DOI:

10.26481/dis. $19880527 \mathrm{~ms}$

Document Version:

Publisher's PDF, also known as Version of record

\section{Please check the document version of this publication:}

- A submitted manuscript is the version of the article upon submission and before peer-review. There can be important differences between the submitted version and the official published version of record.

People interested in the research are advised to contact the author for the final version of the publication, or visit the DOI to the publisher's website.

- The final author version and the galley proof are versions of the publication after peer review.

- The final published version features the final layout of the paper including the volume, issue and page numbers.

Link to publication

\footnotetext{
General rights rights.

- You may freely distribute the URL identifying the publication in the public portal. please follow below link for the End User Agreement:

www.umlib.nl/taverne-license

Take down policy

If you believe that this document breaches copyright please contact us at:

repository@maastrichtuniversity.nl

providing details and we will investigate your claim.
}

Copyright and moral rights for the publications made accessible in the public portal are retained by the authors and/or other copyright owners and it is a condition of accessing publications that users recognise and abide by the legal requirements associated with these

- Users may download and print one copy of any publication from the public portal for the purpose of private study or research.

- You may not further distribute the material or use it for any profit-making activity or commercial gain

If the publication is distributed under the terms of Article $25 \mathrm{fa}$ of the Dutch Copyright Act, indicated by the "Taverne" license above, 



\title{
ANISOTROPIC CONDUCTION AND VENTRICULAR TACHYCARDIA
}

\section{Proefschrlit}

\author{
ter verkrijging van de graad van doctor \\ aan de Rijksuniversiteit Limburg te Maastricht, \\ op gezag van de Rector Magnificus, Prof. Dr. F.I.M. Bonke, \\ volgens het besluit van het College van Dekanen, \\ in het openbaar te verdedilgen \\ op vrijdag 27 mel 1988 om 16.00 uur.
}

door

Martin Jan Schali]

geboren op 25 Januari 1958 te Haarlem 
Promotores: Prof. Dr. M.A. Allessie

Prof. Dr. F.I.M. Bonke

Beoordelingscommissie:

Prof. Dr. H.J.J. Wellens

Prof. Dr. H.A.J. Struyker Boudier

Dr. F.J.L. van Capelle, Universiteit van Amsterdam

Prof. A.L. Wit, PhD, Columbla University, New York

Prof. Dr. Ir. A. Hasman

This investigation was supported by the Foundation of Medical Research MEDIGON (Grant 900-516-091)

Financlal support by the Netherlands Heart Foundation for the publication of this thesis is gratefully acknowledged.

Ontwerp omslag: Jan Schali], Hulshorst. Layout: H. Jas Druk: Elinkwijk, Utrecht 
Ter nagedachtenis aan Martin Bakkes

Dankzij mijn ouders

Voor Nlcoline 



\section{CONTENTS}

$\begin{array}{lll}\text { Chapter 1: Introduction } & 1\end{array}$

1.1 Anisotropic impulse conduction 1

1.2 Structure of ventricular myocardium 2

1.3 Conduction of the cardiac Impulse in anisotropic myocardium 4

$\begin{array}{ll}1.4 \text { Reentrant excitation } & 10\end{array}$

1.5 Reentrant excitation as a mechanism of sustailned ventricular tachycardia 12

$\begin{array}{ll}1.6 \text { Alm of the study } & 14\end{array}$

$\begin{array}{lll}\text { Chapter 2: } & \text { Anisotropic conduction and the wavelength of refractori- } \quad 17\end{array}$ ness in the rabbit ventricle. The effects of rate, premature beats, potassium, temperature, epinephrine and lidocaine

2.1 Introduction

2.2 Methods 18

2.3 Results $\quad 22$

2.4 Discussion $\quad 35$

Chapter 3: Anisotropic conduction block in the epicardial layer of 43 the left rabbit ventricle

3.1 Introduction $\quad 43$

3.2 Methods $\quad 45$

$\begin{array}{ll}3.3 \text { Results } & 48\end{array}$

3.4 Discussion $\quad 68$ 
Chapter 4: Anisotropic reentry as a mechanism of sustained ven- $\quad 73$ tricular tachycardia

$\begin{array}{ll}4.1 \text { Introduction } & 73\end{array}$

$\begin{array}{ll}4.2 \text { Methods } & 74\end{array}$

$\begin{array}{ll}4.3 \text { Results } & 76\end{array}$

$\begin{array}{lll}\text { Chapter 5: General discussion } & 95\end{array}$

5.1 Initlation of anisotroplc reentry 95

$\begin{array}{ll}5.2 \text { Sustained anlsotroplc reentry } & 97\end{array}$

$\begin{array}{ll}5.3 \text { The excitable gap } & 100\end{array}$

5.4 Cellular characteristics of anisotropic reentry 103

5.5 Computer simulation of anisotropic reentry 103

5.6 Anlsotroplc reentry as a mechansim of sustained ventricular 113 tachycardia in the postmyocardial infarction period

List of References

Summary

Samenvatting

Nawoord 




\section{CHAPTER I}

\section{INTRODUCTION}

\subsection{ANISOTROPIC IMPULSE CONDUCTION}

Deviations from the normal sinus rhythm of the heart may have serious pathophysiological implications. The consequences range from only minor impaired pump function during extrasystoles, to complete pump failure during ventricular fibrillation, causing sudden death.

Essentially the disturbances in heart rhythm can be divided into two different groups (Hoffman and Rosen, 1981). 1. Arrhythmlas caused by abnormalities in /mpulse formation and 2. Arrhythmias based on disturbances in impulse conduction. 3. Arrhythmias caused by a combination of abnormalities in impulse formation and disturbances in impulse conduction. Although it is often difflcult to dlstingulsh between these mechanisms and disturbances in impulse formation may also cause serious arrhythmias, in this thesis we will only discuss the mechanlsms underlying disturbances in $1 \mathrm{~m}$ pulse conduction.

The propagation of electrical activity first described and demonstrated by Engelmann $(1874,1875)$ has now been subject of study for more than a century. After the first estimations of conduction velocity by Engelmann in 1875, Burdon-Sanderson and Page (1879) established the criteria for measuring the velocity of electrical propagation in cardlac muscle. According to them conduction velocity had to be measured by calculating the difference between the arrival times at two points, positioned in line with a homogeneously propagating wavefront. These criteria still hold true and it is possible that other ways of indirect measurement of the conduction velocity may yleld large deviations from the actual value (Spach et al., 1981, Spach, 1983, Spach and Kootsey, 1983) as will be discussed later.

Detailed studies of impulse conductlon became within reach after the introduction of the string galvanometer by Einthoven in 1901. Lewis and Rothschild (1915) came up with the actual rates of propagation in Purkinje and ventricular muscle and In a later 
paper a relation between the different types of cardiac fibers and conduction velocity was proposed by Lewis (1924). By that time the effects of tissue anisotropy were thought to be of minor Importance although Lewis and Rothschlld (1915) noted already some differences between conduction velocity parallel and perpendicular to the fiber direction in the right ventricle.

After the early studles of Lewis and Rothschill it was only thirty years later that the effects of fiber direction on conduction velocity were described by Dräper and MyaTu (1959) and Sano et al. (1959). A conduction velocity of $60 \mathrm{~cm} / \mathrm{s}$ was reported during Impulse conduction parallel to the fiber axis opposed to a conduction velocity of only $20 \mathrm{~cm} / \mathrm{s}$ during conduction perpendlcular to the fiber orientation. These values were recently confirmed by studies of Clerc (1976) and Spach et al. (1981, 1982b). Spach also was the first to suggest that anisotropy may play an important role in the initiation of reentrant arrhythmias (Spach et al., 1981, 1987). They stated that conduction disturbances, long thought to be due to "depressed segments" (Schmilt and Erlanger, 1928) or local differences in excitability (Mines, 1914, Hoffman and Cranefield, 1960, Han and Moe, 1964, Cranefield et al., 1971, Cranefield and Hoffman, 1971, Allessle et all, 1976, Kuo et al., 1983, Kimura et al., 1986) may also be caused by geometrical factors influencing the safety factor for conduction in anisotropic myocardlum (Spach, 1981, 1982a, 1986, 1987).

Recent studies on the mechanisms of ventricular tachycardia by Wit et al. (1987) and Dillon et al. (1988), demonstrated that tissue anisotropy played an important role in the occurrence of conduction block and reentry in ventricular myocardium surviving myocardial infarction.

\subsection{STRUCTURE OF VENTRICLILAR MYOCARDIUM.}

Ventricular cells have an average diameter of 10 to $20 \mu$ and a length ranging from 60 to $100 \mu$ (Sommer and Dolber, 1979). The cells are more or less cylindrical in shape. The surface however is curved and sculptured into several step like terraces (Sommer and Dolber, 1979). As a result cells can be coupled to several adjacent cells. Ventricular cells are closely coupled to each other by nexuses (Sjöstrand and Anderson, 1954, Dewey and Barr, 1962, De Mello, 1982). The nexuses allow current flow from cell to 
cell and are essential for normal impulse conduction (Barr et al., 1965, Weidmann, 1966, 1970, De Mello et al., 1969, Daniel et al., 1976).

At the nexus the cells are in intimate contact, the average width of the gap being $200 \AA$. In its central area several structures are present bridging the gap with a periodicity of $100 \AA$ (Loewenstein,1981, De Mello 1982). The nexus is composed of subunits, the connexons, which create direct pathways between adjacent cells. Each connexon is separated from the extracellular space by a lipid wall of high resistivity (Loewensteln, 1981). The nexus is a rather unstable structure and may undergo morphological changes related to a low or high resistance state (Dewey and Barr, 1962, Peracchia, 1973, De Mello, 1982).

Calcium appears to play a key role in the regulation of the opening and closure of the nexus, which reaction is probably mediated by calmodulin (De Mello et al., 1969, De Mello, 1982, Sheung, 1980). If the calcium concentration at the nexus rises the channels close and the resistance Increases. This is an important mechanism to protect cells against short-circuiting when one of the surrounding cells loses its integrity either mechanically or during hypoxla (Deleze, 1965, De Mello et al., 1969, 1972). After injury first the resistance decreases and the space constant for electrical current increases, but after a short time period the space constant decreases below its normal value and the damaged cell becomes "disconnected" (Wojtczak, 1979, De Mello, 1982). This process of "healing over" was already described by Engelmann (1877) who noted that if one end of a fiber was damaged, impulse conduction was impaired first but after a short time period conduction recovered.

The nexuses form almost always end-to-end connections between the cells, allthough sometimes side-to-side connections are found (Sommer, 1983). The number of nexuses is directly related to the dimension of the cells, large cells having more nexuses than smaller cells (Jewett, 1971).

The cells are organized into bundles consisting of 2 or more cells. These "unit" bundles (Johnson and Sommer, 1967) are separated from each other by extracellular space. Within each bundle the cells are well connected to each other by multiple nexuses. Adjacent bundles however may be connected by only one nexus. Somet/mes a complete fusion of two bundles may occur forming a new and larger bundle. This bundle may fuse or divide into two or more new bundles. At a somewhat larger scale adjacent bundles may be divided from each other by blood vessels or collageneous tissue. During aging bundles become more and more separated because of the inter- 
position of collageneous septa. It is apparent that such discontinuities may induce barriers for Impulse conduction (Spach et al $, 1981,1982 a, 1986$ ).

Both left and right ventricle are three-dimensional structures with an unique and complex geometry. Muscle fibers in the ventricular wall are orlentated in helical pathways depending on their position between epicardium and endocardlum. The ventricular wall can be divided in about ten or eleven different layers, in each layer the myocardial fibers are organized more or less parallel to each other. The hellx angle changes gradually from eplcardium to endocardlum from about +60 to -60 degrees, like in a Japanese fan (Streeter, 1979).

\subsection{CONDUCTION OF THE CARDIAC IMPULSE IN ANISOTROPIC MYOCAR- DIUM.}

Although substantial differences exist between nerve and cardiac muscle, myocardial impulse conduction has long been treated as if occurring in a one dimensional continuous cable (Weidmann, 1952, Noble, 1962, 1966, Fozzard, 1979, Walton and Fozzard, 1983a, 1983b. The electrical constants for impulse transmission along an electrical cable were determined by Kelvin (1855). The first attempts to apply the cable equations to cardiac myocardium were performed by Weidman (1952). After the numerical solutions of the cable equations by Hodgkin and Huxley (1952) for impulse conduction in the squil axon, Weidmann (1952) applled the cable equations to sheep Purkinje fibers. Although Purkinje fibers consisted of multiple cells generally the experimental results fitted well with the values predicted by the cable equation (Fozzard, 1979).

The cable equation for constant conduction velocity is (Hodgkin and Rushton, 1946, Walton and Fozzard, 1983):

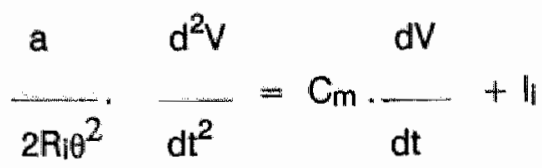

Where $\mathrm{a}$ is the radius of the fiber, $\mathrm{R}_{\mathrm{f}}$ is the specific resistivity of the intracellular fluid, $\theta$ is the conduction velocity, $C_{m}$ is the membrane capacitance per unit length, $V$ 
is the membrane potential per unit area, $1 /$ respresents the sum of the instantaneous ionic currents per unit area of membrane, and $t$ represents time.

From the cable equation a linear relationship between $V_{\max }(\mathrm{dV} / \mathrm{dt} \max )$ and the square of the conduction velocity can be derived (Hodgkin, 1954). Because of this, it has become common practlce to estimate the conduction velocity by measuring the $V_{\max }$ (Cohen et al., 1984, Buchanan et al, 1985). The upstroke velocity of the action potential is determined mainly by the magnitude of the fast sodlum inward current.

In general this seems to fit well with the experimental results and thus was thought to provide information about the relation between the fast sodium inward current and the conduction velocity under a variety of circumstances (Cohen and Strichartz, 1977, Cohen et al., 1984, Buchanan et al., 1985).

The validity of the simple and direct relationship between $V_{\max }$ and conduction velocity was challenged by a number of observations (Dominquez and Fozzard, 1970 , Spear and Moore, 1974a, 1974b, Saito et al., 1978). Dominquez and Fozzard (1970) showed that when the potassium concentration was increased the conduction velocity showed a biphasical pattern. Despite a continuous decrease of $V_{\max }$ the conduction velocity first increased when the potassium concentration was increased to about $7.5 \mathrm{mM}$ and then slowed down when the concentration was further increased. This was explained by assuming, that when the resting membrane potential shifted to less negative values, depolarization of the membrane to threshold voltage required less excitatory current (Domlquez and Fozzard, 1970). At higher potassium concentrations conduction velocity became more and more depressed due to the depresslon of the Vmax.

According to the continuous cable theory the shape and the time course of the action potential can be altered only by altering the membrane properties of the cells. Alterations of the axial resistance should only modify conduction velocity but not the shape and time course of the action potential (Spach et al., 1981).

For a constant conduction velocity and constant membrane properties Hodgkin (1954)

derived $\theta^{2}=k$. 
where $k$ is a constant depending on the membrane properties. Hodgkin concluded that $R_{i}$ and $\theta$ can be changed reciprocally without altering the time course of the action potentlal. When the axial resistance increases, conduction velocity decreases proportionally.

Although Dräper and Mya-Tu (1959) and Sano et al. (1959) already demonstrated that conduction velocity changes by changing the direction of impulse propagation it was not until recently that attempts have been made to quantify the effects of tissue anisotropy on impulse conduction. Because of the anisotropy of the ventricular myocardium the axial resistance is different along and perpendicular to the fiber axis. Sperelakis and MacDonald (1974) measured the ratio between longlitudinal and transverse resistivitles and came up with a ratio of 11.3. Experimental evidence that the anisotropic distribution of the conduction velocity is caused by differences in axlal resistance was also given by Clerc (1976). Trabecular bundles from the right ventricle of the calf heart were used and studied at a low temperature of $25^{\circ} \mathrm{C}$ (to prevent contracture of the muscle). The ratio between longitudinal and transverse intracellular resistance was 9.4. Because conduction velocity is related to the square of the axial resistance this resulted in a ratio of 3.0 between longitudinal and transverse conduction velocity . Action potentlal configuration was not influenced by the direction of impulse spread. Clerc (1976):" For widely different external and internal resistances, thus different conduction velocitles, the shape of the propagating actlon potentlal is the same, as would occur if it was determined exclusively by the properties of the same surface membrane" and from this it emerged that the cable equations fitted well with experimental results.

Spach et al. (1981, 1982a, 1987) however did note consiberable effects on configuration and time course of the action potentlal when the direction of impulse spread was changed. This led him to conclude that the cable equation did not adequately describe impulse conduction In anisotropic myocardium. In a one dimensional continuous cable a high conduction velocity is related to a fast rate of rise of the action potential $\left(V_{\max }\right)$ and a low $\tau$-foot (which represents the time course of the membrane potentlal during the foot of the action potentlal). In anisotropic myocardlum, during slow conduction perpendicular to the fiber axis $V_{\max }$ was significantly higher than during fast conduction parallel to the fiber axis. Also $\pi$-foot was shorter during slow transverse conduction and lengthened when the conduction velocity increased (Spach et al., 
$1981,1987)$. These deviations from the cable theory were explained by Spach by taking into account the effects of recurrent axial resistances in the form of nexuses. Such barriers separate the active membranes in loosely coupled patches and will reduce the space constant of electrical current spread. Because of the elongated cell shape and the packing in parallel bundles relative few barrlers are present in a longitudinal direction (Johnson and Sommer, 1967, Sommer and Dolber, 1979). In a longltudinal direction the space constant for electrotonic current thus is higher and can flow over a considerable distance (Spach et al., 1981). As a result of this high electrotonic current flow in a longitudinal direction, $V_{\max }$ decreases desplte a high conduction velocity. The increase of the space constant also increases the $\tau$-foot of the action potential (Spach et al., 1981). In a transverse direction however electrotonic current spread is less and more current is confined within the cells because of the insulating high resistance barriers. Thus $V_{\max }$ is higher and $\tau$-foot shorter at a lower conduction velocity (Spach et al, 1981, Delmar et al., 1987).

When the axial resistance increases to very high levels the cells become more and more separated and Vmax further increases until a value is reached which can be found under space clamp conditions. This new concept of discontinuity led to a formerly unknown type of cardiac impulse conduction during which the impulse "jumps" from cell to cell and the delay between the cells increases. Conduction velocity In normal myocardium thus may decrease to values of less than $5 \mathrm{~cm} / \mathrm{s}$, previously only measured in depressed myocardlal segments (Cranefield et al., 1971). The occurrence of notches during and after the depolarization phase of the action potentlals Indeed suggests that conduction is discontinuous. The appearance of notches is caused by the depolarization of the next cell after a delay during which the Impulse passes the nexus (Spach et al.,1981, 1987).

Simulation studies by Joyner (1982) using the model of coupled membranes (Beeler and Reuter, 1977) and Dlaz et al. (1983) using a core conductor model demonstrated that when the effects of the nexus resistances were incorparated by including a periodic resistance, impulse propagation became discontinuous which was reflected by the occurrence of notches in the actlon potentlals and multiple low amplitude spikes in computed extracellular potentials.

Spach et al. (1981) further postulated that the geometrical factors in anisotropic myocardium, also affect the "safety factor" for conduction. The "safety factor" is a rather poorly defined parameter (Spach et al., 1981, Schmitt and Schmitt, 1940) and reflects 
the ratio between the maximal current a cell can supply and the current necessary to bring the surrounding cells to threshold. Because of the large current load and the resulting low $V_{\max }$ fongltudinal to the fiber axis the safety factor during fast longitudinal conduction is supposed to be lower than during slow transverse conduction (Spach et al., 1981). As a result, a lowering of the stimulating efficacy of the depolarisation wave by depression of the fast sodium inward current should cause conduction to fail first in a longitudinal direction. Spach et al. (1981) came up with some experimental evidence showing that when the take-off potential was lowered by premature beats, longitudinal conduction became decremental or blocked while slow transverse conduction still proceeded. These findings were confirmed by Tsubol et al. (1985) who demonstrated that when the safety factor was lowered by high concentrations of extracellular potassium, the $V_{\max }$ of the action potential measured during longitudinal conduction was depressed to a greater extent than during transverse conduction.

\section{Computer simulation studies}

The computer simulation studles of Van Capelle (1983) and Rudy et al. (1987) however challenged this concept of preferential longitudinal conduction block. Although they confirmed that over a small range of disc resistances, $V_{\max }$ decreases when the coupling resistance decreases, they showed that at very low coupling resistances the cable loses its lumped character and Vmax tends towards a stable value (Van Capelle, 1983). Furthermore when the disc resistances were Increased to high values (Rudy et al., 1987) a rapid decline of the $V_{\max }$ was reported. This decline of $V_{\max }$ is probably caused by the occurrence of slow foot potentials which inactivated the sodium inward current (Van Capelle, 1983, Rudy et al., 1987).

They also found a different relationship between the $\tau$-foot of the action potential and the axial resistance. When the disc resistance increased, $\tau$-foot also increased, instead of decreasing as reported by Spach et al. (1981). Under all different circumstances, conduction block always occurred more promptly during slow transverse conduction than in a longitudinal direction. Recent experimental studies by Delmar et al. (1987) demonstrated that when the nexus resistance was increased by heptanol, regardless of the changes in $V_{\max }$, transverse conduction block always occurred before longitudinal conduction block. This conduction failure was caused by the occurrence of slow foot potentials partially inactivating the fast sodium inward current. In a 
recent paper Spach et al. (1987) postulated that the opposite results concerning the relationship between the $\tau$-foot of the action potential and the axial resistance can be explained by assuming that the membrane capacitance is different depending on the direction of impulse spread. However there is still no consensus on the role of anlsotropy in the occurrence of local conduction block.

\section{Extracellular potentials}

Fiber geometry and morphollogy also has notable effects on the recorded extracellular potentials. In a one dimensional continuous cable the magnitude of the extracellular potential is primarily determined by the intracellular potential gradient (Rall, 1969, Spach et al., 1972, 1973, Spach and Barr, 1975, Barr, 1984). However it was shown by Spach et al. $(1979,1986)$ and Rudy et al. $(1987)$ that in anisotroplc myocardium the extracellular potentials are determined by the axial current flow. Because of the large axial current flow in a longitudinal direction the amplitude of the extracellular potentials is larger than during transverse conduction. Both experimental work and simulation studies showed that the extracellular potentlal of the wavefront indeed rapidly declines when the direction of impulse spread changes from longitudinal to transverse conduction despite an increase of the action potential amplitude (Roberts et al. 1979, Spach et al. 1979). During fast longitudinal conduction a large positive $R$ wave preceeds the high amplitude Intrinsic deflection, while during transverse conduction a low amplitude negative intrinsic deflection preceded by a small or even absent $A$ wave is recorded. When during aging or after myocardial infarction the degree of anisotropy increases by progressive separation of adjacent myocardial bundles by collageneous septa (Spach et al., 1986, Spear et al, 1983a, 1983b, Richards et al., 1984) longitudinal conduction is not affected and the shape of the extracellular deflections is not changed. In a transverse direction however the impulse now is forced in a complex zig-zag pathway which is reflected in the extracellular electrogram by multiple low amplitude deflections, reflecting the activation of separate but adjacent myocardial bundles near the recording site. 


\subsection{REENTRANT EXCITATION}

The concept of reentrant excitation as a mechanism of ventricular fibrillation was Introduced by MacWilliam in 1887. Mayer $(1906,1908)$, Mines $(1913,1914)$ and Garrey (1914) showed that reentrant excitation could be initlated in ring preparations cut from the jelly fish or from the hearts of tortolse, dogfish, dog and cats. The conditions necessary for initlatlon of reentry were recognized by Mines $(1913,1914): 1$. Block of an impulse at some site within the myocardium. 2. Slow conduction over an alternate pathway, 3. Delayed activation of tissue beyond the block and 4. Reexcitation of tissue proximal to the block.

Two different types of reentrant excitation can be distinguished: 1 . Circus movement excitation involving an anatomical barrier (Mines, 1913, 1914, Lewis et al., 1920, 1921, Rosenblueth and Garcia Ramos, 1947, Page et al.. 1983, Frame et al., 1986) and 2. Circus movement excitation involving a functionally determined area of conduction block (Moe, 1962, Allessie et al., 1977, Wit et al., 1987, Dillon et al., 1988)

\section{Reentrant excitation involving an anatomicall barrler.}

Lewis et al. (1920) demonstrated the presence of reentrant excitation in atrial flutter in the dog heart by mapping the spread of excitation during the arrhythmia. They showed that the impulse circulated around the orifices of the superior and inferior caval veins. Rosenblueth and Garcla Ramos (1947), Kimura et al. (1954), Hayden et al (1967), Page et al. (1983), Frame et al. (1986) further studled the principles of reentrant excitation Involving an anatomical barrier. When the Impulse circulates around an anatomical obstacle the length of the circular pathway is determined by the size of the anatomical barrier. Usually the length of the excltation wave (e.g. the product of conduction velocity and refractory period) is shorter than the length of the reentrant pathway and consequently an excitable gap between the crest and the tail of the circulating impulse is present. The cycle length of the arrhythmia is determined by the length of the circular pathway and the conduction velocity (Lewis, 1925). Because the length of the circuit is fixed, the rate of the arrhythmia can be modified only by changing the conduction velocity. Due to the presence of an excitable gap, it is possible to entrain, reset or terminate these tachycardlias by programmed electrical stimulation (Wellens et al., 1975b, 1978, Waldo et al.,1987, Frame et al., 1986). 
In man reentrant excitation around an anatomical obstacle was first demonstrated in patlents suffering from the Wolff-Parkinson-White syndrome (Durrer et al., 1967a, 1967b, Durrer and Wellens, 1974, Wellens, 1975b, 1975c, Wellens et al., 1980, 1984). In these patients the impulse propagated in a circuitous pathway involving the atria, ventricles, A-V node and an accessory pathway (Kent, 1913). This reentrant arhythmia, already predicted by Mines (1914) can be terminated by cutting the accessory bundle (which is the ultimate proof that the arrhythmia is caused by reentrant excitation, Mines, 1913). Although direct evidence is not yet available it is likely, that also sustained ventricular tachycardia initiated in the chronic phase after a myocardial infarction is based on reentry around an anatomical barrier (Wellens et al., 1974, Josephson and Wellens, 1984, De Bakker et al., 1983).

\section{Beentry without the involvement of gross anatomical obstacles}

Although Garrey in 1914 already postulated that anatomical barrlers are not essential for the maintaince of reentrant excitation, it was not until sixty years later, that Allessie et al. in 1973 demonstrated circus movement excitation in atrial myocardium without the involvement of a gross anatomical barrler. The characteristics of functlonal reentry, as postulated in the leading circle theory are (Allessie et al., 1977): 1. Absence of an anatomical obstacle in the centre of the circuit. 2. No excitable gap between the crest and tall of the circulating Impulse. 3. The length of the circult is determined by the wavelength of the impulse (i.e. product of refractory period and conduction velocity). 4 . The cycle length of the reentrant tachyarrhythmia is determined by the duration of the refractory period. 5. Size and localization of the circuit are not fixed, but may vary by changes in electrophysiological properties. Leading circle reentry is considered to be an important pathophysiological mechanism of atrial or ventrlcullar fibrillation. Moe and co-workers $(1962,1964)$ postulated that due to local differences in refractoriness, multiple areas of conduction block developed resulting in degeneration of the impulse into multiple wavelets. These chaotically wandering wavelets are fully determined by the functional properties of the myocardium. Recently Allessie et al. (1985) provided experimental evidence for the multiple wavelet theory.

In conclusion a number of important differences exists between anatomically and functionally determined reentry circuits. 
1. The reentrant pathway is determined by the dimension of the anatomical barrier during "anatomical" reentry. In the leading circle type of reentrant excitation the dimension of the circuit are determined by the electrophysiological properties of the myocardlum and the length of the circuit can change with alterations in electrophysiologlc properties.

2. During "anatomical" reentry usually the length of the reentrant pathway exceeds the length of the excitation wave and consequently an excitable gap is present. Because during functional reentry the length of the circult is equal to the length of the excitation wave no excitable gap is present.

3. Due to the presence of an excitable gap anatomical circuits are stable and long lasting, while functional reentry tends to terminate spontaneously.

4. The cycle length of anatomically determined circuits is inversely related to the conduction velocity wheras in leading circle reentry the revolution time is proportional to the refractory period.

\subsection{REENTRANT EXCITATION AS A MECHANISM OF SUSTAINED VENTRICU- LAR TACHYCARDIA}

Ventricular tachycardla is an arrhythmia arising distal to the subdivision of the bundle of HIs, caused elther by the rapld discharge of an ectopic focus or by reentrant excitation within the ventricles. Not only the high rate of ventricular tachycardia may lead to Impaired pump function of the heart, but also degeneration into ventricular fibrillation frequently occurs resulting in sudden cardlac death (Moss et al., 1977, Moss 1980). Ventricular tachycardia and ventricular fibrillation occur most frequently in patients suffering from coronary heart disease. During the acute phase of myocardial infarction ectopic ventrlcular beats and short periods of ventricular tachycardia frequently occur (Lie et al., 1975). The mortality rate during the acute phase of myocardial infarction is about 20 to $30 \%$. After this phase, which lasts for about 30 minutes, 
sinus rhythm returns and less arrhythmias occur. However after about five hours, a second period of arrhythmlas starts which may last for several days. In the chronic phase of myocardial infarction in some patients episodes of ventricular tachycardia or ventricular fibrillation occur. In this phase, both nonsustained or sustained ventricular tachycardia can be initiated by programmed electrical stimulation (Wellens et al., 1974). Both clinical (Wellens et al., 1974, 1975a, Josephson et al.,1978, 1979, 1982, 1984, Josephson, 1986, De Bakker et al., 1983) and experimental studies (El-Sherif et al., 1977b, 1981, 1985, Mehra et al., 1983, Gough et al., 1985, Wit et al., 1982, 1987, Kramer et al., 1985, Garan et al., 1987, Pogwidz and Corr, 1987, Dillon et al., 1988) have demonstrated that reentry is the most likely mechanism of sustained ventricular tachycardia after myocardial infarction. High resolution mapping studies revealed that reentrant circuits within surviving myocardlal layers overlying the infarct may be the source of some ventricular tachycardlas (El-Sherlf et al., 1981, 1985, Mehra et al., 1983, Cardinal et al., 1984, Wit et al., 1982, 1987 and Dillon et al, 1988). The border zone myocardium of the infarct consists of thin layers of surviving myocardium. Between these fibers destroyed and necrotic myocardial cells are found (Spear et al., 1983a, 1983b, Richards et al., 1984, Gardner et al., 1985). These surviving myocardial cells have normal electrophysiological properties (Spear et al. 1983a, 1983b, Richards et al., 1984, Gardner et al., 1985). However due to the interposition of collageneous fibers and necrotic myocardial cells conduction velocity during transverse impulse propagation decreases significantly (Spear et al., 1983a, 1983b). The reduction of the conduction velocity is accompanied by the appearance of fractionated deflections in the extracellular electrograms and a reduction of the space constant of electrical current flow in a transverse direction (Spear et al., 1983a, 1983b, Gardner et al., 1985). Because the longitudinal conduction velocity is not altered the ratio between longitudlnal and transverse conduction velocity increases. The studles of Wit et al., (1987) and Dillon et al. (1988) have provided evidence that conduction block and reentry could occur due to this enhanced degree of anisotropy. They demonstrated that the reentrant loop was circulating around a line of functional conduction block, orlentated parallel to the epicardial fiber direction.

Anisotropy may also play an important role in ventricular tachycardia in patients. Epicardial and endocardial mapping studies during cardiac surgery revealed the presence of "continuous" local activity near the site of "earllest" actlvation during ventricular tachycardia. These fragmentated electrograms may reflect areas of poor elec- 
trical coupling and non-uniform anisotropic conduction. However it is still uncertain whether these areas are part of small reentrant circuits (Josephson et al., 1978, 1982, 1984, Fenoglio et al ${ }_{\text {. }}$ 1983). In a recent study Brugada et al.(1985) demonstrated that, although in about $40 \%$ of the patients the anatomical substrate causing continuous activity is present, only a minority of the patients will actually suffer from periods of sustained ventricular tachycardla.

\subsection{AIM OF THE STUDY}

Although a number of theoretical problems of anisotropic conduction have been resolved there lis still considerable debate about the role of anisotropy in the genesis of conduction block and reentry (Spach et al., 1981, 1982, 1986, 1987, Van Capelle, 1983, Rudy et al., 1987, Wit et al., 1987, Dillon et al., 1988). One of the objectives of this study was to investigate the role of tissue anisotropy in impulse conduction and conduction block. In the left ventricle of a rabbit heart, perfused according to the Langendorff technique, conduction velocity and refractory period were measured and the wavelength of refractoriness (product of conduction velocity and refractory period) was calculated. Because of the anisotropic morphology the conduction velocity and the wavelength were measured in two directions, e.g. parallel and perpendicular to the fiber orlentation. Conduction parallel to the epicardial fiber direction was about three times faster than conduction perpendicular to the fiber direction, i.e. the ratio between longitudinal and transverse wavelength was about three. Although slow transverse conduction and the short transverse wavelength should facilitate the initiation of reentry (Smeets et al., 1986, Rensma, 1987, Rensma et al., 1988) no ventricular tachycardias could be induced in the Intact rabbit ventrlcle. Due to the three dimensional impulse spread, sllow transverse impulse conduction did not occur over a long distance, because within a short distance it was bypassed by fast conduction along an alternative route. This three dimenslonal spread of activation complicated the detalled study of anisotropic conduction and conduction block. To facilitate the study of anisotropy we developed an experimental two-dlmensional model of anisotropy. By destroying the intramural and endocardial layers of the ventricle by liquid nitrogen it was possible to create a perfused epicardial layer. The electrophyslological properties (conduction velocity, refractory period and maximal pacing rate) of this two-dimensional epicardial layer were not significantly different from those measured in the in- 
tact ventricle. However due to the removal of the intramural and endocardial layers, slow transverse impulse conduction was no longer interrupted by eplcardlal breakthrough and the effectivity of anisotropy was greatly enhanced.

Another aim of this study was to evaluate the role of anisotropy in the initiation of reentry. Wit et al. (1987) and Dillon et al. (1988) demonstrated that local loss of myocardial tissue in the healing phase after a myocardial infarction enhanced the degree of anisotropy and may facilitate the initlation of sustained ventricular arrhythmias. However in these studies ischemic alteratlons of the cells also might have contributed to the enhanced risk of the initiation of reentry. In the experimental epicardial layer created by freezing it was possible to study the role of tissue anisotropy in the initiation of reentrant ventricular tachycardia without ischemic alterations of the cells. After freezing sustained ventricular tachycardla could be easlly initlated by electrical stimulation. High resolution extracellular mapping (simultaneous recording of electrical activity at 192 different epicardial sites) was performed to reconstruct the spread of excitation during tachycardia. Reentrant excitation around a functlonal line of conduction block turned out to be the underlying mechanism of these tachycardlas. However in contrast with the leading circle type of reentry (Allessie et al., 1977) these tachycardias possessed a clear excitable gap. Due to the presence of an excitable gap the tachycardlas were stable and longlasting. 
$-16-$ 


\section{CHAPTER II}

\section{ANISOTROPIC CONDUCTION AND THE WAVELENGTH OF REFRACTORINESSIN THE RABBIT VENTRICLE}

\section{The effects of rate, premature beats, potassium, temperature,epinephrine and lidocaine}

\subsection{INTRODUCTION}

Small reentrant circuilts either within atrial (Allessie et al., 1976, 1977, 1984) or ventricular myocardium (Janse et al., 1980, Wit et al., 1982, 1987, Allessie et al., 1987, DIlIon et al., 1988) around a functionally determined area of conduction block may play an important role in the pathogenesis of atrial or ventricular arrhythmias (El-Sherif et al., 1977b, 1981, 1983, Wit et al., 1987, Dillon et al., 1987). In contrast to the flxed pathway during circus movement tachycardias involving a gross anatomical obstacle (Rosenblueth and Garcia Ramos, 1947, Page et al., 1983, Frame et al., 1986) both the size and rate of reentrant tachycardias involving a functionally determined area of conduction bilock are completely determined by the electrophysiological properties of the myocardium (Allessie et al., 1977). The minimal perimeter of such a clrcult will be equal to the length of the excitation wave (refractory period $x$ conduction velocity, Allessle et al., 1977). When the wavelength is shortened either by depresslon of conduction velocity or by shortening of the refractory perlod, the size of the circuit will decrease. On the other hand a lengthening of the wavelength will result in an increase of the size of the circuit (Smeets et al., 1986). A short wavelength was found to correlate with a high vulnerability to reentrant arrhythmilas either in isolated rabbit atrium or in consclous dogs (Smeets et al., 1986, Rensma et al., 1988). The wavelength of refractoriness emerged to be a sensitive and specific index of the susceptlbility of the heart to atrial arrhythmlas with an overall predictive power of $75 \%$ (Rensma et al., 1988). 
There are some important morphological differences between atrium and ventricle which makes it difficult to extrapolate the wavelength concept to ventricular arrhythmias. In contrast to the more or less random fiber orientation in the atria, the ventricular cells are organized more in parallel to each other (Sommer and Dolber, 1979). Ventricular cells have an average diameter of 10 to $20 \mu$ and a length ranging from 60 to $100 \mu$ and are coupled to each other by nexuses. The nexuses form almost always end-to-end connections between the cells, although sometimes side-to-side connections are found (Sommer, 1983). Due to the different contribution of the cytoplasmic resistance and the nexus resistance to the effective axial resistance measured along and perpendicular to the fiber direction (Spach et al., 1979, 1981), the axial resistance Is about nine times larger perpendicular to the fiber direction than parallel to the fiber orlentatlon (Clerc, 1976). As a consequence, conduction parallel to the fiber orlentatlon is about three times faster than perpendicular to the fiber orientation (Clerc, 1976, Spach et al., 1981, 1982b). Due to the anlsotropic distribution of conduction velocity, the wavelength varies with different directions of Impulse propagation. A short wavelength will be found during slow transverse impulse conduction, while in the same area the wavelength will be long during longitudinal conduction. Because of anisotropy in passive electrical properties, variations in nexus resistances and modifications of the active membrane properties may have different effects on longitudinal and transverse conduction velocity (Spach et al., 1981, 1982b, 1987, Tsubol et al., 1985, Kadish et al., 1986, Delmar et al., 1987). Consequently the ratlo between the longitudinal and transverse wavelength will be changed by these modiflcations.

The aim of the present study was to measure the longltudinal and transverse wavelength in the intact Langendorff perfused rabblt left ventricle and to evaluate the effects of heart rate, premature beats, potasslum, temperature, epinephrine and lidocaine.

\subsection{METHODS}

Flemish rabbits $(n=35)$ of both sexes weighing between 4.5 and $5.5 \mathrm{~kg}$ were used In this study. After heparinization (1000 I.U/I.V.) the animals were klled by a cervical dislocation. The thorax was opened by a midsternal incision and the heart was rapidly removed and placed in cold perfusion fluid $\left(10^{\circ} \mathrm{C}\right)$. The aorta was cannulated and the heart was connected to a Langendorff perfusion system. The coronary arterles 
were perfused with a perfusion pressure of $50 \mathrm{~mm} \mathrm{Hg}$, resulting in a flow of 35 45 $\mathrm{ml} / \mathrm{min}$. The millimolar composition of the perfusion fluld was: $\mathrm{NaCl} 130 ; \mathrm{NaHCO}_{3} 20.1$; $\mathrm{KCl} 5.6 ; \mathrm{CaCl}_{2} 2.2 ; \mathrm{MgCl}_{2} 0.6 ; \mathrm{NaH}_{2} \mathrm{PO}_{4} 1.2$ and glucose 12 . The solution was saturated with a mixture of $95 \% \mathrm{O}_{2}$ and $5 \% \mathrm{CO}_{2}$. $\mathrm{pH}$ was 7.35 , and temperature was kept at $37^{\circ} \mathrm{C} \pm 0.5$. Drugs could be administered to the perfusion fluid via the aorta canule using a infusion pump (Razel A-99).

\section{Recording and Stimulation.}

To measure conduction velocities and local refractory periods at the eplcardial surface of the left ventricle, a high resolution multiterminal electrode was used containing 30 single electrodes (silver wires diameter $0.3 \mathrm{~mm}$ ) at regular distances of 2 $\mathrm{mm}$ (figure 1). Programmed electrical stimulation was performed with a programmable constant current stimulator delivering square pulses of $2 \mathrm{msec}$ duration and 2-4 times diastolic threshold. The hearts were stimulated through a central pair of electrodes. Unipolar electrograms were recorded using the stainless steel cannula in the aorta as indifferent electrode. The recorded electrograms were fed into 30 individual ampliflers (bandwidth 2-400 Hz) and displayed in groups of eigth on two Textronix $5103 \mathrm{~N}$ oscilloscopes.

\section{Measurement of refractory period.}

Local refractory periods were determined by programmed electrical stimulation. After each 15 th beat a single premature stimulus (4 times diastolic threshold) was applied to the stimulating electrodes in the center of the multiple recording electrode. The functional refractory period was defined as the shortest possible interval between a regular impulse and a premature beat, at which a propagated impulse was present (shortest $\mathrm{V}_{1}-\mathrm{V}_{2}$ Interval). This $\mathrm{V}_{1}-\mathrm{V}_{2}$ Interval was measured at a recording electrode close to the site of stimulation.

The maximal pacing rate (e.g. the shortest possible pacing rate) was determined by progressive shortening of the pacing interval untll the stimulus was blocked elther at the stimulus site or at a distal electrode. The maximal pacing rate (Fmax) was defined as the shortest pacing interval which resulted in a 1:1 propagated response. 


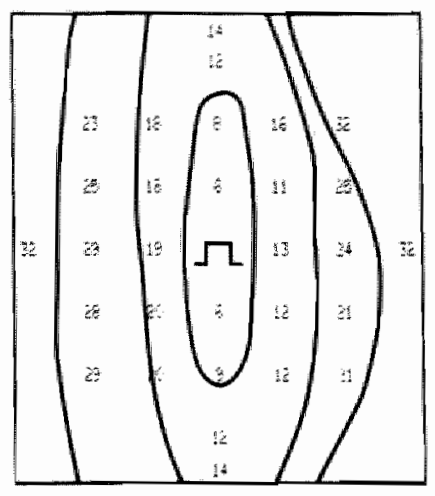

BASIC BEAT

PREMATURE BEAT
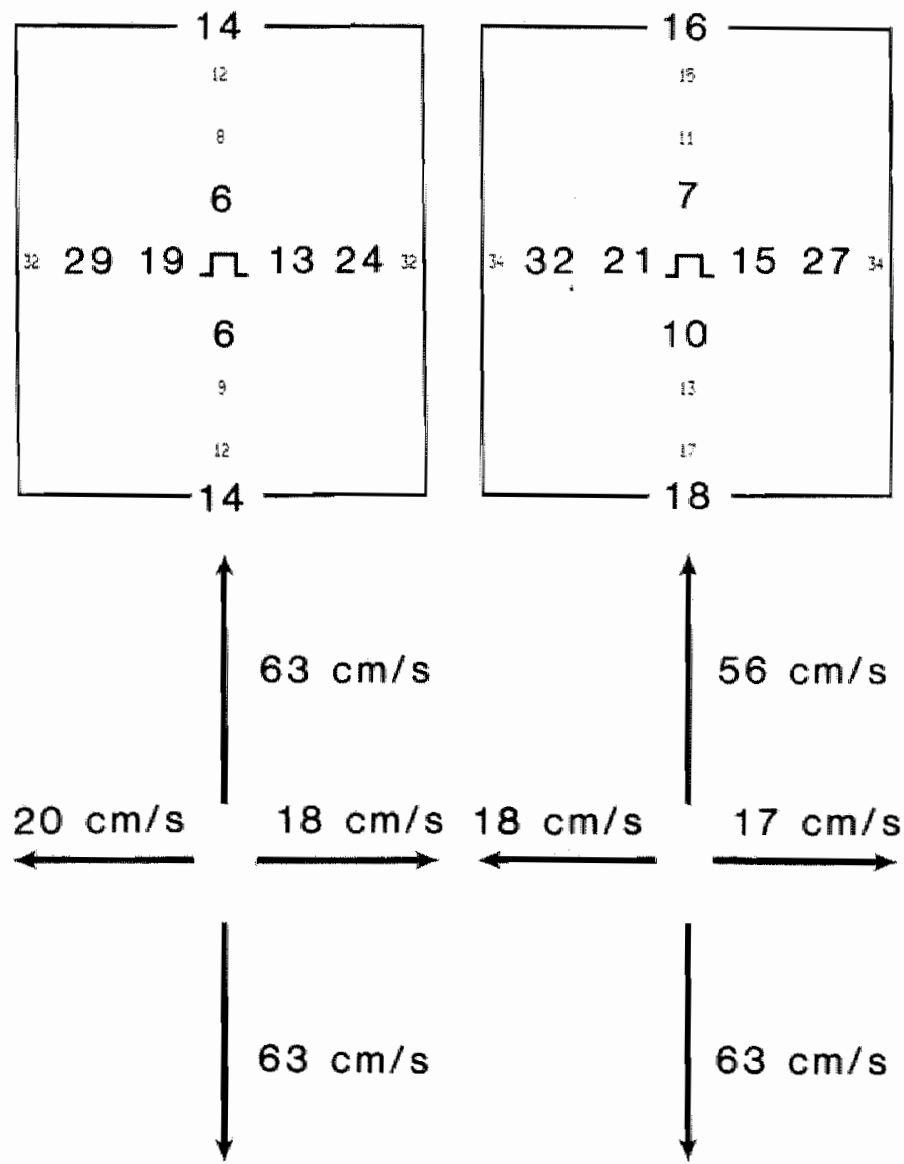
To accurately measure the refractory period, an electrogram recorded near the site of stimulation was fed into a transient recorder (Datalab DL901). From this translent recorder, activation times could be read with an accuracy of $1 \mathrm{~ms}$.

\section{Measurement of conduction velocity.}

The conduction velocity of the cardlac impulse was determined in different directions using the high resolution mapping electrode (figure 1). The heart was stimulated through a pair of stimulating electrodes located in the center of the probe. Electrograms were monitored from 4 rows of electrodes, forming a cross with the central stimulating electrodes. The long axis of the electrode was positioned parallel to the epicardial fiber directlon by looking for the highest amplitude and slope of the electrograms recorded along the long axis together with the shortest activation time between the proximal and distal electrodes (Kleber et al, 1986). After proper allignment conduction velocity in the longitudinal $\left(V_{L}\right)$ and transverse $\left(V_{T}\right)$ direction can be calculated from the differences in activation time along the rows of electrodes. Along the longitudinal axis of the probe the distance over whlch the conduction veloclty was measured was $5 \mathrm{~mm}$, whereas in the transverse direction only the first two recording electrodes (distance $2 \mathrm{~mm}$ ) could be used, because at larger distances transverse conduction was interrupted by epicardial breakthrough (figure 1). The $V_{L} / V_{T}$ ratio was taken as an index of the degree of anisotropy of the eplcardlum.

Eloure 2.1. Measurement of conduction velocity. An activation map recorded during pacing at a cycle length of $350 \mathrm{~ms}$ from the central pair of electrodes with the high resolution mapping electrode is shown. An ellipsoid wavefront, with slow conduction perpendicular to the fiber direction and fast conduction parallel to the fiber direction was recorded. The conduction velocity of the cardiac impulse was determined in different directions. Electrograms were monitored from 4 rows of electrodes, forming a cross with the central stimulating electrodes. The long axis of the electrode was positioned parallell to the epicardial tiber direction. After proper alignment conduction velocity in the longitudinal $N_{L}$ ) and tranisverse $\left(V_{T}\right) d$ drection can be calculated from the differences in activation time allong the rows of electrodes. Along the longltudinal axls of the probe the distance over which the conduction velocity was measured was $5 \mathrm{~mm}$, whereas in the transverse direction only the first two recording electrodes (distance $2 \mathrm{~mm}$ ) could be used, because at greater distances transverse conduction was interrupted by eplcardial breakthrough 
Measurement of the wavelength.

The wavelength of the cardiac impulse is defined as the distance travelled by the impulse during the time the myocardium restores its excitability (Wiener and Rosenblueth, 1946, Smeets et al, 1986, Rensma, 1987, Rensma et al., 1988). It can be calculated by multiplying conduction velocity and the functional refractory period.

\section{WAVELENGTH(mm) $=$ \\ CONDUCTION VELOCITY(cm/s) x REFRACTORY PERIOD(ms)}

Because of the differences between longitudinal and transverse conduction, the wavelength has to be calculated in both directions. The wavelength of a premature beat was measured by adding a second shortest possible coupled extrastimulus to the stimulation protocol. When the hearts were paced at their maximal pacing frequency $\left(F_{\max }\right.$ ) the wavelength was defined as the product of conduction velocity and the interval of Fmax.

Statistical analysis.

The level of significance between groups was calculated using Students T-Test. The level of significance was taken as $p<0.05$.

\subsection{RESULTS}

\section{The effects of rate and premature beats.}

To investlgate the effects of rate and premature beats on the wavelength and the degree of anisotropy in the ventricles, the hearts were paced at different pacing intervals and premature stimull were applied at different degrees of prematurity and at different pacing intervals.

In figure 2.2A and table 2.IA the effects of rate on refractoriness, conduction velocity and wavelength as measured in 18 hearts are given. The ventricles were paced 
A

REFRACTORY PEFIOO

(m)

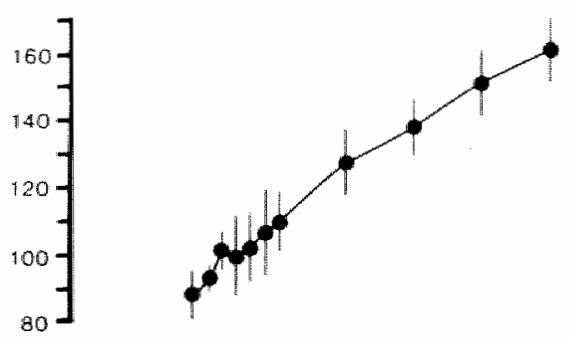

$$
100-
$$

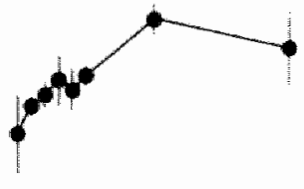

GONDUCTION VELOGITY

$$
\text { - }
$$

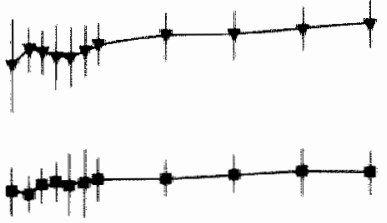

$(\mathrm{cm} / \mathrm{sec})$
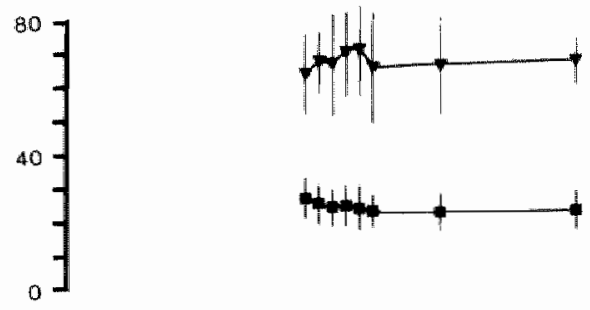

WAVELENGTH

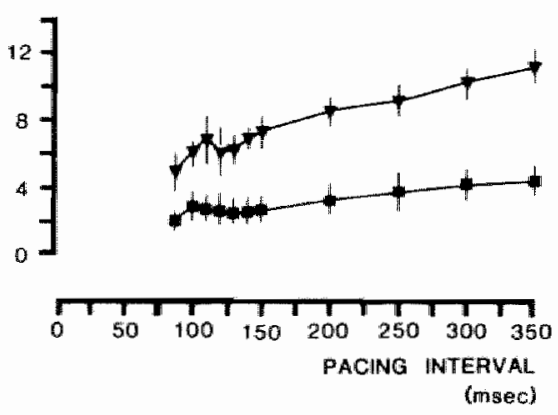

(cm)

$$
12-
$$
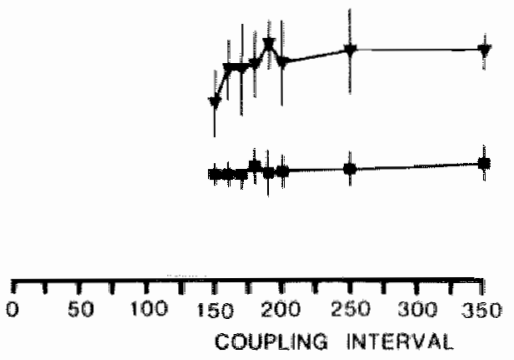

(mage)

Figure 2.2. Panel A: The effects of incremental pacing on refractory perlod, conduction velocity and wavelength of regularly driven impuises. The mean values $(n=18)$ and standard deviations of the refractory period ( $\bullet$ ), the longitudinal ( $\mathbf{v}$ ) and transverse conduction velocity ( $\boldsymbol{v}$ ), and the longitudinal and transverse wavelength are given as a function of the pacing interval. Because of a strong shortening of the refractory perlod and a reduction of both the longitudinal and the transwerse conduction velocity, the wavelength in both directions is shortened with about $55 \%$. In panel B the effects of the degree af prematurity during regular pacing at a pacing interval of $350 \mathrm{~ms}$ on the wavelength is given. Both the longitudinal and transwerse wavelength shortened respectively with $20 \%$ and $11 \%$ 


\section{Table 2.1}

A

Effects of pacing frequency on the wavelength.

\begin{tabular}{|c|c|c|c|c|c|c|}
\hline $\begin{array}{c}V_{1} V_{1} \\
m s\end{array}$ & $\begin{array}{c}\mathrm{V}_{1} \mathrm{~V}_{2} \\
\mathrm{~ms}\end{array}$ & $\begin{array}{c}V_{L} \\
\mathrm{~cm} / \mathrm{s}\end{array}$ & $\begin{array}{c}V_{T} \\
\mathrm{~cm} / \mathrm{s}\end{array}$ & $V_{L} N_{T}$ & $\begin{array}{l}\text { WLL } \\
\mathrm{cm}\end{array}$ & $\begin{array}{l}W L T \\
\mathrm{~cm}\end{array}$ \\
\hline 350 & $158 \pm 12$ & $68 \pm 7$ & $24 \pm 6$ & $2.9 \pm 0.9$ & $10.5 \pm 1.1$ & $3.9 \pm 1.1$ \\
\hline 200 & $\begin{array}{c}128 \pm 10 \\
* *\end{array}$ & $\begin{array}{c}65 \pm 7 \\
\text { ns }\end{array}$ & $\begin{array}{c}23 \pm 6 \\
n s\end{array}$ & $\begin{array}{c}2.9 \pm 0.9 \\
\mathrm{~ns}\end{array}$ & $\operatorname{l.2}_{\star \star} \pm 1.1$ & $3.0 \pm 1.1$ \\
\hline 150 & $\underset{* *}{109 \pm 9}$ & $\underset{*}{64 \pm 7}$ & $\begin{array}{c}22 \pm 7 \\
\text { ns }\end{array}$ & $\begin{array}{c}3.0 \pm 1.0 \\
\mathrm{~ns}\end{array}$ & $\underset{\star \star}{7.0 \pm 1.0}$ & $2.5 \underset{\star \star}{ \pm 0.9}$ \\
\hline$F_{\max }$ & $87 \pm 8$ & $57 \pm 15$ & $\begin{array}{c}21 \pm 8 \\
\mathrm{~ns}\end{array}$ & $\begin{array}{c}2.9 \pm 1.1 \\
\mathrm{~ns}\end{array}$ & $4.7 \underset{\star \star}{ \pm} 1.2$ & $1.7 \underset{\star *}{ \pm 0.7}$ \\
\hline
\end{tabular}

B

Effects of prematurity $\left(V_{1}-V_{1}=350 \mathrm{~ms}\right.$.

\begin{tabular}{|c|c|c|c|c|c|c|}
\hline $\begin{array}{c}\mathrm{V}_{1} \mathrm{v}_{2} \\
\mathrm{~ms}\end{array}$ & $\begin{array}{c}\mathrm{V} 2 \mathrm{~V} 3 \\
\mathrm{~ms}\end{array}$ & $\begin{array}{c}\mathrm{VL}_{\mathrm{L}} \\
\mathrm{cm} / \mathrm{s}\end{array}$ & $\begin{array}{c}V_{T} \\
\mathrm{~cm} / \mathrm{s}\end{array}$ & $V_{L} N_{T}$ & $\begin{array}{c}W L L \\
\mathrm{~cm}\end{array}$ & $\begin{array}{c}\text { WLT } \\
\mathrm{cm}\end{array}$ \\
\hline 350 & $158 \pm 12$ & $68 \pm 7$ & $24 \pm 6$ & $2.9 \pm 0.9$ & $10.5 \pm 1.1$ & $3.9 \pm 1.1$ \\
\hline 250 & $\begin{array}{c}166 \pm 5 \\
\text { ns }\end{array}$ & $\begin{array}{c}66 \pm 15 \\
\mathrm{~ns}\end{array}$ & $\begin{array}{c}23 \pm 6 \\
\text { ns }\end{array}$ & $\begin{array}{c}2.9 \pm 1.3 \\
\mathrm{~ns}\end{array}$ & $\begin{array}{c}10.5 \pm 2.5 \\
\text { ns }\end{array}$ & $\begin{array}{c}3.6 \pm 1.1 \\
\mathrm{~ns}\end{array}$ \\
\hline 200 & $\begin{array}{c}150 \pm 1 \\
*\end{array}$ & $\begin{array}{c}66 \pm 17 \\
\mathrm{~ns}\end{array}$ & $\begin{array}{c}24 \pm 5 \\
n s\end{array}$ & $\begin{array}{c}3.1 \pm 1.3 \\
\mathrm{~ns}\end{array}$ & $\begin{array}{c}9.8 \pm 2.5 \\
\mathrm{~ns}\end{array}$ & $\begin{array}{c}3.4 \pm 1.0 \\
\mathrm{~ns}\end{array}$ \\
\hline 170 & ${ }_{*} 144 \pm$ & $\begin{array}{c}67 \pm 15 \\
\mathrm{~ns}\end{array}$ & $\begin{array}{c}25 \pm 6 \\
\text { ns }\end{array}$ & $\begin{array}{c}2.9 \pm 0.8 \\
\mathrm{~ns}\end{array}$ & $\begin{array}{c}9.4 \pm 2.7 \\
\text { ns }\end{array}$ & $\begin{array}{c}3.2 \pm 0.9 \\
\mathrm{~ns}\end{array}$ \\
\hline 160 & $141 \pm 3$ & $\begin{array}{c}68 \pm 9 \\
\text { ns }\end{array}$ & $\begin{array}{c}26 \pm 6 \\
\text { ns }\end{array}$ & $\begin{array}{c}2.6 \pm 0.7 \\
\mathrm{~ns}\end{array}$ & $\begin{array}{c}9.4 \pm 1.8 \\
\mathrm{~ns}\end{array}$ & $\begin{array}{c}3.2 \pm 0.8 \\
\mathrm{~ns}\end{array}$ \\
\hline 150 & $\underset{* *}{132 \pm 12}$ & $\begin{array}{c}64 \pm 12 \\
\mathrm{~ns}\end{array}$ & $\begin{array}{c}26 \pm 6 \\
\mathrm{~ns}\end{array}$ & $\begin{array}{c}2.4 \pm 0.6 \\
\text { ns }\end{array}$ & $\begin{array}{c}7.4 \pm 2.0 \\
\text { ns }\end{array}$ & $\begin{array}{c}3.2 \pm 1.0 \\
\mathrm{~ns}\end{array}$ \\
\hline
\end{tabular}


C

The effects of rate on the wavelength of the earliest premature beat.

\begin{tabular}{|c|c|c|c|c|c|c|}
\hline $\begin{array}{l}\mathrm{V}_{1 \mathrm{~V}} \\
\mathrm{~ms}\end{array}$ & $\begin{array}{c}\mathrm{V} 1 \mathrm{~V} 2 \\
\mathrm{~ms}\end{array}$ & $\begin{array}{c}\mathrm{VL}_{\mathrm{L}} \\
\mathrm{cm} / \mathrm{s}\end{array}$ & $\begin{array}{c}V_{T} \\
\mathrm{~cm} / \mathrm{s}\end{array}$ & $V_{U} N_{T}$ & $\begin{array}{l}W L_{L} \\
\mathrm{~cm}\end{array}$ & $\begin{array}{c}W L T \\
\mathrm{~cm}\end{array}$ \\
\hline 350 & $140 \pm 10$ & $62 \pm 11$ & $27 \pm 6$ & $2.5 \pm 0.9$ & $9.3 \pm 2.1$ & $3.3 \pm 0.8$ \\
\hline 200 & $\underset{* \star}{104} \pm 9$ & $\begin{array}{c}60 \pm 9 \\
\mathrm{~ns}\end{array}$ & $\begin{array}{c}23 \pm 6 \\
\mathrm{~ns}\end{array}$ & $\begin{array}{c}2.7 \pm 0.9 \\
\mathrm{~ns}\end{array}$ & $\underset{\star \star}{6.4} \pm 1.6$ & $2.4 \pm 0.8$ \\
\hline 150 & $93 \pm 10$ & $57 \pm 10$ & $\begin{array}{c}22 \pm 7 \\
\mathrm{~ns}\end{array}$ & $\begin{array}{c}2.8 \pm 0.8 \\
\mathrm{~ns}\end{array}$ & $5.7 \underset{* *}{ \pm 1.6}$ & $\underset{* *}{2.2 \pm 1.0}$ \\
\hline
\end{tabular}

with cycle lengths ranging from $350 \mathrm{~ms}$ to the shortest possible pacing interval ( 87 $\mathrm{ms}$ ). The refractory period during pacing at a moderate rate of $350 \mathrm{~ms}$ cycle length was $158 \mathrm{~ms}$. The refractory period shortened with about $45 \%$ when the pacing interval was gradually shortened from $350 \mathrm{~ms}$ to the shortest pacing interval $(p<0.005)$. The longitudinal conduction velocity decreased from $68 \mathrm{~cm} / \mathrm{s}$ with about $16 \%$ to 57 $\mathrm{cm} / \mathrm{s}(\mathrm{p}<0.05)$. The transverse velocity decreased from $24 \mathrm{~cm} / \mathrm{s}$ with about $12 \%$ to 21 $\mathrm{cm} / \mathrm{s}\left(\mathrm{ns}\right.$ ). The degree of anlsotropy (the ratio between $V_{L}$ and $V_{T}$ ) was 2.9 and did not change significantly. Because of the shortening of the refractory period and the slowIng of conduction, at higher heart rates the wavelength shortened from $10.5 \mathrm{~cm}$ to 4.7 $\mathrm{cm}(-56 \%, p<0.005)$ during longitudinal conduction and from $3.9 \mathrm{~cm}$ to $1.7 \mathrm{~cm}(-54 \%$, $\mathrm{p}<0.005)$ during transverse propagation.

The effects of the premature beats on refractoriness, conduction velocity and wavelength during pacing at a regular rate of $350 \mathrm{~ms}$ are given in table 2.IB and figure $2.2 B(n=7)$. The coupling interval of the premature stlmulus was varled between 150 $\mathrm{ms}$ and $250 \mathrm{~ms}$. The refractory period of a premature beat decreased with about $21 \%$, from $166 \mathrm{~ms}$ to $132 \mathrm{~ms}(\mathrm{p}<0.005)$ when the coupling interval was shortened from 250 to $150 \mathrm{~ms}$. The longitudinal conduction velocity varled between $68 \mathrm{~cm} / \mathrm{s}$ and $64 \mathrm{~cm} / \mathrm{s}$ (ns) and transverse conduction between $23 \mathrm{~cm} / \mathrm{s}$ and $26 \mathrm{~cm} / \mathrm{s}(\mathrm{ns})$. The degree of ani- 
sotropy was 2.9 during late premature beats and 2.4 during early premature beats (ns). Because of the shortening of the refractory period both the longitudinal and the transverse wavelength of early premature beat decreased from $10.5 \mathrm{~cm}$ to $7.4 \mathrm{~cm}(-20 \%)$ and from $3.9 \mathrm{~cm}$ to $3.2 \mathrm{~cm}(-11 \%)$.

The effects of the pacing rate on the wavelength of the earliest premature beat and the degree of anisotropy is summarized in table $2 . I C(n=10)$. The refractory period of the earllest premature impulse (the shortest V2-V3 interval) shortened from $140 \pm 10$ ms during pacing with $350 \mathrm{~ms}$, to $93 \mathrm{~ms}$ during a basic cycle lenght of $150 \mathrm{~ms}(-44 \%$, $p<0.005)$. The longitudinal conduction velocity of the earliest premature beat decreased from $62 \mathrm{~cm} / \mathrm{s}$ to $57 \mathrm{~cm} / \mathrm{s}(-8 \%, p<0.05)$ and the transverse velocity from 27 $\mathrm{cm} / \mathrm{s}$ to $22 \mathrm{~cm} / \mathrm{s}(-18 \%, \mathrm{~ns})$. The degree of anisotropy increased from 2.5 to $2.8(+12 \%$, ns). The longltudinal wavelength shortened from $9.3 \mathrm{~cm}$ to $5.7 \mathrm{~cm}(-39 \%, p<0.005)$ and the transwerse wavelength from $3.3 \mathrm{~cm}$ to $2.2 \mathrm{~cm}(-33 \%, p<0.005)$.

\section{The effects of potassium.}

The effects of potasslum were studled during pacing at a pacing rate of $350 \mathrm{~ms}$ $(n=5)$ and during maximal pacing $(n=5)$. The potassium concentratlon was increased gradually starting from $5.6 \mathrm{mM}$. Every 15 minutes a sample of the perfusion fluid was taken and the electrophysiological parameters were measured. After the experiment the exact potassium concentration was determined in the samples of the perfusion fluid.

In figure 2.3 and table 2.II the effects of increasing concentrations of extracellular potassium are given. During pacing at $350 \mathrm{~ms}$ interval the refractory period and the conduction velocitles were not altered as long as the potassium concentration remalned lower than $8.0 \mathrm{mM}$. When the concentration was further increased the refractory period lengthened from 160 to $252 \mathrm{~ms}$ ( $+58 \%, \mathrm{p}<0.05$ ). Longitudinal conduction was strongly affected and slowed down from 66 to $30 \mathrm{~cm} / \mathrm{s}(-55 \%, p<0.05)$. At the same time the transverse conduction velocity was not changed significantly (24 versus $22 \mathrm{~cm} / \mathrm{s}$ ). As a result the degree of anlsotropy sharply decreased from 2.8 during control to 1.5 during hyperkalemia $(-44 \%, p<0.05)$. In a longitudinal directlon the slowing of conduction clearly exceeded the lengthening of the refractory period and consequently the longitudinal wavelength decreased from 10.5 to $7.9 \mathrm{~cm}(-25 \%, p<0.05)$. In a transverse direction conduction velocity was not altered and the prolongation of 


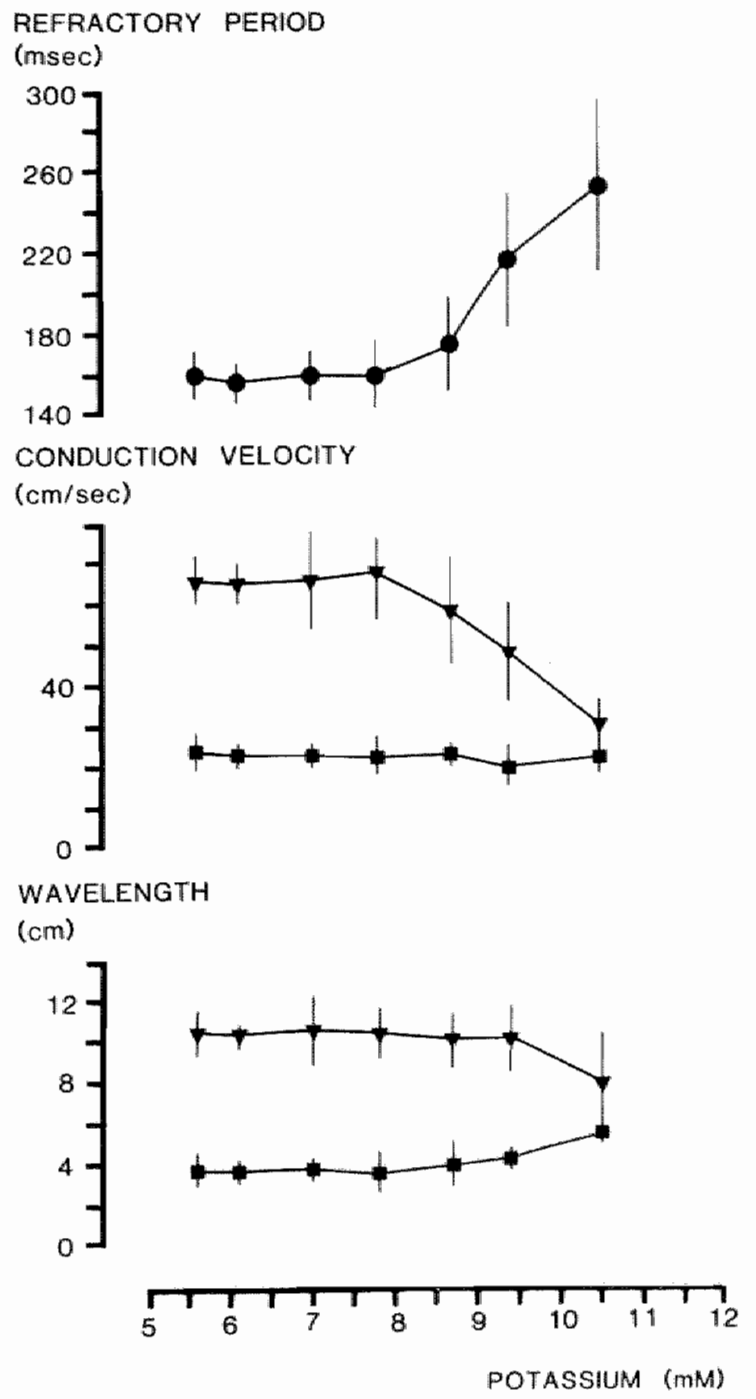

Eloure 23. The effects of extracellular potasslum concentration on the wavelength during regular pacing ( $350 \mathrm{~ms}$ cycle length $n=5$ ). The longlitudinal wavelength shortened from $10.5 \pm 1.0 \mathrm{~cm}$ to $7.9 \pm$ $2.4 \mathrm{~cm}$ due to a slowing of the longitudinal conduction velocity from $64 \pm 6 \mathrm{~cm} / \mathrm{s}$ to $32 \pm 4 \mathrm{~cm} / \mathrm{s}$. The transverse wavelength however prolonged from $3.8 \pm 0.8$ to $5.5 \pm 0.5 \mathrm{~cm}$ because the transverse conduction velocity is only slightly depressed while the refractory periad lengthened from $160 \pm 11 \mathrm{~ms}$ to $252 \pm 43 \mathrm{~ms}$. 
Table 2.II

A

The effects of extracellular potassium during slow pacing (V1V1 $350 \mathrm{~ms})$.

\begin{tabular}{|c|c|c|c|c|c|c|}
\hline $\begin{array}{l}\text { Potassium } \\
\mathrm{mM}\end{array}$ & $\begin{array}{l}\text { FRP } \\
\text { ms }\end{array}$ & $\begin{array}{l}\mathrm{VL}_{\mathrm{L}} \\
\mathrm{cm} / \mathrm{s}\end{array}$ & $\begin{array}{l}V_{T} \\
\mathrm{~cm} / \mathrm{s}\end{array}$ & $V_{L} N_{T}$ & $\begin{array}{l}\text { WLL } \\
\mathrm{cm}\end{array}$ & $\begin{array}{c}W L T \\
\mathrm{~cm}\end{array}$ \\
\hline 5.6 & $160 \pm 11$ & $66 \pm 6$ & $24 \pm 5$ & $2.8 \pm 0.6$ & $10.5 \pm 1.0$ & $3.8 \pm 0.8$ \\
\hline 7.0 & $\begin{array}{c}160 \pm 17 \\
n s\end{array}$ & $\begin{array}{c}67 \pm 11 \\
\text { ns }\end{array}$ & $\begin{array}{c}23 \pm 4 \\
n s\end{array}$ & $\begin{array}{c}3.0 \pm 0.9 \\
\mathrm{~ns}\end{array}$ & $\begin{array}{c}10.4 \pm 1.2 \\
\text { ns }\end{array}$ & $\begin{array}{c}3.6 \pm 1.0 \\
n s\end{array}$ \\
\hline 9.4 & $\underset{*}{216 \pm 33}$ & $48 \pm 11$ & $\begin{array}{c}20 \pm 5 \\
\mathrm{~ns}\end{array}$ & $\begin{array}{c}2.5 \pm 0.5 \\
\mathrm{~ns}\end{array}$ & $\begin{array}{c}10.0 \pm 1.6 \\
\mathrm{~ns}\end{array}$ & $\begin{array}{c}4.2 \pm 0.6 \\
\mathrm{~ns}\end{array}$ \\
\hline 10.5 & $c_{*}^{252 \pm 43}$ & $30 \pm 6$ & $\begin{array}{c}22 \pm 4 \\
\text { ns }\end{array}$ & $\begin{array}{c}1.5 \pm 0.5 \\
\mathrm{~ns}\end{array}$ & $7.9 \pm 2.4$ & $5.5 \pm 0.5$ \\
\hline
\end{tabular}

B

The effects of extracellular potassium during maximal pacing.

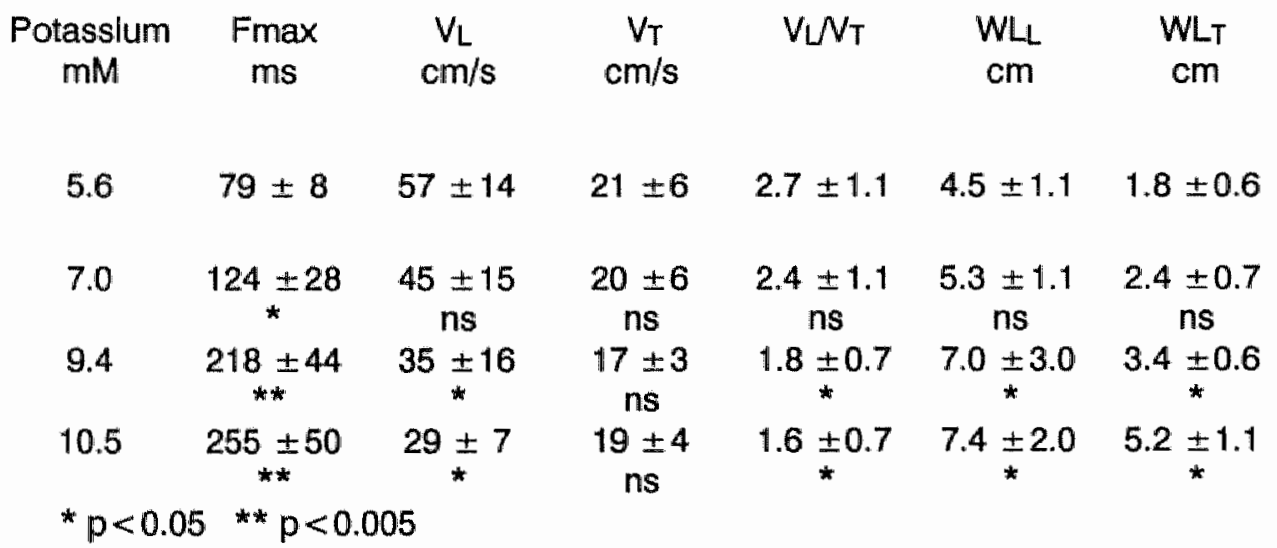


the refractory period thus resulted in a clear prolongation of the transverse wavelenght from 3.8 to $5.5 \mathrm{~cm}(+44 \%, \mathrm{p}<0.05)$.

During potassium administration (table 2.|lB) the shortest possible pacing interval gradually increased (from 79 to $255 \mathrm{~ms}(+179 \%, \mathrm{p}<0.005)$. Longitudinal conduction velocity during Fmax slowed from 57 to $29 \mathrm{~cm} / \mathrm{s}(-49 \%, \mathrm{p}<0.05)$ and the transverse velocity from 21 to $19 \mathrm{~cm} / \mathrm{s}(-10 \%, n s)$. This resulted in a marked decrease of the degree of anisotropy from 2.7 to $1.6(-41 \%, p<0.05)$. Because the lengthening of the shortest pacing interval was not fully counteracted by the slowing of conductlon, both in the longitudinal and in the transverse direction the wavelength increased. During Fmax the longitudinal wavelength prolonged from 4.5 to $7.4 \mathrm{~cm}(+64 \%, p<0.05)$ and the transverse wavelength from $1.8 \mathrm{~cm}$ to $5.2 \mathrm{~cm}(+188 \%, p<0.05)$.

\section{The effects of temperature.}

The effects of temperature were studied during pacing at a cycle length of $950 \mathrm{~ms}$ and during the maximum pacing frequency $(n=5)$. In figure 2.4 and table 2. III the mean values of the refractory period, conduction velocity and wavelength are given. Changes in temperature had pronounced effects on both conduction velocity and refractory perlod. When during pacing at a constant cycle length of $950 \mathrm{~ms}$ the temperature was lowered from $37^{\circ} \mathrm{C}$ to $23^{\circ} \mathrm{C}$ the refractory perlod lengthened from $185 \mathrm{~ms}$ to $441 \mathrm{~ms}$ $(+24 \%, p<0.005)$. At the same time longitudinal conduction velocity slowed down from $64 \mathrm{~cm} / \mathrm{s}$ to $32 \mathrm{~cm} / \mathrm{s}(-50 \%, p<0.05)$ and the transverse velocity from $29 \mathrm{~cm} / \mathrm{s}$ to $11 \mathrm{~cm} / \mathrm{s}(-62 \%, p<0.05)$. During cooling the $V_{L} N_{T}$ ratlo increased from 2.3 to 2.8 $(+21 \%, n s)$.

As can be seen from flgure 4 the effects of cooling on the wavelength are blfasic both in a longitudinal and a transverse direction. When the temperature was lowered from $37^{\circ} \mathrm{C}$ to $29^{\circ} \mathrm{C}$, the wavelength first increased from $11.8 \mathrm{~cm}$ to $15.0 \mathrm{~cm}(+27 \%$. $\mathrm{p}<0.05)$ and from $5.4 \mathrm{~cm}$ to $6.8 \mathrm{~cm}(+26 \%, \mathrm{p}<0.005)$ respectively. In this temperature range the lengthening of the refractory perlod was greater than the decrease in conduction velocity. However when the temperature was further lowered from $29^{\circ} \mathrm{C}$ to $23{ }^{\circ} \mathrm{C}$ the wavelength shortened again to $13.8 \mathrm{~cm}(+16 \%, \mathrm{~ns})$ and $5.0 \mathrm{~cm}(-7 \%, \mathrm{~ns})$ because the conduction velocity was stronger affected than the refractory perlod.

In table III B the effects of cooling on the wavelength are given during pacing at the maximum pacing frequency. The shortest possible pacing interval increased from 

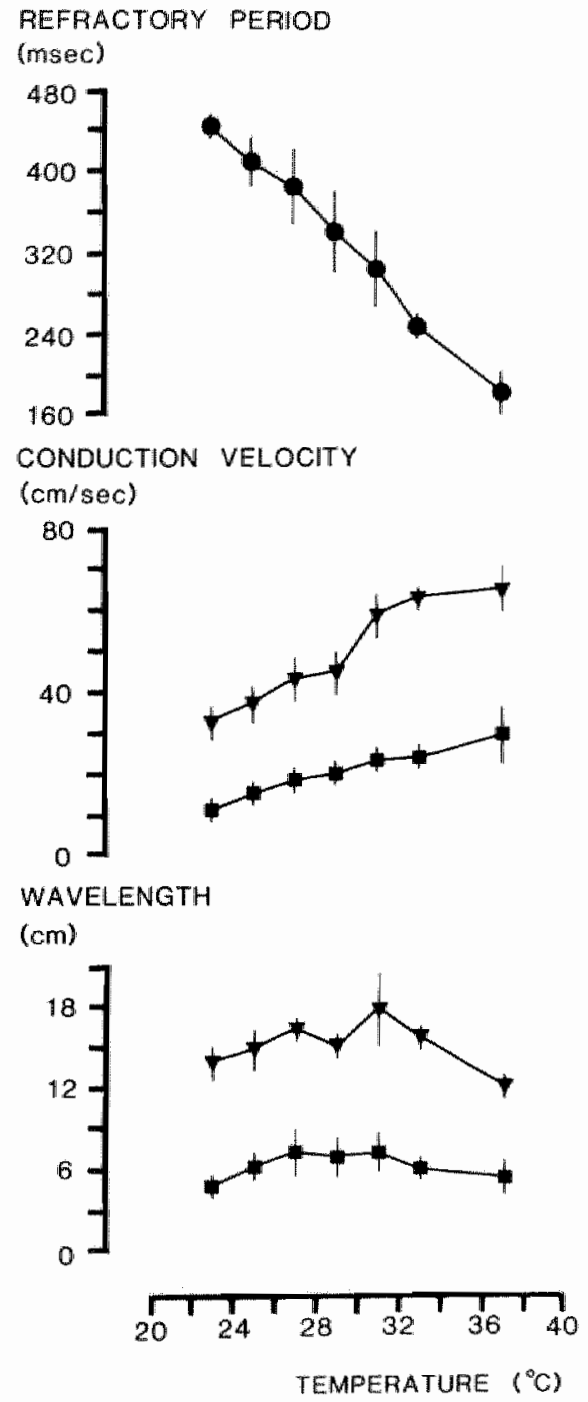

Eloure 2.4. The influence of temperature on the wavelength during slow regular pacing $(950 \mathrm{~ms}$, $(n=6)$. When the temperature was lowered to $29^{\circ} \mathrm{C}$, both the longitudinal and the transverse wavelength lengthened (respectively from $11.9 \pm 1.1 \mathrm{~cm}$ to $15.1 \pm 0.5 \mathrm{~cm}$ and from $5.4 \pm 1.4 \mathrm{~cm}$ to $6.8 \pm 1.5 \mathrm{~cm}$ ). A further lowering of the temperature to $23{ }^{\circ} \mathrm{C}$ resulted in a shortening of the longitudinal and the transwerse wavelength. However both the longitudinal and the transverse wavelength were not significantly altered compared with the values determined at $37^{\circ} \mathrm{C}$. 


\section{Table 2.III}

A

The effects of Temperature $\left(V_{1}-V_{1} 950 \mathrm{~ms}\right)$.

\begin{tabular}{|c|c|c|c|c|c|c|}
\hline $\begin{array}{l}\text { Temp } \\
{ }^{\circ} \mathrm{C}\end{array}$ & $\begin{array}{l}\text { Frp } \\
\text { ms }\end{array}$ & $\begin{array}{c}V_{L} \\
\mathrm{~cm} / \mathrm{s}\end{array}$ & $\begin{array}{c}V_{T} \\
\mathrm{~cm} / \mathrm{s}\end{array}$ & $V \sqcup N_{T}$ & $\begin{array}{l}W L \\
\mathrm{~cm}\end{array}$ & $\begin{array}{c}W L T \\
\mathrm{~cm}\end{array}$ \\
\hline 37 & $185 \pm 16$ & $64 \pm 6$ & $29 \pm 7$ & $2.3 \pm 0.6$ & $11.9 \pm 1.1$ & $5.4 \pm 1.4$ \\
\hline 29 & $\underset{\star \star}{342 \pm 39}$ & $\underset{\star \star}{45}$ & $\begin{array}{c}20 \pm 3 \\
*\end{array}$ & $\begin{array}{c}2.3 \pm 0.4 \\
\text { ns }\end{array}$ & $\underset{*}{15.1 \pm 0.5}$ & $6.8 \pm 1.5$ \\
\hline 25 & $\underset{* \star}{408 \pm 23}$ & $\underset{* \star}{ \pm 7}$ & $\underset{*}{15 \pm 1}$ & $\begin{array}{c}2.4 \pm 0.3 \\
\text { ns }\end{array}$ & $\begin{array}{c}14.8 \pm 1.6 \\
\mathrm{~ns}\end{array}$ & $\begin{array}{c}6.2 \pm 0.4 \\
\mathrm{~ns}\end{array}$ \\
\hline 23 & $\underset{\star \star}{441 \pm 15}$ & $\begin{array}{c}32 \pm 4 \\
\star \star\end{array}$ & $\begin{array}{c}11 \pm 1 \\
*\end{array}$ & $\begin{array}{c}2.8 \pm 0.5 \\
\mathrm{~ns}\end{array}$ & $\begin{array}{c}13.8 \pm 1.2 \\
\mathrm{~ns}\end{array}$ & $\begin{array}{c}5.0 \pm 0.5 \\
\mathrm{~ns}\end{array}$ \\
\hline
\end{tabular}

\section{B}

The effects of Temperature ( $\left.F_{\max }\right)$.

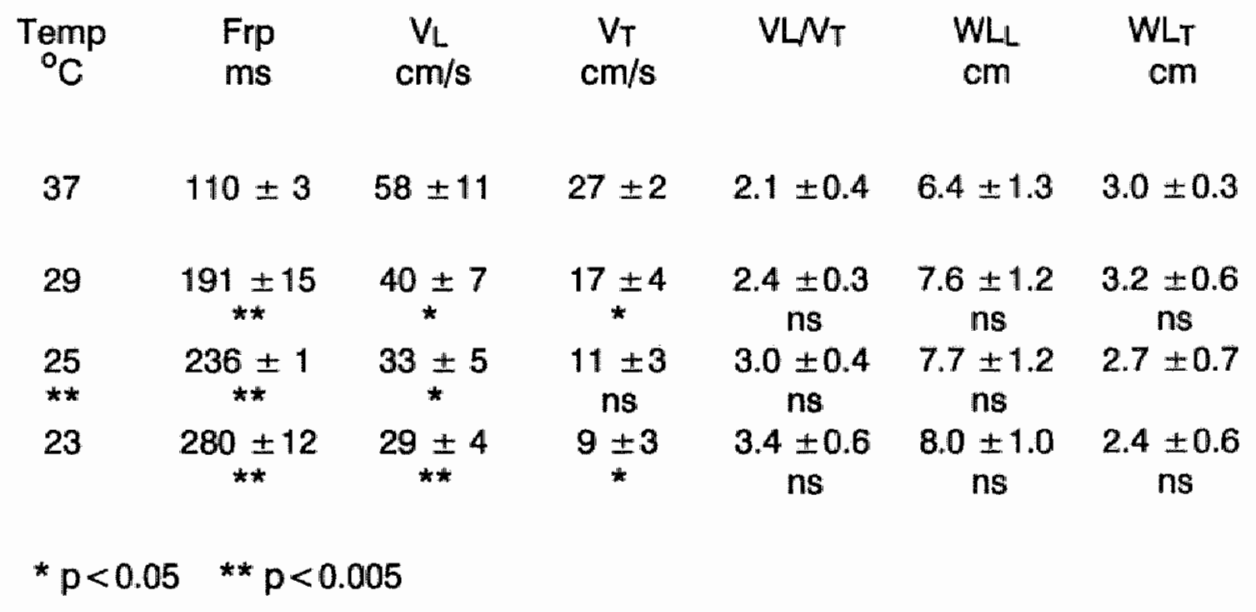


$110 \mathrm{~ms}$ to $322 \mathrm{~ms}(+193 \%, \mathrm{p}<0.005)$ when the temperature was lowered from $37^{\circ} \mathrm{C}$ to $23{ }^{\circ} \mathrm{C}$. The longitudinal conduction velocity decreased from $58 \mathrm{~cm} / \mathrm{s}$ to $29 \mathrm{~cm} / \mathrm{s}(-$ $50 \%, p<0.005)$ and transverse conduction velocity from $27 \mathrm{~cm} / \mathrm{s}$ to $9 \mathrm{~cm} / \mathrm{s}(-67 \%$.

$p<0.005)$ resulting In an increase of the $V_{L} N_{T}$ ratio from 2.1 to $3.4(+62 \%$, ns). During rapid pacing the decrease of the longitudinal conduction velocity was exceeded by the lengthening of the refractory period resulting in an lengthening of the longitudinal wavelength from $6.4 \mathrm{~cm}$ to $8.0 \mathrm{~cm}(+25 \%$, ns). However because of the strong slowing of conduction velocity in a transverse direction the transverse wavelength actually decreased from $3.0 \mathrm{~cm}$ to $2.4 \mathrm{~cm}(-20 \%$, ns). This opposite effect of cooling on the wavelength in a longitudinal and transverse direction resulted in an exaggeration of the difference in wavelength in different directions. Whereas during normal temperature the longitudinal wavelength was 2 times as long as the transverse wavelength, at $23^{\circ} \mathrm{C}$ the longltudinal wavelength was about four times as long as the transverse wavelength.

\section{The effects of epinephrine.}

The effects of epinephrine $(n=5)$ on refractoriness, conduction velocity and wavelength are summarized In table 2.IV and flgure 2.5A. Because it is known that the effectiveness of eplnephrine increases when the pacing frequency is increased the preparations were paced at a cycle length of $200 \mathrm{~ms}$. The concentration of epinephrine was increased in steps from $0.9 \times 10-7 \mathrm{M}$ to $4.5 \times 10-7 \mathrm{M}$. The refractory period shortened from $148 \mathrm{~ms}$ during control to $123 \mathrm{~ms}(-17 \%, p<0.05)$ at the highest concentration of epinephrine. The longitudinal conduction velocity increased from $52 \mathrm{~cm} / \mathrm{s}$ to $57 \mathrm{~cm} / \mathrm{s}$ $(+10 \%, \mathrm{~ns})$, and the transverse conduction velocity increased from $19 \mathrm{~cm} / \mathrm{s}$, to 21 $\mathrm{cm} / \mathrm{s}(+11 \%, \mathrm{~ns})$. The degree of anlsotropy was not changed by epinephrine. The longitudinal wavelength decreased from $7.7 \mathrm{~cm}$ to $7.0 \mathrm{~cm}(-7 \%, \mathrm{~ns})$ and from $2.9 \mathrm{~cm}$ to $2.5 \mathrm{~cm}(-14 \%$, ns) perpendlcular to the fiber direction.

\section{The effects of lidocaine.}

Figure 2.5B and table 2.V give the effects of different concentrations of lidocaine $(n=5)$ on conductlon velocity, refractory period and wavelength. Because of the rate dependent properties of lidocalne the hearts were paced at a relatively high rate (200 
(msec)
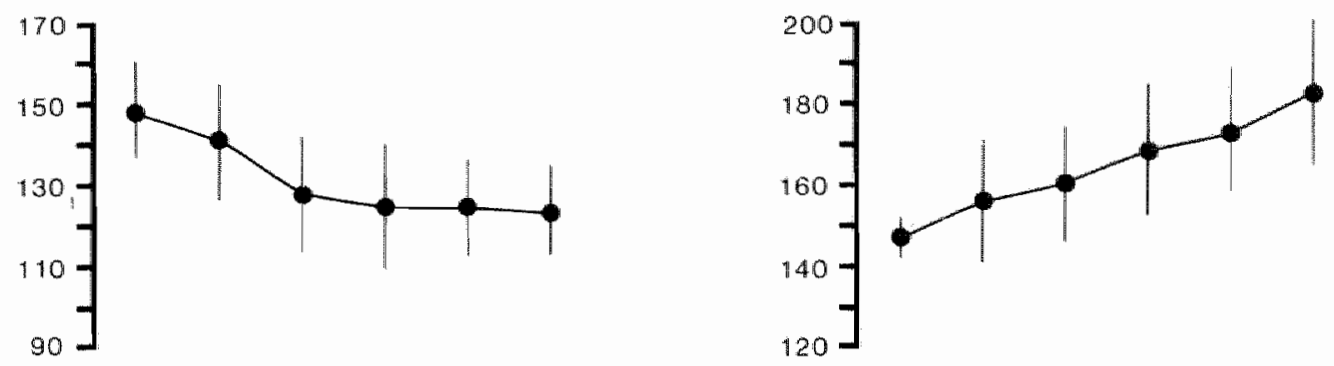

CONDUCTION VELOCITY

$(\mathrm{cm} / \mathrm{sec})$
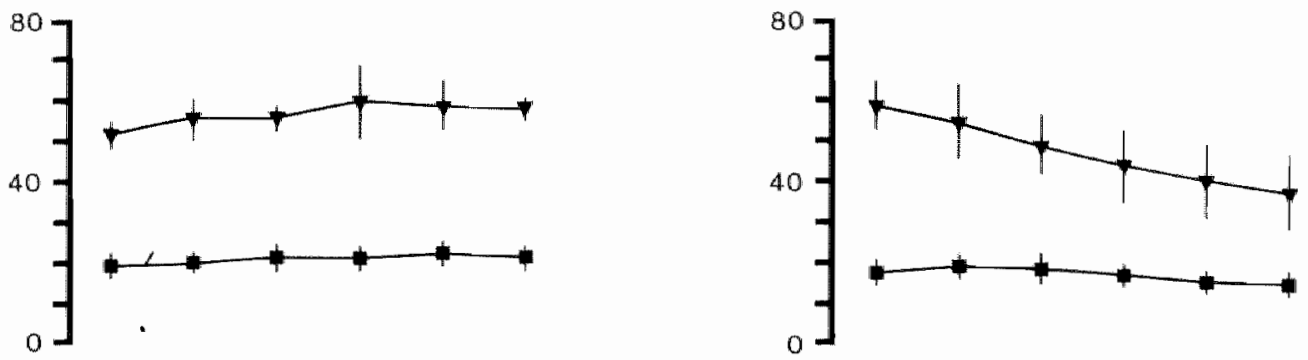

WAVELENGTH

(cm)
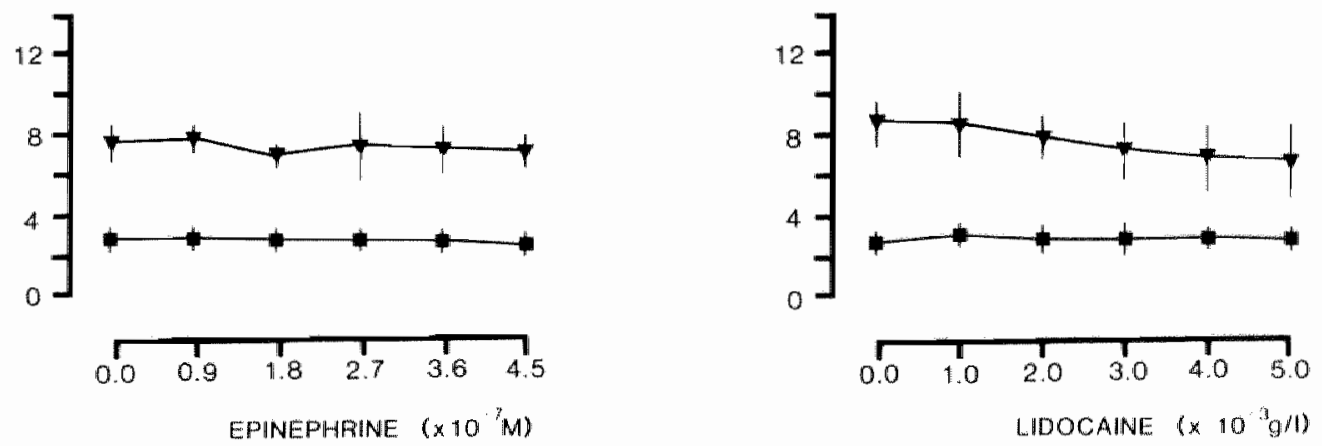

Eigure 2.5. The effects of increasing concentrations of epinephrine $(n=5$, panel A) and Lidocaine $(n=5$, panel $B)$ on the wavelength during regular pacing with a oycle length of $200 \mathrm{~ms}$. During eplne. phrine the wavelength was not changed because the shortening of the refractory period (from $148 \pm 12$ $\mathrm{ms}$ to $123 \pm 11 \mathrm{~ms}$ ) was abolished by a slight increase of both the longitudinal (from $52 \pm 3 \mathrm{~cm} / \mathrm{s}$ to 57 $\pm 3 \mathrm{~cm} / \mathrm{s}$ ) and the transverse conduction velocity (from $19 \pm 2 \mathrm{~cm} / \mathrm{s}$ to $21 \pm 1 \mathrm{~cm} / \mathrm{s}$ ). During lldocaine the refractory period increased gradually from $146 \pm 4 \mathrm{~ms}$ during control to $182 \pm 18 \mathrm{~ms}$ at the highest concentration $\left(5 \times 10^{-3} \mathrm{~g} / \mathrm{l}\right)$. Longitudinal conduction velocity slowed from $58 \pm 5 \mathrm{~cm} / \mathrm{s}$ to $36 \pm 9 \mathrm{~cm} / \mathrm{s}$ and the longitudinal wavelength shortened from $8.5 \pm 1.0 \mathrm{~cm}$ to $6.5 \pm 1.8 \mathrm{~cm}$. The transverse wavelength was not altered and remained $2.7 \pm 0.3 \mathrm{~cm}$. 


\section{Table IV}

The effects of Eplnephrline $\left(V_{1} V_{1}=200 \mathrm{~ms}\right)$

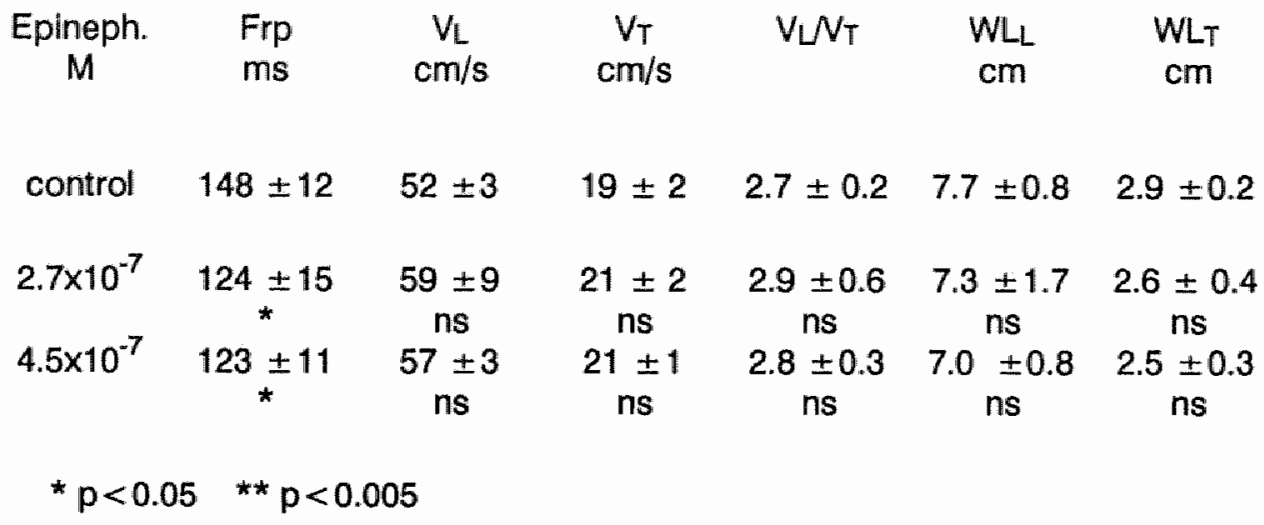

\section{Table V}

The effects of Lidocaine N1V1 $=200 \mathrm{~ms})$.

$\begin{array}{ccccccc}\text { Lidocaine } & \text { Frp } & V_{L} & V_{T} & V_{L} N_{T} & W L L & W L_{T} \\ \mathrm{~g} / \mathrm{ml} & \mathrm{ms} & \mathrm{cm} / \mathrm{s} & \mathrm{cm} / \mathrm{s} & & \mathrm{cm} & \mathrm{cm}\end{array}$

Control $\quad 146 \pm 4 \quad 58 \pm 5 \quad 19 \pm 3 \quad 3.1 \pm 0.5 \quad 8.5 \pm 1.0 \quad 2.7 \pm 0.3$

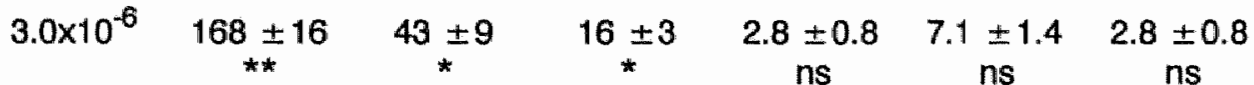
$\begin{array}{ccccccc}4.0 \times 10^{-6} & 173 \pm 15 & 39 \pm 9 & 14 \pm 3 & 2.8 \pm 0.7 & 6.7 \pm 1.6 & 2.8 \pm 0.7 \\ & * \star & * & * \star & \text { ns } & \text { ns } & \text { ns }\end{array}$

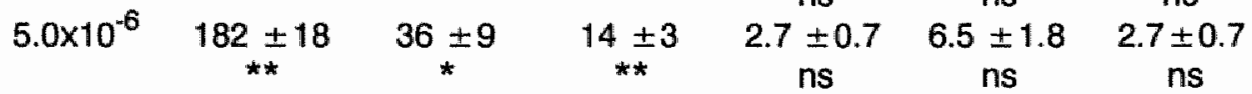
${ }^{\star} \mathrm{p}<0.05{ }^{* *} \mathrm{p}<0.005$ 
ms cycle length) (Buchanan et al., 1985). When the lidocaine concentration was in: creased stepwise from 0 to $5.10^{-6} \mathrm{~g} / \mathrm{ml}$, the refractory period increased from $146 \mathrm{~ms}$ to $182 \mathrm{~ms}(+20 \%, p<0.005)$. The longitudinal conductlon velocity decreased from 58 $\mathrm{cm} / \mathrm{s}$ to $36 \mathrm{~cm} / \mathrm{s}(-38 \%, p<0.05)$ and transverse conduction velocity decreased from $19 \mathrm{~cm} / \mathrm{s}$, to $14 \mathrm{~cm} / \mathrm{s}(-26 \%, \mathrm{p}<0.005)$. Because longitudinal conduction was affected more by lidocaine than transverse conduction, lidocaine caused a decrease of the degree of anisotropy from 3.1 to $2.7(-13 \%, n s)$. The wavelength measured along the longitudinal axis decreased from $8.6 \mathrm{~cm}$ to $6.5 \mathrm{~cm}(-24 \%, \mathrm{~ns})$, whereas the transverse wavelength was not altered by lidocaine and remained $2.7 \mathrm{~cm}$.

\subsection{DISCUSSION}

The wavelength of refractoriness and the spatial Inhomogeneity in conduction have shown to be key factors in the induction of reentrant arrhythmlas (Smeets et al., 1986, Rensma et al., 1988, Lammers et al., 1988). In addition in recent years several investigators have reported that anlsotropy plays an important role in the occurrence of local conduction block and the initiation of reentry (Spach et al., 1981 „1986, 1987, Wit et al., 1987, Dillon et al., 1988). First the effects on the degree of anisotropy (the ratio between longitudinal and transverse conduction velocity) will be discussed. The different groups are grouped on their effects on the degree of anisotropy and regrouped on their effects on the wavelength of refractoriness.

\section{Effects of rate.}

In 1976 Clerc demonstrated that the axial resistance is 9.4 times larger in a transverse than in a longitudinal direction. Because conductlon velocity is inversely related to the square root of the axial resistance (Hodgkin and Huxley, 1952), conduction in a tranverse direction is about three times slower than in a longitudinal direction (Clerc 1976, Spach et al.,1981, 1982b, Tsubol et al., 1985, Delmar et al.,1987). The results of our control studies are in agreement with thls. During pacing with a pacing interval of $350 \mathrm{~ms}$ the longitudinal conduction velocity was $68 \mathrm{~cm} / \mathrm{s}$ and the transverse conduction velocity $24 \mathrm{~cm} / \mathrm{s}$ resulting in a $V_{L} V_{T}$ ratio of 2.9 . Due to the different contribution of the cytoplasmic resistance and the nexus resistance to the effective axlal resistance 
measured parallel and perpendicular to the fiber direction (Spach et al.., 1979, 1981), an increase of the nexus resistance will slow down transverse conduction to a greater extent than longitudinal conduction resulting in an increase of the VL $N_{T}$ ratio. Spach et al. (1982), Tsubol et al. (1985) and Delmar et al. (1987) showed that when the nexus resistance was increased by rapid pacing or heptanol administration transverse conduction slowed to a greater extent than longitudinal conduction resulting in an increase of the $V_{L} N_{T}$ ratio. The increase of the nexus resistance during rapid pacing was explained, by assuming that during rapid pacing the calcium concentration rises due to an increased sodium-calclum exchange (Bredikis et al., 1981, Cohen et al., 1982, Spach et al., 1982, DeMello, 1976, 1983). This was supported by the finding that verapamil partially abollshed the slowing of the transverse conduction velocity by blockIng the calclum inward current (Tsuboi et al., 1985, Delmar et al., 1987). In our study however the $V_{L} N_{T}$ ratlo was not altered during rapid pacing, longitudinal and transverse conduction being slowed down to the same extent. This difference in our results and the data of Spach et al.(1982), Tsuboi et al.(1985) and Delmar et al.(1987) might be explained by the different preparations used in these studies. In most studies isolated sheets of myocardium and paplllary muscle preparations superfused in a tissue bath are used to study anisotropic conduction (Clerc, 1977, Spach et al., 1982b, 1986, Tsubol et al., 1985, Kadish et al., 1986, Delmar et al., 1987). To maintain stable conduction, such experiments had to be carried out at reduced temperatures $\left(25-30^{\circ} \mathrm{C}\right)$ or within a limited range of pacing frequencies. Under normothermic conditions the conductlon velocity of In vitro preparatlons is strongly rate dependent and conduction block occurs at a lower pacing frequency than in a perfused heart (Spach et al., 1982b, Tsubol et al., 1985, Delmar et al., 1987). In the intact Langendorff perfused rabbit left ventricle as used in our studles, the maximal pacing frequency is 2-3 times higher than in superfused preparations. At the maximal pacing rate conduction velocity slowed down only $15 \%$ and stable conditions could be maintalned for more than eight hours without any significant change of the electrophysiological properties. It can thus be concluded that the results obtained by using a Langendorff perfused heart are

\section{Effects of premature beats and potassium}

When the membrane properties of anisotropic myocardium are depressed homogeneously the $V_{U} N_{T}$ ratio should not be altered (Spach et al.,1981, 1982b). In agree- 
ment with this Spach et al. (1982b), Tubol et al., (1985), and Delmar et al. (1987) demonstrated that the VUNT ratio was not changed by premature beats or increased extracellular potassium concentration. In our study we found that conduction was not changed during premature beats and the degree of anisotropy was not altered.

However in contrast with the results of Tsubol et al. (1985) we demonstrated that when the extracellular potassium concentration was increased to $10.5 \mathrm{mM}_{\text {" }}$ longitudlnal conduction was slowed down to a greater extent than transverse conduction, both during regular pacing and during pacing at the maximal pacing frequency. The $V_{L} N_{T}$ ratio decreased, from 2.8 to 1.5 during regular pacing (350 $\mathrm{ms}$ interval) and from 2.7 to 1.6 during pacing at the maximal pacing frequency. Dominquez and Fozzard (1970) showed that when the potassium concentration is elevated above $7.5 \mathrm{mM}$ both conduction velocity and Vmax decreased and a linear relation between the Vmax of the action potential and the square of the conduction velocity was found (Dominquez and Fozzard, 1970, January and Fozzard, 1984, Buchanan et al., 1985, Kishida et al., 1979). Because it is known that the longitudinal $V_{\max }$ is depressed to a greater extent than the transverse Vmax (Tsuboll et al., 1986) the ratio between the longitudinal and transverse upstroke velocity $\left(V_{\max }\right)$ of the actlon potential decreased significantly. According to the results of Dominquez and Fozzard (1970) the decrease of the ratio between the longitudinal and transverse Vmax should thus be accompanied by a decrease of the $\mathrm{V} \sqcup N_{\mathrm{T}}$ ratio which is in accordance with the results of our study.

\section{Effects of cooling}

It is known that during coolling the activity of the $\mathrm{Na} / \mathrm{K}$ pump is depressed (Jack et al., 1975, Noble, 1975). Because the $\mathrm{Na} / \mathrm{K}$ pump is necessary to maintain a low intracellular sodium concentration, cooling of the heart results in an increase of the intracellular sodium concentration. As a result of this increase of the sodium concentration, sodium will be exchanged by calcium leading to an increased intracellular calcium concentration (DeMello, 1976). The increase of the intracellular calclum concentration results in increase of the junctional resistance. Due to the different contribution of the junctional resistance to the effective axial resistance in anisotropic myocardium (Clerc, 1977, Spach et al., 1979 "1981) transverse conduction is slowed to a greater extent than the longitudinal conduction. Our results demonstrated that the VLNT ratio increased from 2.3 to 2.8 during slow pacing (950 $\mathrm{ms}$ interval) and from 2.1 
to 3.4 during pacing at a maximal pacing frequency. Due to the limited number of experiments $(n=5)$ however this increase of the $V_{L} N_{T}$ ratio was not statistically significant.

\section{Effects of epinephrine and لlidocaine}

Epinephrine increases the calcium inward current resulting in an increased intracellular calcium concentration (Noble ${ }_{1}$ 1975). As a result of the increased intracellular calcium concentration it can be expected that the nexus resistance increases (DeMello, 1983). However epinephrine also stimulates the uptake of free intracellular calcium Into internal membraneous organells such as mitochondria and sarcoplasmic reticulum. As a result of this a low intracellular free calclum concentration is maintained and the nexus resilstance is not changed (Jack et al., 1975, Noble, 1975). Because epinephrine has no effects on the sodlum inward current (Noble, 1975) the Vmax of the actlon potentlal will not be affected and conduction velocity will not change, which is in agreement with the results of the study of Antoni and Zerweck (1967). During epinephrine administration in our study conduction velocity was not changed and the degree of anisotropy remained 2.7 .

Class I antlarrhythmic drugs which depress conduction velocity by blocking the fast sodlum channels (Hoffman and Cranefleld, 1960, Buchanan et al., 1985, Kadish et al., 1986, Spach et al., 1987), have been reported to exert different effects on longitudinal and transverse conduction. Kadish et al.(1986) demonstrated that during the administration of procainamide, longitudinal conduction was slowed down to a greater extent than tranverse conduction resulting in a decrease of the $V_{\sqcup} N_{T}$ ratio. This was explained by assuming a different drug binding capacity (Kadish et al., 1986, Spach ot al., 1987). It is known that the amount of drug binding depends on the opening time of the fast sodlum channels (Arnsdorf and Blgger, 1976, Buchanan et al, 1985). Spach and Kootsey (1985) showed that the opening time of the sodium channels is longer during longitudinal conduction than during transverse conduction resulting in a longer drug binding time during longltudinal conduction than during transverse conduction. In our study lldocaine administration resulted in a small and not significant decrease In the degree of anisotropy from 3.1 to 2.7. Desplte the differences between class I A, $B$ and $C$ antiarrhythmica it can be expected that after administration these drugs 
change the degree of anisotropy, e.g. the $V_{U} N_{T}$ ratio, because they all affect the upstroke velocity of the action potential by depressing the sodlum inward current.

Iissue anisotropy and the wavelength of refractoriness.

Among other things the inducibility of reentrant arrhythmias is determined by the wavelength of refractoriness (wavelength $=$ conduction velocity $\times$ functional refractory period, Smeets et al., 1986, Rensma et al., 1988). When the wavelength is shortened either by slowing of conduction or by shortening of the refractory period only a small area of conduction block will be needed to initiate reentry. A short wavelength was found to correlate with a high vulnerability to reentrant arrythmias either in Isolated rabbit atrium and in consclous dogs (Smeets et al., 1986, Rensma et al., 1988). In the latter studies the wavelength of refractoriness was shown to be a sensitive and specific index of the susceptibility of the heart to atrial arrhythmias with an overall predictive power of $75 \%$. Although in the present study we did not directly correlate the length of the excitation wave with the inducibility of ventricular arrhythmlas the results seems to support the wavelength concept.

It is known from experimental (El-Sherif et al.,1977b, Dillon et al., 1988) and clinical studlies (Wellens et al.,1972, 1974, Wellens, 1975a) that rapid ventricular pacing or premature stimuli may initiate reentrant ventricular arrhythmias. The observation that during incremental pacing and during premature beats the longltudinal and transverse wavelength shortened is in agreement with the enhanced risk of the initation of reentry. During incremental pacing when the pacing interval decreased from $350 \mathrm{~ms}$ to 85 $\mathrm{ms}$, the shortening of the wavelength with $55 \%$ was caused by a shortening of the refractory period with $45 \%$ and a slowing of conduction with $\pm 15 \%$. During premature beats the shortening of the wavelength was completely caused by a shortening of the refractory period $(-21 \%)$, both the conduction velocity in a longitudinal and transverse direction not changing significantly.

\section{The effects of potassium and cooling}

Increased extracellular potassium depresses conduction and prolongs refractoriness in cardiac tissue (Fish et al., 1963). Conduction velocity and refractory period were affected to the same extent when the concentration was increased upto $7.0 \mathrm{mM}$ 
and the wavelenght was not changed. However when the potassium concentration was increased to $10.5 \mathrm{mM}$ the wavelength was significantly changed. During regular pacing ( $350 \mathrm{~ms}$ pacing interval) the longitudinal wavelength (-25\%) decreased because the lengthening of the refractory perlod $(+58 \%)$ was less than the slowing of the conduction velocity $(-55 \%)$. The transverse wavelength increased $(+41 \%)$ due to the lengthening of the refractory period wheras transverse conduction was not changed. During pacing at the maximal pacing frequency both the longitudinal and tranverse wavelength lengthened (respectively with $64 \%$ and $188 \%$ ) due to a $176 \%$ increase of the maximal pacing interval despite a slowing of longitudinal conduction $(-49 \%)$ and transverse conduction (-10\%). This lengthening of the wavelength during maximal pacing is in accordance with the known defibrillatory action of potassium infusion (Wiggers, 1953) and may explain that a single dose of high potassium administered during fibrillation or tachycardia in patients will terminate the arrhythmias, before the hearts become totally inexcitable (Grumbach et al., 1954).

It is a frequent observation that ventricular tachycardia, initiated in patients after a myocardlal infarction sometimes could not be Initlated anymore during cardlac surgery under hypothermia (Josephson and Wellens, 1984). If these arrhythmias are caused by reentrant excitation it can be expected that during cooling the wavelength prolongs. We found that during slow pacing and during pacing at the maximal pacing frequency the wavelength prolonged when the temperature was lowered from $37^{\circ} \mathrm{C}$ to $29^{\circ} \mathrm{C}$. A further lowering of the temperature from $29^{\circ} \mathrm{C}$ to $23^{\circ} \mathrm{C}$ resulted in a shortening of the longltudinal and transverse wavelength, but compared to $37^{\circ} \mathrm{C}$ the wavelength was not changed. During pacing at the maximal pacing rate a decrease of the temperature from $29^{\circ} \mathrm{C}$ to $23^{\circ} \mathrm{C}$ resulted in a further prolongation of the longitudinal wavelength $(+25 \%)$ due to a prolongation of the refractory period (193\%) which exceeded the slowing of conduction $(-50 \%)$. The transverse wavelength was slightly shortened $f$ $20 \%$ because the slowing of conduction $(-67 \%)$ counteracted the prolongation of the refractory period. The prolongation of the longitudinal and transverse wavelength during cooling from $37^{\circ} \mathrm{C}$ to $29^{\circ} \mathrm{C}$ thus can explain the reduced vulnerability to ventricular reentry during hypothermia. 
Effects of epinephrine and lidocaine.

Epinephrine administration increases the risk of the initiation of ventricular arrhythmias in humans (Lown and Verrier, 1971). Epinephrine shortens the refractory period (Noble, 1975, Millar et al., 1985) while conduction velocity is not changed (Antoni and Merzweck, 1967). We found that during epinephrine administration the refractory period shortened $(-17 \%)$, however because of a small nonsignificant increase of the conduction velocity this resulted only in a minimal shortening of the wavelength. The increased risk of the initiation of arrhythmias can not be explained by the small shortening of the wavelength Presumably the increase of the sinus rate during epinephrine administration, or the accelaration of an ectopic pacemaker may account for the increased risk of arrhythmias (Cranefield, 1974, Noble, 1975).

Lidacaine is one of the most frequently used antl-arrhythmic drugs during the acute phase of a myocardial infarction (Lie et al., 1974). It prolongs the refractory perlod despite a shortening of the action potential duration and depresses conduction velocity (Josephson et al., 1972, Arnsdorf and Wasserstrom, 1986). In atrial myocardium, lidocaine administration results in a slight prolongation of the wavelength but did not prevent the initiation of reentry (Smeets et al.,1986, Rensma et al., 1988). We found that due to the slowing of both longitudinal and transverse conduction velocity, in ventricular myocardium the wavelength actually decreased despite a prolongation of the refractory period. This is in agreement with the results of clinical studies, which demonstrated that lidocaine is ineffective ineffective in terminating ventricular arrhythmias in the chronic phase after myocardial infarction (Horowitz et al., 1978, Josephson, 1986). During acute Ischemia the sodium channels appeared to be extremely sensitive to lidocaine (Lazzara et all., 1978, El-Sherlf et al., 1977a) As a consequence, conduction in ischemic areas will be depressed whereas conduction in healthy myocardium is less affected. Because of this selective actlon reentry circuits within the ischemic myocardium might be prevented. 


\section{CHAPTER III}

\section{ANISOTROPIC CONDUCTION BLOCK OF THE LEFT RABBIT VENTRICLE.}

\subsection{INTRODUCTION}

Local unidirectional conduction block is a key phenomenon in the initiation of reentry arrhythmias. For some decades the occurrence of local conduction block has been attributed to spatial dispersion in refractory period (Alessie et al., 1958, Han and Moe, 1964, Zipes et al., 1974, Allessie et al., 1976, Boineau et al., 1980, Gough et al., 1985), local differences in excitablity (Schmitt and Erlanger, 1928, Cranefield et al. 1971 . Cranefield and Hoffman, 1971) or nonuniformity in the amount of excitatory current generated by the cell membrane (Woodburry and Crill, 1961, Cranefield et al., 1971). More recently geometrical factors of the cardiac syncitium have been considered as a potential cause of unidirectional conduction block (De la Fuente 1971, Mendez et al., 1969, 1970, Rawling et al. 1984, Van Capelle et al., 1976, Spach et al.,1981, 1982a, 1982b, 1986, 1987). In a serles of excellent papers Spach and coworkers (Spach et al., 1981, 1982a, 1982b, 1983, 1986, 1987) have emphasized that not only branching sites or junctions of muscle bundles may form areas with a low safety factor for propagation, but that also anisotropy in passive electrical propertles of the myocardium plays an important role in impulse conduction. The Importance of anisotropy in the genesis of reentrant arrhythmias is supported by the observation that ventricular tachycardias, developing 3-4 days after myocardial infarctlon, orliginate from a thin surviving epicardlal muscle layer showing enhanced anisotroplc properties (Gardner et al., 1985, Wit et al. 1982, 1987, Dillon et al. „1988). In normal ventricular myocardium conduction velocity is about three times faster parallel to the longitudinal fiber axis than in a transverse direction (Dräper and Mya-Tu, 1959, Clerc 1977, Roberts et al. 1979, Spach et al. 1981, 1982b). This anisotropy in propagation is caused by dilrectional differences in effective axial resistance and membrane capacitance (Spach et al., 1981, 1987). Spach et al. showed that, as a result of the different degree of electrotonic load on the propagating depolarization wave, the amplitude and rate of rise 
of the action potential is higher during transverse conduction than during longitudinal propagation (Spach al al., 1981, 1982a, 1982b, 1986, 1987).

However there is still considerable debate about the role of anisotropy in the occurrence of local conduction block. Spach et al. (1981) have argued that because of the lower current load imposed on the depolarization wave during transverse conduction, the margin of safety for transverse propagation is higher than for longitudinal conduction. They postulated that impuises with a decreased stimulating efficacy would preferentially block in a longitudinal direction (Spach et al., 1981). In their experimental studies on the crista terminalis they found that premature impulses were blocked in a longltudinal direction whereas uniform propagation proceeded in a transverse direction. This example of functional "transverse dissociation" which in some cases led to reentry of the crista terminalis was attributed to anisotropic cellular coupling (Spach et al., 1981). On the other hand there are a number of studies showing preferential block in a transverse direction (Schmitt and Erlanger 1928, Anderson et al., 1970, Myerburg et al., 1973, Delmar et al., 1987). In a computer simulation of impulse conduction In a two-dimensional anisotropic sheet of cardiac cells Van Capelle (1.983) was unable to produce longitudinal block. However they found that a critically timed premature impulse could be blocked in a transverse direction.

The aim of the present study was to investigate the role of anisotropy in conduction block and reentry in a perfused two-dimensional sheet of uniform anisotropic ventricular myocardium. We found that if the safety factor of conduction was lowered, either by premature stimulation, rapid pacing or elevation of extracellular potassium, conduction block first occurred in a transverse direction. In contrast to its frequent appearance however, transverse block rarely led to reentry, because the tissue distal to the arc of transverse block was activated by fast longitudinal conduction. The rapid activation of the area distal to a transverse block provided insufficient delay for the cells proximal to the block to restore their excitabillty and reentry was thus often prevented. On the other hand, if (more rarely) a line of longitudinal block occurred, the chance of initiation of a reentrant tachycardia was much higher because of slow transverse conduction distal to the arc of longitudinal block. 


\subsection{METHODS}

Flemish rabbits ( $n=40$ ) of both sexes weighing between 4.5 and $6.5 \mathrm{~kg}$ were used in this study. After heparinization (1000 I.U/I.V.) the animals were killed by a cervical dislocation. The thorax was opened by a midsternal incision and the heart was rapidly removed and placed in cold perfusion fluid $\left(10^{\circ} \mathrm{C}\right)$. The aorta was cannulated and the heart was connected to a Langendorff perfusion system. The coronary arteries were perfused with a perfusion pressure of $50 \mathrm{~mm} \mathrm{Hg}$, resulting in a flow of $35-45$ $\mathrm{ml} / \mathrm{min}$. The millimolar composition of the perfusion fluid was: $\mathrm{NaCl} 130 ; \mathrm{NaHCO}_{3} 20.1$; $\mathrm{KCl} 5.6 ; \mathrm{CaCl}_{2} 2.2 ; \mathrm{MgCl}_{2} 0.6 ; \mathrm{Na}_{2} \mathrm{HPO}_{4} 1.2$ and glucose 12 . The solution was saturated with a mixture of $95 \% \mathrm{O}_{2}$ and $5 \% \mathrm{CO}_{2} \mathrm{pH}$ was 7.35 , and temperature was kept at $37^{\circ} \mathrm{C} \pm 0.5$. In some experiments the potassium concentration of the perfusion fluid was increased by infusion of $\mathrm{KCl}(0.28 \mathrm{M})$ into the aorta cannula with an infusion pump (Razel A-99).

To study the anisotropic properties of the epicardium of the left ventricle, the endocardial and intramural layers were destroyed by freezing (see figure 3.1). The Langendorff perfused rabbit heart was immersed in a tissue bath, containing perfusion fluid of $30^{\circ} \mathrm{C}$. A cryoprobe was installed in the left ventricular cavity and the coronary circulation was temporarily interrupted. The cryoprobe was then filled with liquid nitrogen $\left(-192^{\circ} \mathrm{C}\right)$ and the heart was frozen for 7 minutes. After this period the coronary circulation was restored and the probe removed. In some cases the cryoprobe was also inserted in the right ventricular cavity without interrupting the coronary circulation and without submerging the heart in the tlssue bath. As a result of this procedure the endocardial and intramural parts of the free wall of the left ventricle, the total right ventricular wall and the interventricular septum were destroyed. Only a thin left ventricular epicardial layer of about $1 \mathrm{~mm}$ thick survived. After freezing coronary flow was 0 to $20 \%$ lower than during control (perfusion pressure $50 \mathrm{mmHg}$ ). The heart was allowed to recover for at least 20 minutes before measurements were made. To evaluate the cryoprocedure, at the end of the experiment the heart was perfused with TTC (a buffered 2,3,5 Triphenyl Tetrazolium Chloride solution, Merck). This substance is a specific indicator of dehydrogenase enzymes by ylelding a bright red formazan pigment. No staining occurs at sites where the myocardlum has lost its dehydrogenase activity. This macroscopical staining method has been shown to correlate well with the (ultra) structural signs of myocardial necrosis as demonstrated with standard histologi- 


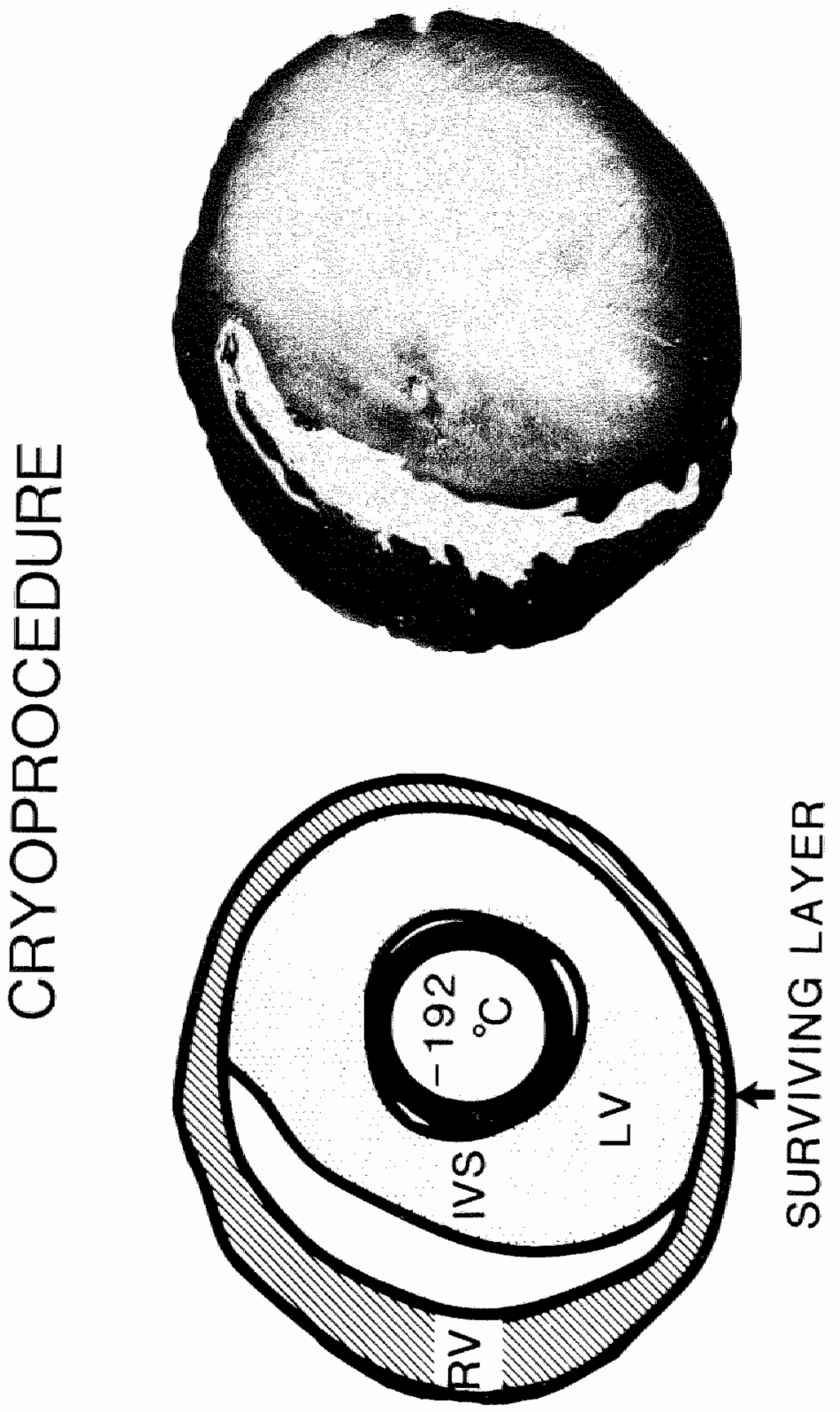


cal or electronmicroscopical techniques (Nachlas and Shnitka, 1963, Fishbein et al, 1981, Vivaldi et al., 1985).

\section{Becording and stimulation.}

For high resolution mapping of epicardial excitation a rectangular (13 $\times 15 \mathrm{~mm})$ electrode, containing 192 ellectrodes with an interelectrode distance of $1 \mathrm{~mm}$ was used. Programmed electrical stimulation was performed with a programmable constant current stimulator delivering square pulses of $2 \mathrm{~ms}$ duration and 2-4 times diastolic threshold. Experimental protocols included pacing at different rates and the application of one to three premature stimuli. Stimuli could be applied to any pair of electrodes of the multi terminal probe. For regular pacing a stimulus strength of two times threshold was used. The intensity of premature stimull was set at four times threshold. Unipolar electrograms were recorded using the cannula in the aorta as indifferent electrode. The recorded electrograms were fed into 192 individual ampliflers (bandwidth 2 - 400 $\mathrm{Hz}$ ) and displayed in groups of eigth on two Tektronix $5103 \mathrm{~N}$ oscilloscopes. The outputs of the amplifiers were multiplexed (sampling rate $2000 \mathrm{~Hz}$ ), digitised ( 8 bit) and after Pulse Code Modulation (Kalser PCM system K1280-00) recorded on tape (Ampex PR 2230). After the experiment the data were analyzed using a PDP 11-73 computer (Digital). An algorithm to detect the Intrinsic negative deflection in the electrograms was used to mark local activation times. Isochrone maps were displayed on the computer video display (VT240, Digital). Details of the mapping system enabling simultaneous recording of 192 electrograms have been described elsewhere (Allessle et al, 1984).

Eigure 31. Left: Schematic representation of the cryoprocedure. A plastio test-tube (diameter 12 $\mathrm{mm}$ ) was inserted into the cavity of the left ventricle and filled with liquid nitrogen. The eplcardium was protected by immersing the heart into a tissue bath of $30^{\circ} \mathrm{C}$. As a result the interventricular septum and the endocardial and intramural layers of the free wall of the left ventricle were destroyed. Only a thin eplcardial layer of about $1 \mathrm{~mm}$ thick survived. Right: TTC staining after the cryoprocedure. The dark epicar* dial rim of tissue represents surviving myocardium. In this case the right ventricle was not frozen and was also stained by TTC. 
Measurement of conduction velocity and refractory period.

Epicardial conduction was analyzed using the rectangular high resolution mapping electrode. The heart was stimulated through a pair of stimulating electrodes in the centre of the probe. One axis of the electrode was positioned parallel to the epicardial fiber direction. This alignment was checked on basis of the highest amplitude and slope of the electrograms recorded along the long fiber axis and by the shortest possible conduction time (Kleber et al, 1986). Conduction velocity was measured both In a longitudinal $\left(V_{L}\right)$ and in a transverse direction $\left(V_{T}\right)$, the degree of anisotropy being expressed by the $V_{L} / V_{T}$ ratio. In addition complete epicardial velocity maps were constructed by calculating the vector of impulse propagation from the activation times of four neighbouring electrodes.

Refractory periods were determined at nine different epicardial sites during pacIng with a cycle length of 350 or $150 \mathrm{~ms}$. After each 15 th regular stimulus a single premature stimulus ( $4 \mathrm{t}$ imes diastolic threshold) was applied and the functional refractory period was determined as the shortest attainable interval between the regular and the premature impulse (shortest $\mathrm{V} 1-\mathrm{V} 2$ interval) at a recording electrode close to the site of stimulation.

To correlate the electrophysiological axis of longitudinal conduction with the anatomical fiber direction the position of the mapping electrode was marked by stainless steel pins and the block of tissue was cut out. After fixation in $4 \%$ formaldehyde serial sectioning (thickness $10 \mu \mathrm{m}$ ) was performed parallel to the eplcardial surface and the sections were stained with Hematoxiline-eosine. Photographs of the sections were used to compare the eplcardial fiber axis with the spread of excitation.

\subsection{RESULTS}

Morphological effects of total endocardial freezing.

To investigate the anisotropic properties of a Langendorff perfused rabbit heart a cryotechnique was used to destroy the endocardial and intramural parts of the left ventricle leaving only a thin layer of epicardial fibers intact. After freezing, the surviving epicardial layer remained adequately perfused through the coronary arteries. Perfu- 

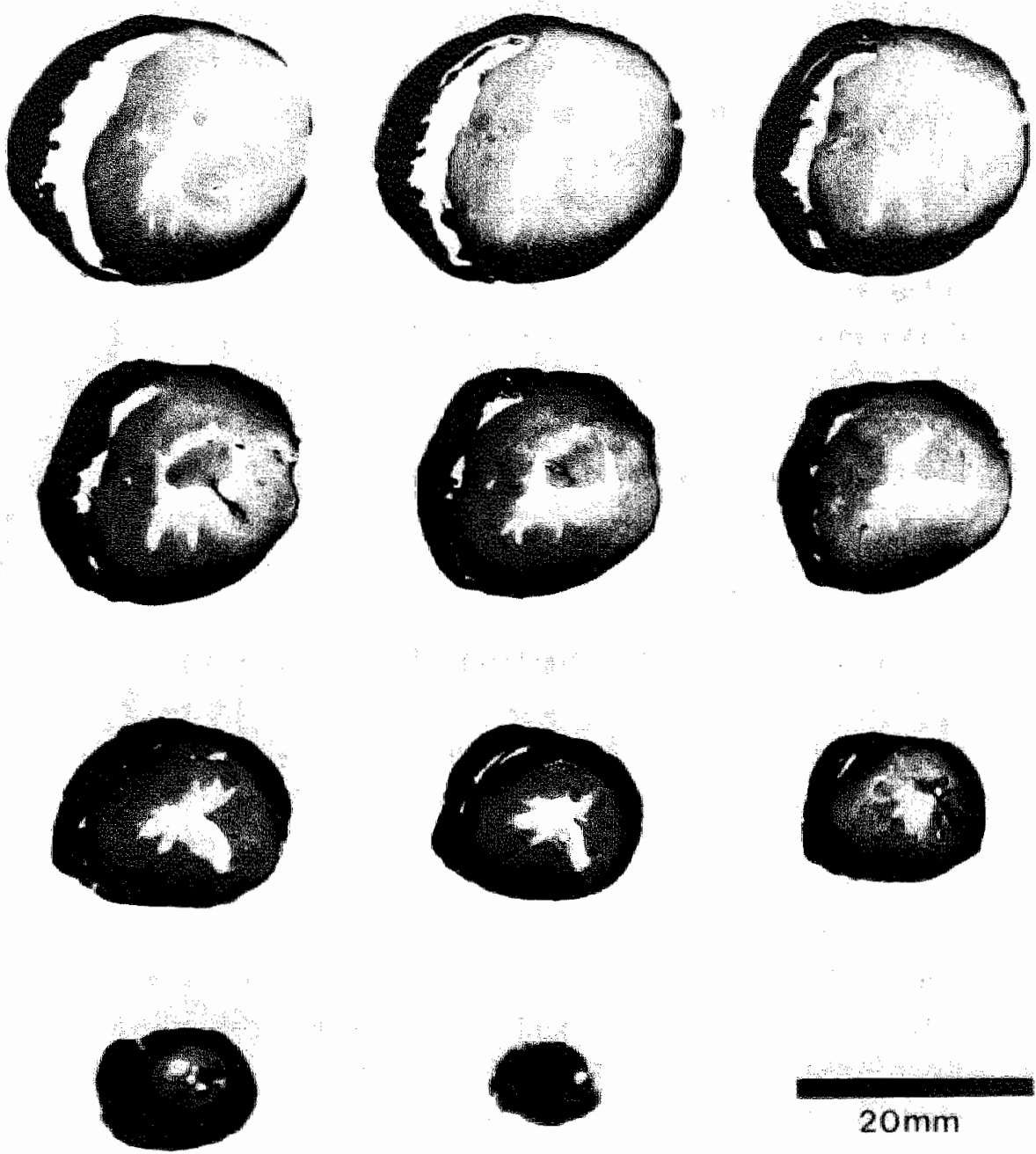

Eigure 3.2. A series of $2 \mathrm{~mm}$ thick slices of rabbit ventricle, cut parallel to the AV-ring and stained with TTC after the cryoprocedure. The darkly stained myocardium represents surviving tlssue. Surviving and destroyed myocardium are sharply separated. No surviving cells could be detected in the destroyed myocardium. Despite the fact that the right ventricle was not frozen, the interventricular septum was completely destrayed. 
sion with triphenyl tetrazolium chloride (TTC) was used to distinguish between surviving and destroyed tissue. After staining, the ventricles were cut in $2 \mathrm{~mm}$ thick sections parallel to the AV ring from base to apex. Figures 3.1 and 3.2 show an example in which the surviving epicardial layer can be recognized by its dark color. In this case only the left ventricular cavity was frozen and therefore in addition to the surviving left epicardlal layer, the right ventricle completely consisted of viable myocardium. The transition between surviving and dead tissue was sudden. Histological examination showed no islands of viable tissue in the destructed parts of the myocardium and no dead fibers in the surviving eplcardlum. The thickness of the surviving epicardial wall, measured at intervals of $2 \mathrm{~mm}$ in 11 hearts was $1.0 \pm 0.4 \mathrm{~mm}(n=99)$. The variation in local thickness of the surviving muscle layer was caused by the presence of epicardial fat and major blood vessels. At places where epicardial fat or a coronary artery was present the surviving rim of the underlying myocardium was thinner. Obviously the interposition of these structures between the epicardium and the tissue bath decreased the protecting effect of the warm surrounding perfusion fluld during freezing.

\section{Electrophysiological evaluation of the surviving epicardial layer.}

To Investigate the effects of the cryoprocedure, refractory periods were measured at 9 different epicardial places of the free wall of the left ventricle. In figure 3.3 the mean epicardial refractory periods as measured in 10 hearts during regular pacing with a cycle length of $350 \mathrm{~ms}$ before and after freezing are shown. In the intact heart local refractory periods varied between 166 and 177 ms (upper numbers) (mean $171 \pm 11$ $\mathrm{ms}$ ). After freezing (lower numbers) the refractory period ranged between 165 and 184 $\mathrm{ms}$ (mean $172 \pm 10 \mathrm{~ms}$ ). At none of the recording sites the endocardiall freezing procedure resulted in a statistically significant change in refractory periods. Also the maximal pacing rate $\left(F_{\max }\right)$ was not affected by the freezing procedure. Before and after freezing the interval of $F_{\text {max }}$ was less than $90 \mathrm{~ms}$.

The effects of the cryoprocedure on the epicardial spread of excitation was also evaluated (figure 3.4). The epicardium was stimulated through a pair of electrodes in the center of the mapping electrode. In the upper part of figure 3.4 , electrograms recorded along and transverse to the fiber orientation are shown.

Before freezing the electrograms recorded along the longitudinal fiber axis (vertical) exhibited smooth high amplitude biphasic deflections and gradually prolonging 


\section{REFRACTORY PERIODS BEFORE / AFTER FREEZING}

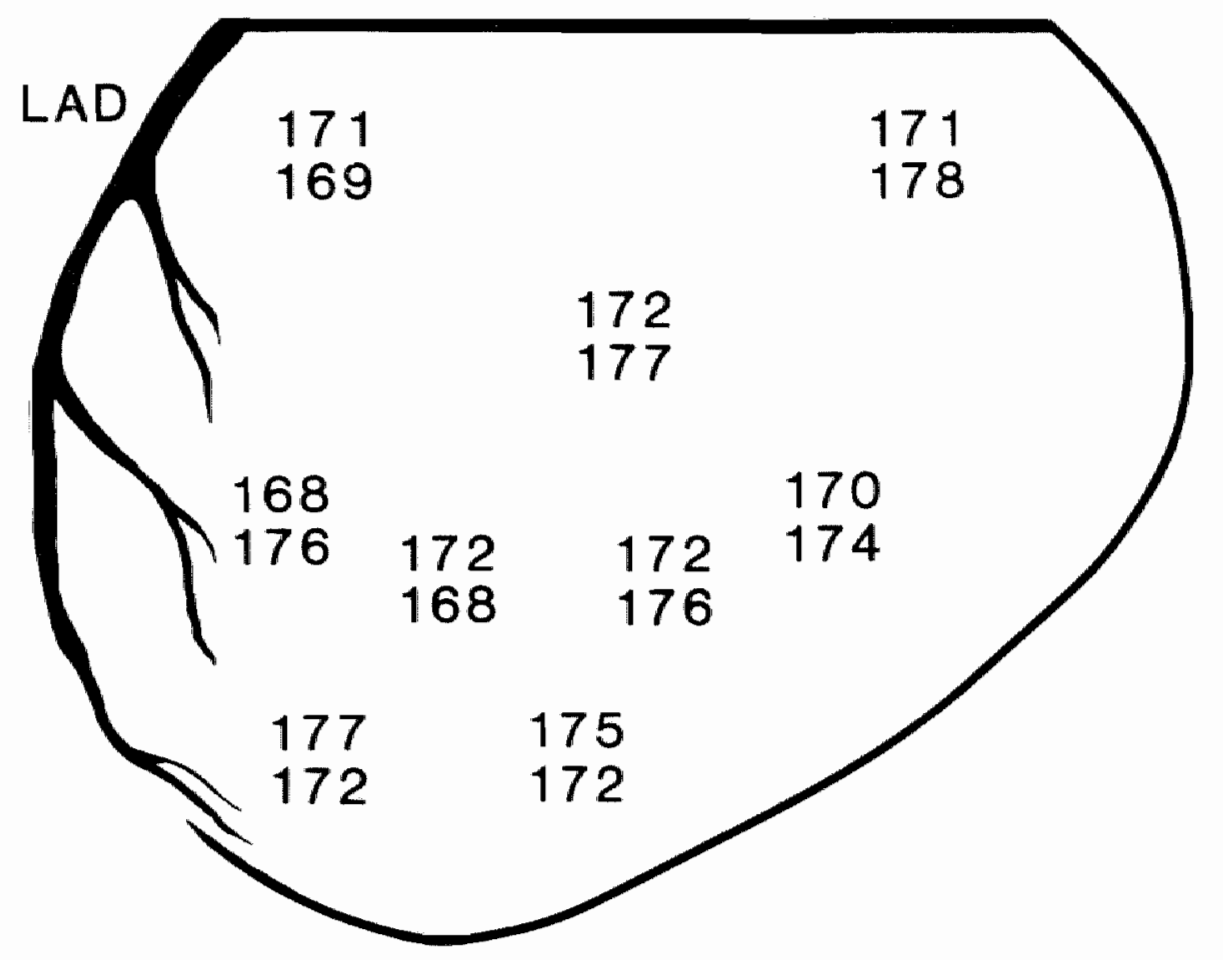
APEX

Eigure 3.3. Average values of epicardial refractory perlods measured in 10 hearts at 9 different epicardial locations betore and after freezing. The values measured during control are plotted above the average duration of the refractory period after the cryoprocedure. At none of the epicardial sites the refractory period was altered significantly after freezing. 


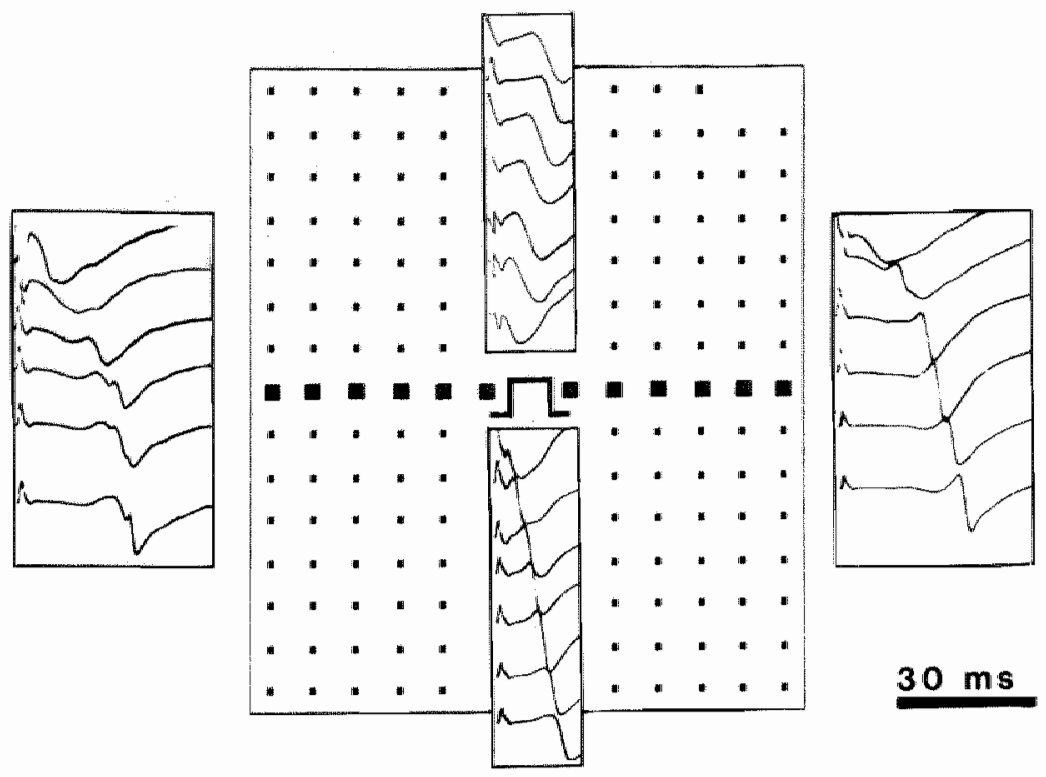

\section{CONTROL}

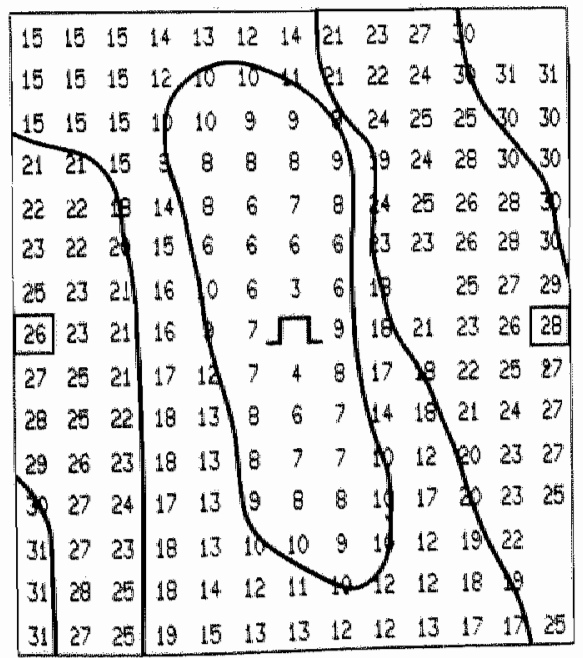

\section{AFTER FREEZING}

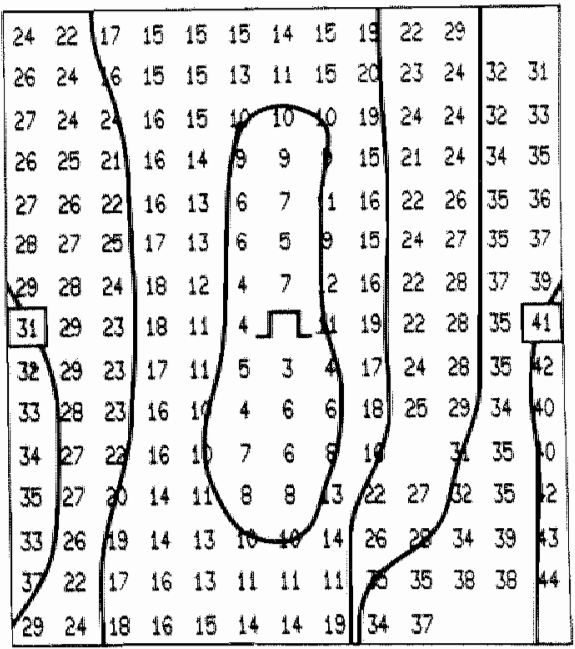


activation times. The row of horizontal electrodes orientated perpendicular to the fiber axis showed a different pattern. Electrograms recorded close to the stimulation electrodes were of low amplitude with no or only small $\mathrm{B}$ waves, typical for uniform transverse propagation (Spach et al., 1979, 1981a, 1986). Already within a distance of $3 \mathrm{~mm}$ from the stimulation site, however, the characteristics of transwerse propagation disappeared and electrograms typical for longitudinal conduction were recorded. This transition from transverse to longitudinal electrograms was accompanied by a sudden decrease in interelectrode conduction times. In the lower panels of figure 3.4, epicardial activation is shown before and after freezing. Propagation along the fiber axis was not affected by the cryoprocedure and the activation times of the distal longitudinal electrograms remained unaltered. However in a transverse direction the activation times were clearly prolonged. During control the transverse distal electrodes were activated at 26 and $28 \mathrm{~ms}$ compared to 31 and $41 \mathrm{~ms}$ after freezing.

To study transverse conduction over a longer distance, the eplcardium was stimulated through a pair of electrodes at the periphery of the electrode array. In figure 3.5 activation maps of transverse conduction before and after freezing are given together with maps of the local conduction velocities. Agaln removal of the subepicardlum resulted in a marked prolongation of the transverse conduction time. In this example the time required to activate the area under the mapping electrode was increased from 40 to $83 \mathrm{~ms}$. From the velocity maps at the bottom of figure 3.5 it can be seen that the prolongation of conduction was not caused by a depression of transverse conduction velocity. Instead the longer conduction times were the result of a greater effective dis: lance of slow transverse conduction. In the intact heart stimulation at the peripheral pair of electrodes produced an initial transverse epicardial wavefronit which however

Eloure 3.4. Epicardial conduction before and after freezing.

In the upper panel electrograms recorded from four rows of electrodes (positioned in a cross) are com. pared. During longitudinal conduction (vertical axis), high amplitude biphasic deflections were recorded. During transverse conduction (horizontal rows) only the two or three proximal electrograms were typical for transverse conduction. Also the conduction time between electrodes increased sudidenly after $2-3 \mathrm{~mm}$ from the site of stimulation. In the lower panels the actiwation maps recorded during pacing with 350 oycle length before and after freezing are shown. The impulse spread in an ellipsoidal pattern with fast conm duction parallel to the fiber axis and slow conduction perpendlicular to it. Longitudinal conduction was not altered by the cryopracedure. However "transverse conduction times were markedly prolonged after freezing, the activation times measured at the distal transwerse electrodes increasing respectively from 26 and $28 \mathrm{~ms}$ before freezing to 31 and $41 \mathrm{~ms}$ after freezing. 
was interrupted after about 3-4 mm by epicardial breakthrough of a deeper longitudinal wavefront. As a result large areas of the epicardium were activated nearly simultaneously resulting in a sudden increase in the calculated local conduction velocities. True transverse epicardial impulse propagation was assumed when the local conduction velocitles were less than $30 \mathrm{~cm} / \mathrm{s}$ (shaded area). Comparing the velocity maps before and after freezing, it is obvious that the area which is activated by transverse propagation is considerably enlarged by removal of the subepicardial muscle layers.

In figure 3.6 the effects of endocardial freezing on the effective distance of transverse conduction are plotted. In panels $A$ and $B$ a series of 8 electrograms are shown recorded along the transverse axis of the epicardium. In the intact heart (A) epicardial breakthrough is apparent at the third electrogram. After freezing $(B)$ the sudden changes in morphology and interelectrode conduction time had disappeared and transverse conduction proceeded along the whole line of electrodes. In panel $\mathrm{C}$ the mean values of interelectrode conduction times along the transverse fiber axis as measured in 12 experiments are plotted as a function of the distance to the site of stimulation. Within $3 \mathrm{~mm}$ from the point of stimulation conduction times were not statistically different. However at greater distances the local differences in conduction times became significantly shorter in the control hearts compared to the frozen hearts (p.05). Thus the destruction of the subeplcardium by endocardial freezing did not depress the velocity of epicardial impulse propagation nor did it change the ratio between longitudinal and transverse conduction velocities. The major effect was a selective prolongation of the distance over which slow transverse conduction could proceed without being Interrupted by epicardial breakthrough. This resulted in a considerable enlargment of the effective area of anisotropy.

\section{Anlsatropy and conduction block.}

We tested the hypothesis of preferential anisotropic conduction block in three different ways. 1) By gradually increasing the extracellular potassium concentration. 2) By incremental rapld pacing at normal potassium concentrations, and 3) by the induction of multiple premature beats. 


\section{ACTIVATION MAP}
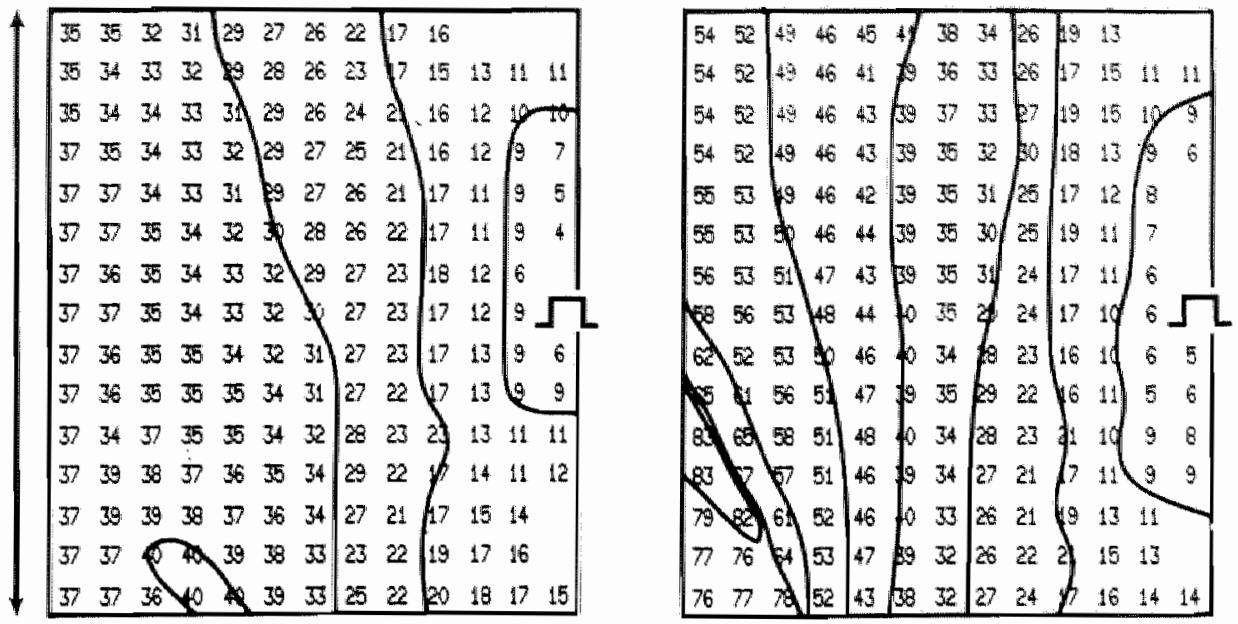

\section{VELOCITY MAP}

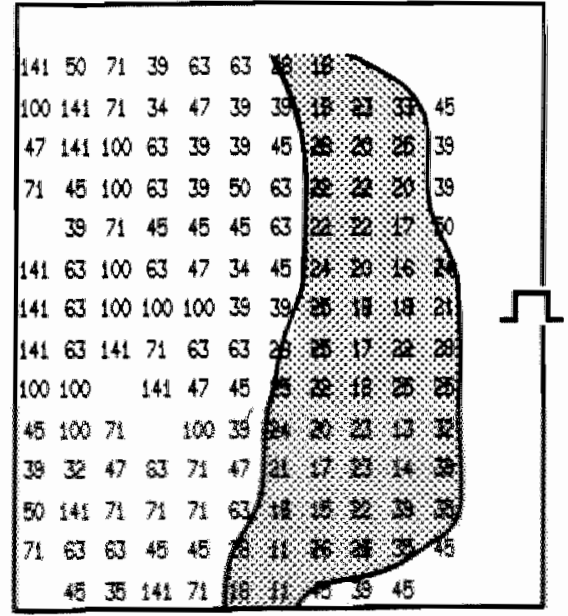

CONTROL

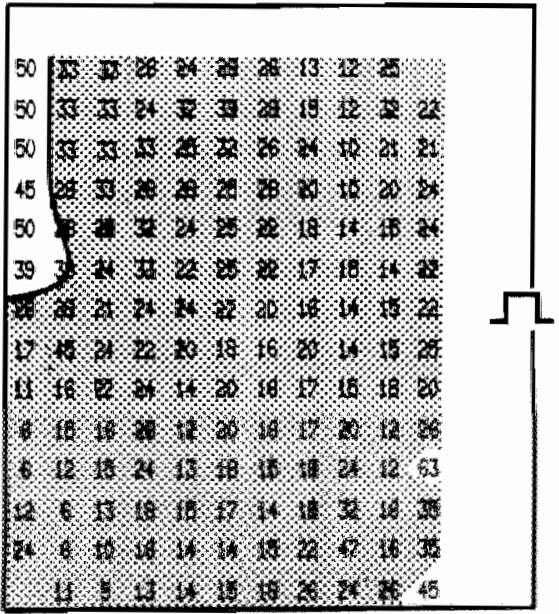

AFTER FREEZING

Bowe 3.5. Activation maps fop) and velocity maps (bottom) of trenswerse conduotion betore and after reezing. The eplcardim was paced through pair of stimulating electrodes the right border of the mapping eloctrode. In the velocity maps, the are of transwerse conduction wh welocty lower than $35 \mathrm{~cm} / \mathrm{s}$ is stippled. Betore heazing at a distance of less than $\mathrm{mm}$, transverse pioardiat conduction was

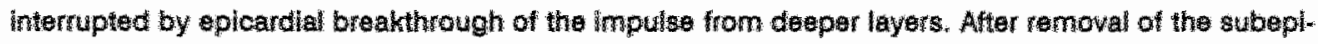
cardial layors by freezing the effective distance of transwara conduction was contiderably inoreased because eplcardiat breakthrough could no longer accur. 
A
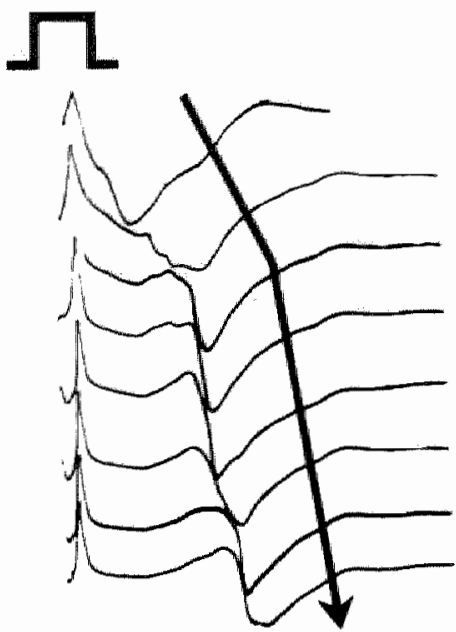

C

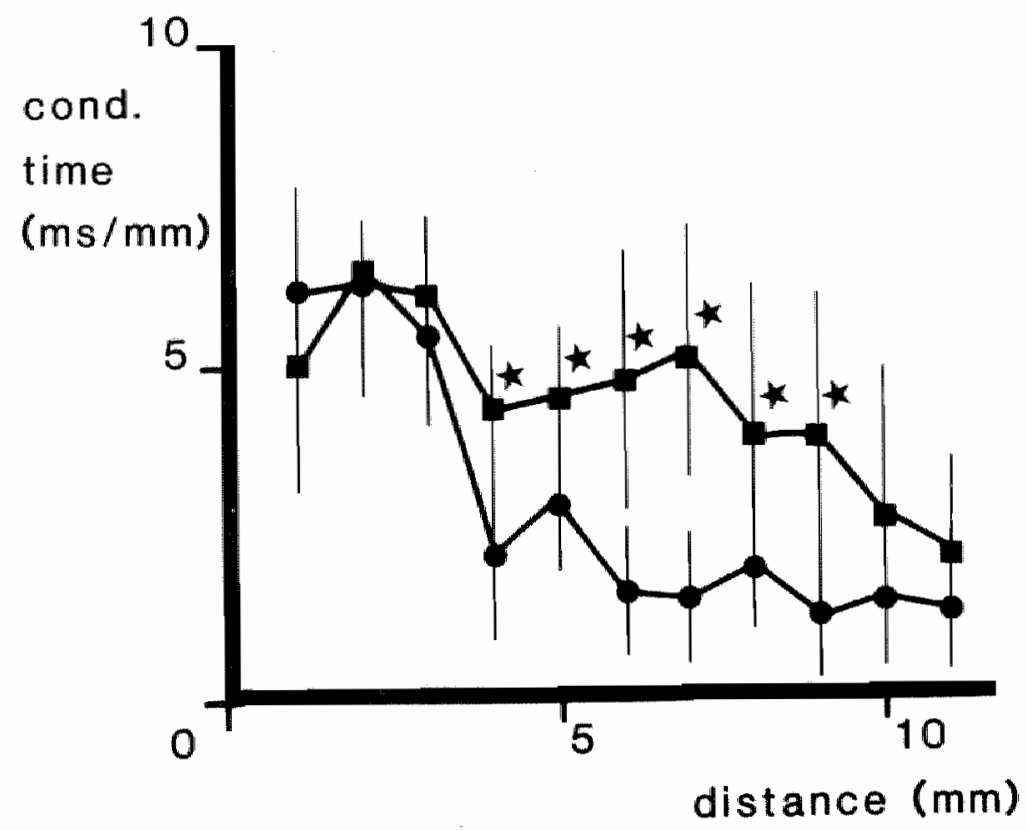




\section{High extracellular potasslum}

Increasing the extracellular potassium results in a progressive decrease of the membrane resting potential and a depression of the fast sodium inward current. This leads to a gradual diminishment of the safety factor for Impulse conduction and a lengthening of the refractory period (Dominquez and Fozzard, 1970, Tsuboi et al., 1985). Because we wanted to exclude the possibility that conduction block could accur on basis of existing spatial dispersion in refractory periods, the ventricles were paced at a very slow rate (cycle length $2000 \mathrm{~ms}$ ) to ensure complete recovery of excitability in all parts of the eplcardium. In figure 3.7 the eplcardlal propagation during slow pacing from the center of the mapping electrode is shown at three different concentrations of potassium. During control $\left(\mathrm{K}^{+}=5.6 \mathrm{mM}\right)$, normal anisotropic conduction was recorded with a $V_{L}: V_{T}$ ratio of $3.5\left(V_{L}=74 \mathrm{~cm} / \mathrm{s} ; V_{T}=21 \mathrm{~cm} / \mathrm{s}\right)$. No signs of impaired conduction or local conduction block were seen. At low heart rates $(30 / \mathrm{min})$ impulse conduction proved to be very resistant to increased extracellular potassium. At a concentration of $19.0 \mathrm{mM}$ conduction velocity was still not different from control and local conduction block was not observed neither in a longitudinal nor in a transverse direction. At an extracellular potassium concentration of $24.0 \mathrm{mM}$ impulse propagation became clearly depressed. In a transverse direction crowding of isochrones and lines of conduction block (thick lines) can be seen. The areas retrograde to the block were activated in a longitudinal direction by the impulse furning around the edges of the lines of transverse block. Both the position and the length of the lines of block were not flxed but could change from beat to beat emphasizing the functional nature of the conduction block. In contrast to the frequent occurrence of transverse block, longitudinal block was not observed until the myocardium became totally inexcitable. The electro-

Figure 3.6. Transwerse electrograms before and after freezing. Before freezing transwerse conduction was recorded by the two or three proximal electrodes. At more remote sites electrogram morphology showed characteristics of longitudinal conduction and inter-electrode conduction times decreased. After freezing the sudden change in interelectrode conduction time had disappeared and transverse electrograms were recorded by all electrodes. In the lower part of the figure the interelectrode conduction

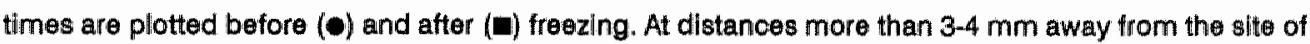
stimulation significant differences in conduotion time were found.

$$
\text { (* }=p<0.05 \text { ) }
$$




\section{EFFECTS OF POTASSIUM}

$5.6 \mathrm{mM}$

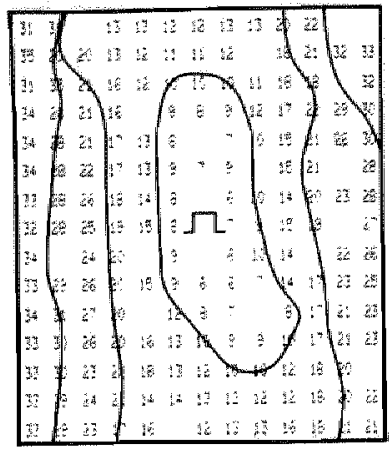

$19.0 \mathrm{mM}$

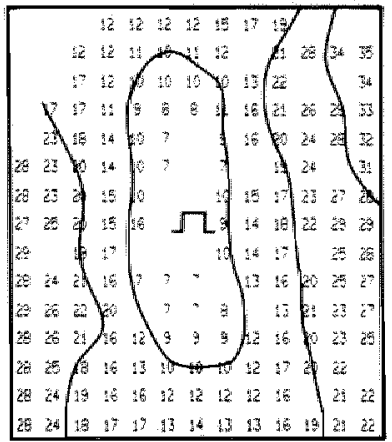

$24.0 \mathrm{mM}$

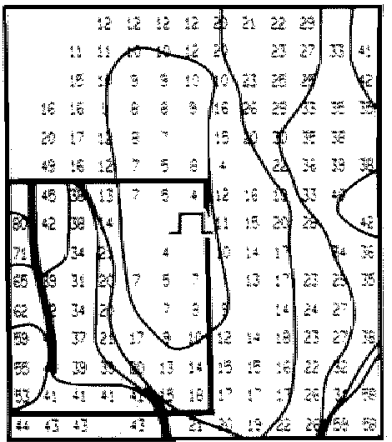

Figure 3.7. Activation maps at three different extracellular potassium concentrations $(5.6,19.0$, and $24.0 \mathrm{mM}$ ). The heart was paced at a regular interval of $2000 \mathrm{~ms}$ from the center of the mapping electrode. The rectangular area delineated in the map recorded at $24.0 \mathrm{mM}$ potassium, shows an arc of transverse conduction block and is plotted in figure 3.8 together with the corresponding electrograms.

grams assoclated with the phenomenon of transverse block are plotted In flgure 3.8. High amplitude electrograms are recorded at sites where the impulse propagates longitudinally to the fiber orientation (vertical). Low amplitude signals correlate with transverse propagation. Electrograms recorded from the transverse line of block consisted of two distinct deflections, the first caused by the approaching transverse conducting wavefront, and the second due to electrotonic current flow from the retrograde longitudinal impulse. The double component electrograms did not show multiple low amplitude fragmented deflections which are seen during slow transverse conduction in nonuniform anisotropic tissue (Spach et al., 1982a, 1986).

Elqure 3.8. Demonstration of transverse conduction block by high extracellular potassium ( $24.0 \mathrm{mM})$. The area corresponds with the rectangular area indicated on the map in figure 7 . In the lower part of the figure the electrograms recorded at the respective sites of the map are given. The electrograms start at the moment of the stimulus. A time window of $100 \mathrm{~ms}$ is displayed. The enclircled electrograms were recorded at the line of transverse conduction block. 

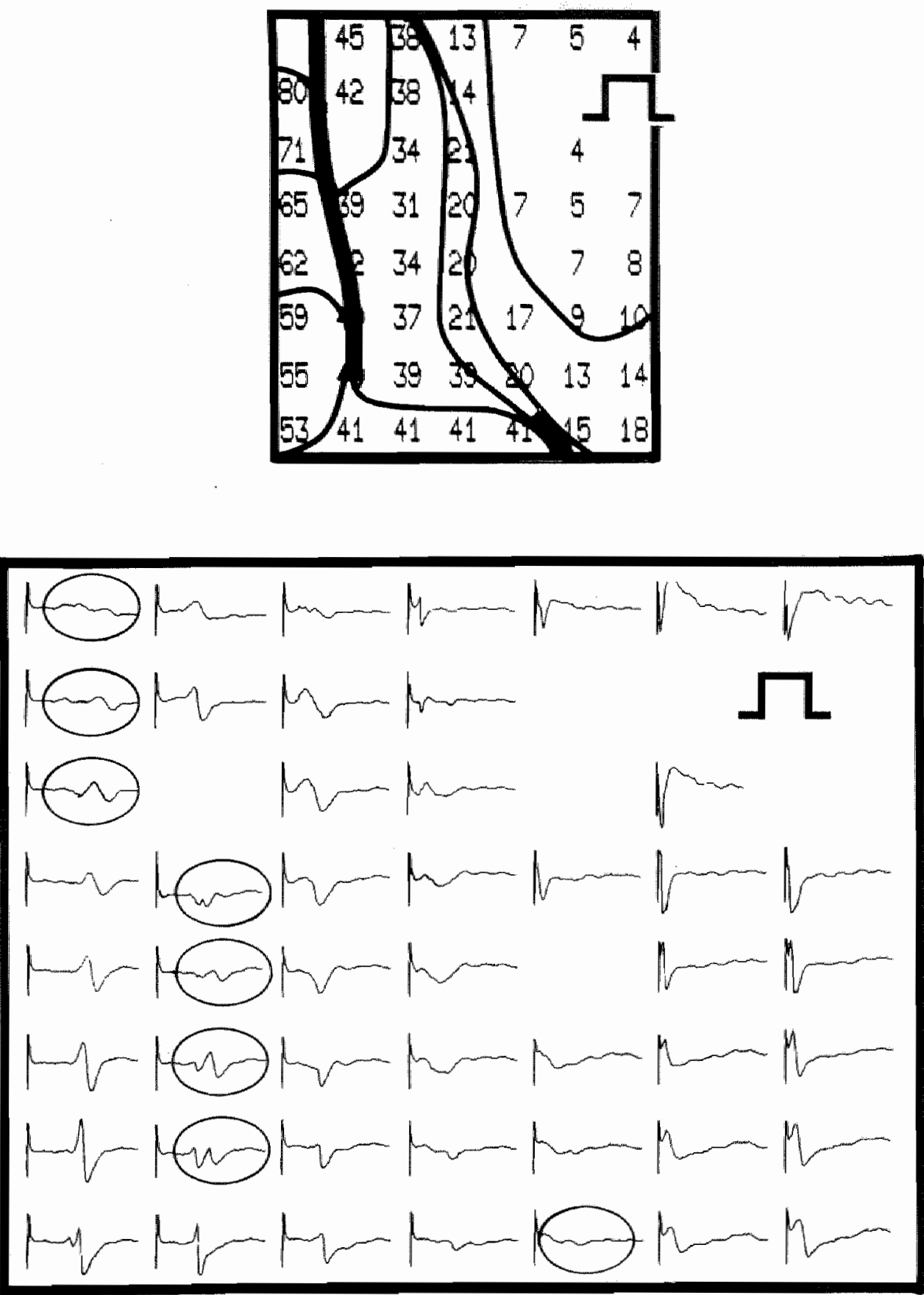


\section{EFFECTS OF RATE}

\section{$350 \mathrm{~ms}$}

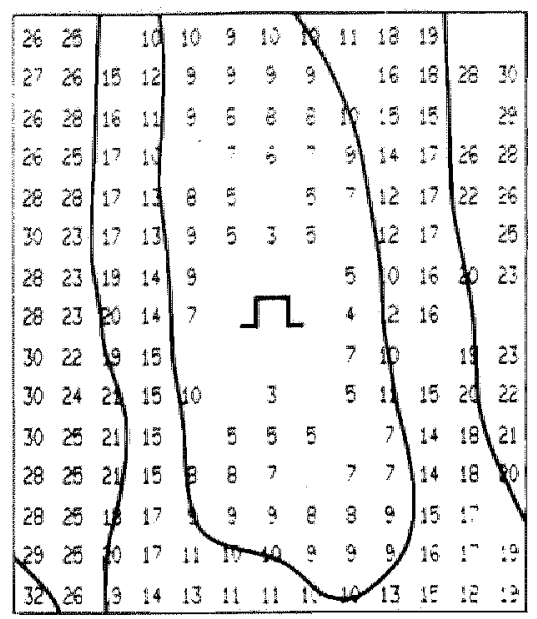

$200 \mathrm{~ms}$

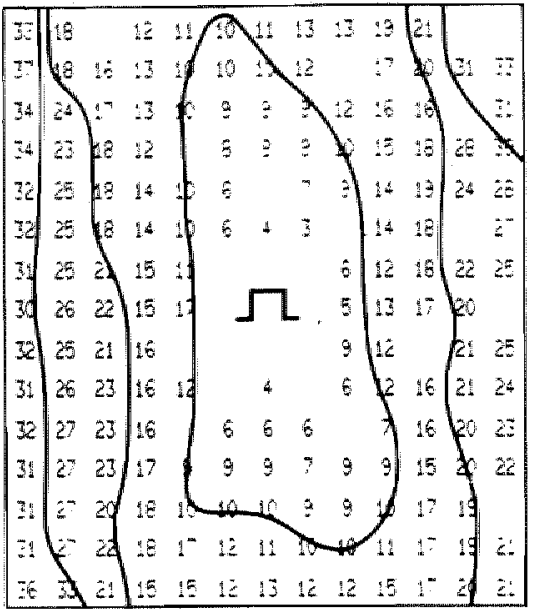

$110 \mathrm{~ms}$

\section{ALTERNANS}
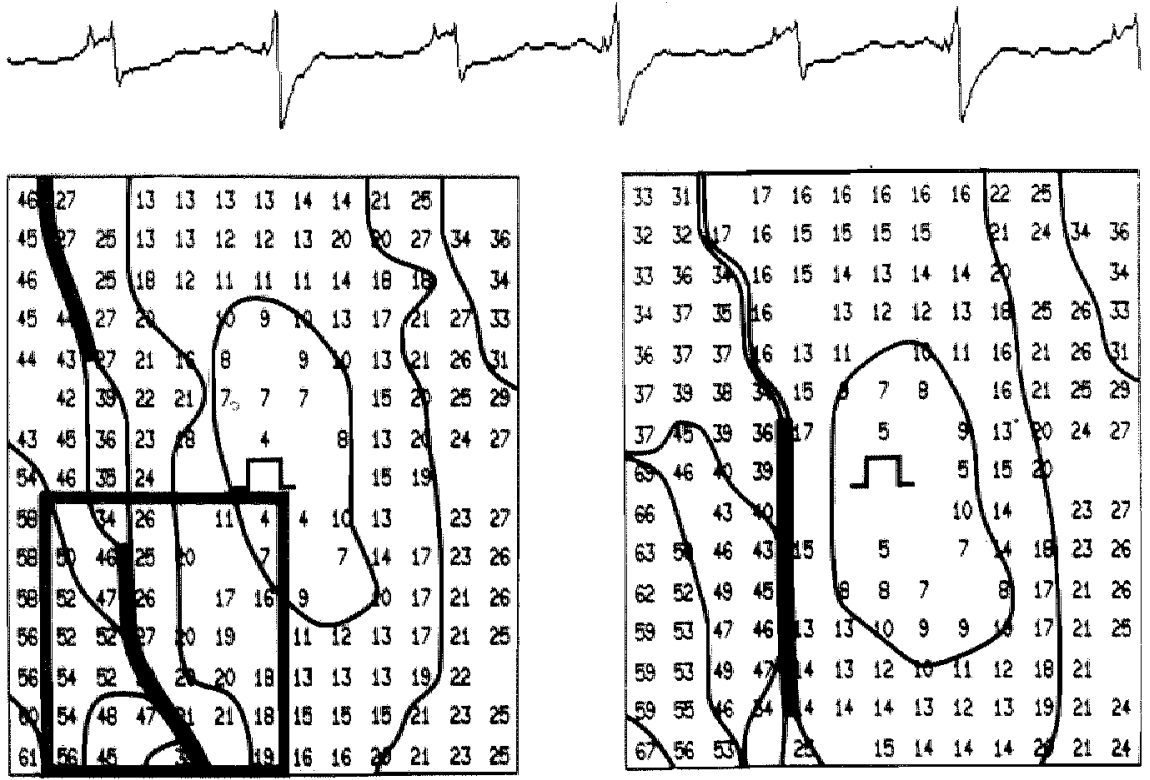


\section{Rapid pacing}

The effects of incremental rapid pacing are shown in figure 3.9. Activation maps are given during pacing with a cycle length of 350,200 and $110 \mathrm{~ms}$. During pacing with an interval of $350 \mathrm{~ms}$ the spread of excitation was regular with fast conduction (65 $\mathrm{cm} / \mathrm{s}$ ) parallel to the fiber orientation and slower conduction $(20 \mathrm{~cm} / \mathrm{s})$ in a transverse direction $\left(V \cup N_{T}\right.$ ratio 3.25 ). No reglons of conduction block or impaired conduction were found. During pacing with a cycle length of $200 \mathrm{~ms}$ this pattern of activation was unaltered and longifudinal and transverse conduction velocity were only slightly decreased. When the pacing rate was increased to $110 \mathrm{~ms}$ an electrical alternans developed. In the lower part of figure 3.9 activation maps of the alternating beats are given. The maps show that the electrical alternans is based on an alternation in pattern of activation. Especially in a transverse direction major differences in conduction between two successive impulses were seen. During one beat two lines of transverse conduction block were present in the left part of the map. In the next beat the two areas of block had disappeared and were replaced by a single longer line of block close to the stimulus site. This pattern of alternating transverse conduction block was stable and repeated itself as long as rapid pacing was continued. The electrograms recorded from the area of rate dependent transverse conduction block are plotted in figure 3.10. The signals recorded at the line of block exhibited double component electrograms. At those sites where the two components are widely separated a clear isoelectric segment was present between the two deflections.

\section{Premature beats}

The role of anisotropy on conduction of premature beats is shown in figure 3.11. During regular pacing (S1) two closely coupled premature stimull ( $\mathrm{S} 2$ and $\mathrm{S} 3$ ) were

Eloure 3.9. The effects of rapid pacing on anisotropic conduction. Top: Activation maps durlng pacing with a cycle length of 350 and $200 \mathrm{~ms}$. Bottom: Two consecutive activation maps during pacing at a maximal rate (110 ms cycle length). As shown by the electrogram at the top of these maps an electrical alternans existed at this high pacling rate. The delineated area of conduction block in the left lower panel is shown in figure 10 with the corresponding electrograms. 

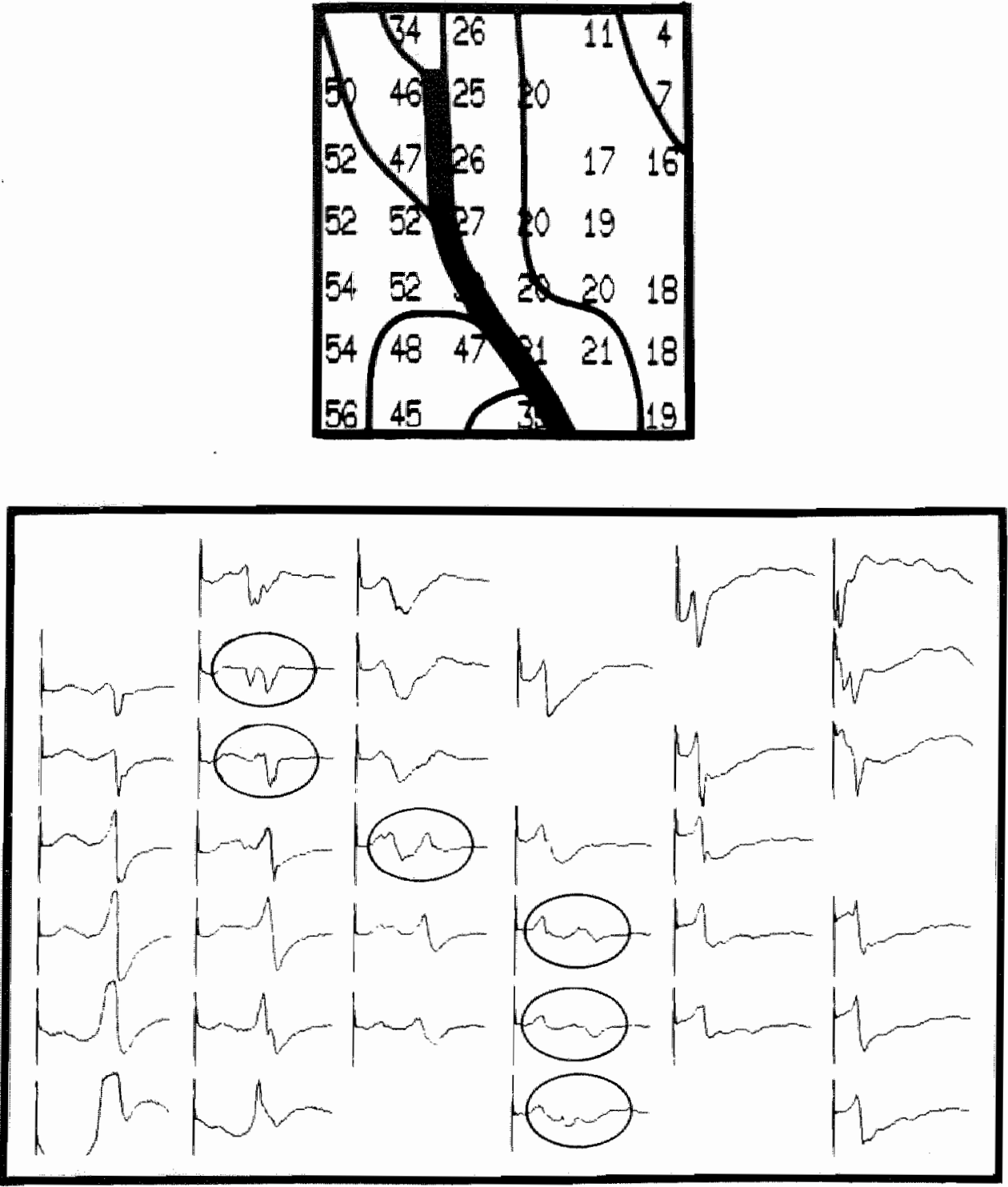

Elqure 3.10. Electrograms from an area of transverse conduction block induced by rapid pacing. An electrogram window of $100 \mathrm{~ms}$ is displayed starting at the moment of the stimulus. The isochrone map corresponds with the rectangular area indicated on the lower left panel of figure 9 . The encircled electrograms were recorded from the line of transwerse conduction block. 


\section{MULTIPLE PREMATURE BEATS}

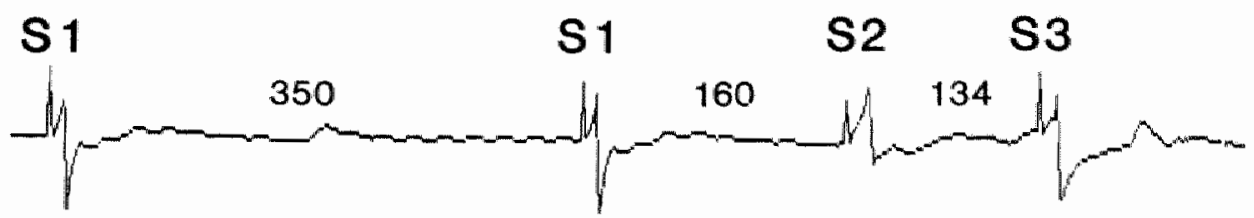

\section{S1}

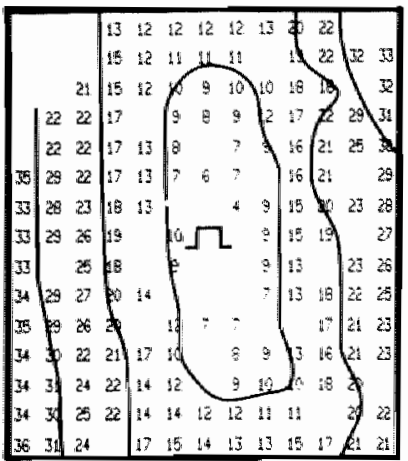

S2

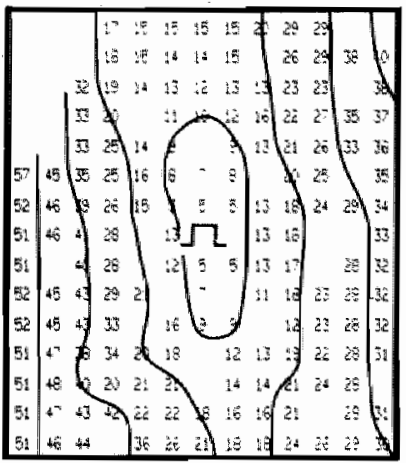

S3

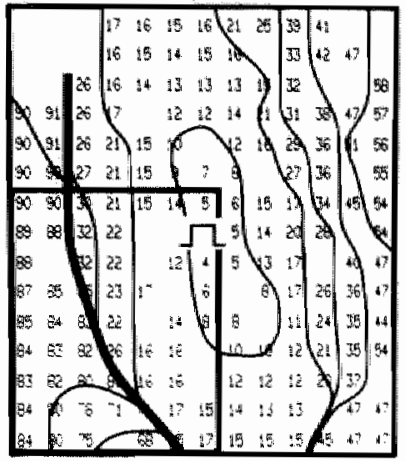

Eigure 3.11. The effects of multiple premature beats on anisotropic conduction during regular pacing $(\mathrm{S} 1-\mathrm{S} 1=350 \mathrm{~ms})$. The hearts were paced from the centre of the mapping electrode. Panel $\mathrm{S} 1$ gives the activation map during regular pacing. The maps designated by $S 2$ and S3 give the spread of activa. tion during two closely coupled premature beats $(S 1-S 2=160 \mathrm{~ms}$; $S 2-S 3=134 \mathrm{~ms})$. During the sacond premature impulse (\$3) a long line of transverse conduction block developed. The myocardium retrograde to the line of block was activated by a longitudinal fast conducting wavefront. The electrograms recorded from the area of black are shown in figure 12 . 

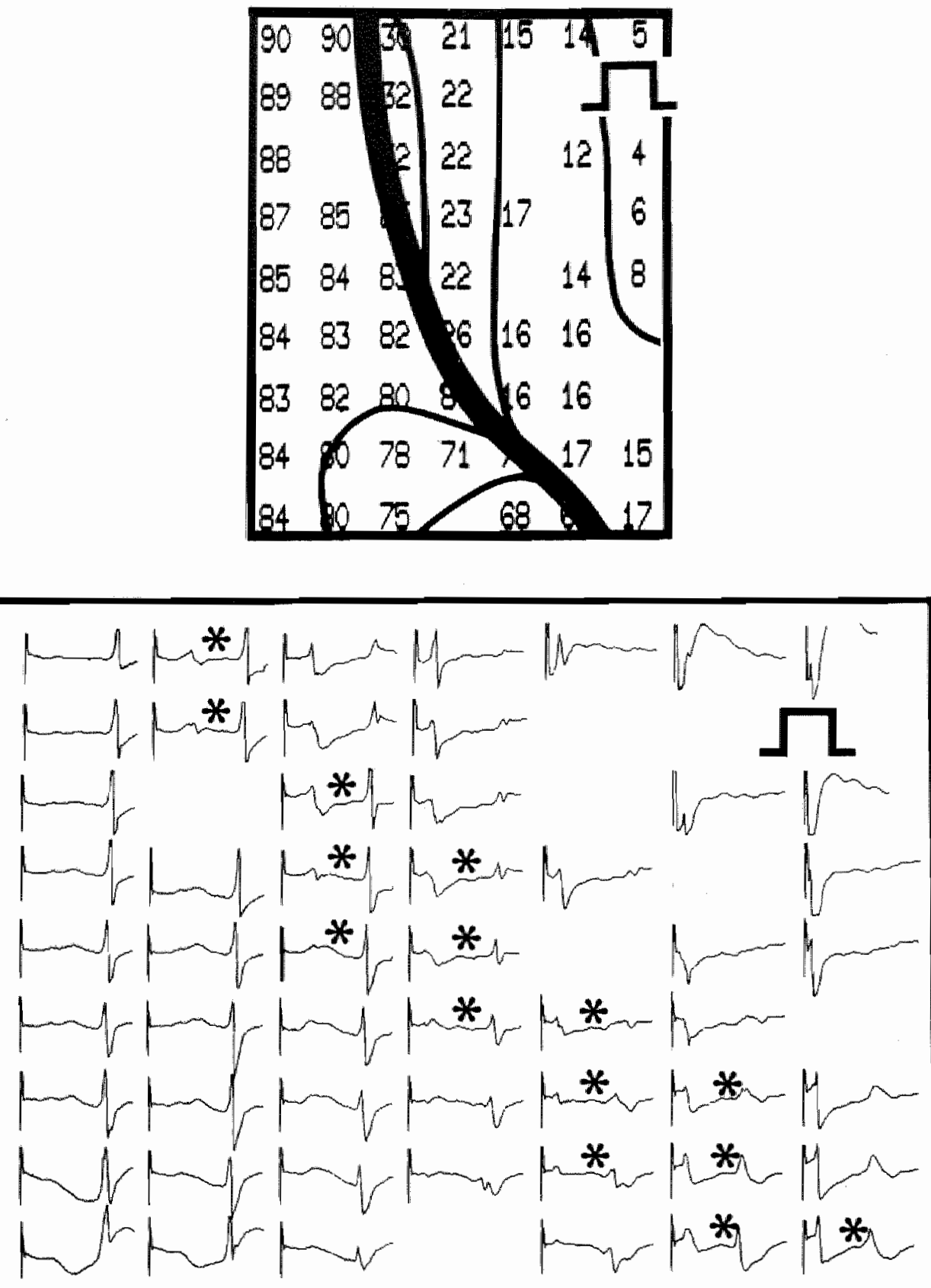
given. Compared to the regular rhythm, the first premature beat was conducted more slowly both in longitudinal and transverse direction but propagation was still uniform. During the second premature beat marked differences in propagation along both axes became apparent. In the longitudinal direction conduction remained uniform and was not different from the first premature beat. However in a transverse direction conduction became more depressed resulting in further slowing of conductlon and the appearance of an arc of transverse conduction block. The myocardium retrograde to the line of transverse block was activated by a longitudinal wavefront plvoting around the lower edge of the line of block. Thus premature impulses showed markedly increased anisotropy because propagation along the transverse fiber axis was more affected than longitudinal conduction. The electrograms recorded from the line of block are plotted in figure 3.12. Proximal to the line of block all electrograms exhibited the characteristics of transverse conduction, e.g. low amplitude deflections with no or small initial R-waves. Again the signals recorded from the line of block (indlcated by asterisks) showed double component electrograms. Due to the delay in activation of the area retrograde to the llne of block, the two components of the electrograms were widely separated. This makes it easier to see the absence of fragmented electrical activity between the two components of the electrograms. The presence of an isoelectrical segment between the two wavefronts is good evidence that true transverse conductlon block of the premature impulse was present.

\section{Anisotropy and reentry.}

In the intact isolated rabblt ventricle rapid pacing can induce ventricular fibrillation but ventricular tachycardia was never observed. However after endocardial freezing of the $4 / 5$ part of the left ventricular wall, the opposite was true. Now fibrillation could no longer be induced. Instead the application of one or more premature stimull or a short period of rapid pacing could initiate eplsodes of sustained ventricular tachycardia. The cycle length of these tachycardlas in the surviving left ventricular eplcardium

Elgure 3.12. Transverse conduction block and related electrograms during premature activation. The signals start at the moment of the premature stimulus and cover a time window of $100 \mathrm{~ms}$. The electrograms marked with an asterisk were recorded at the line of block. Same experiment as figure 11. See text for further description. 


\section{$\begin{array}{llllll}\text { S1 } & \text { S1 } & \text { S2 } & \text { S3 } & \text { S4 } & \text { TACHYCARDIA }\end{array}$}

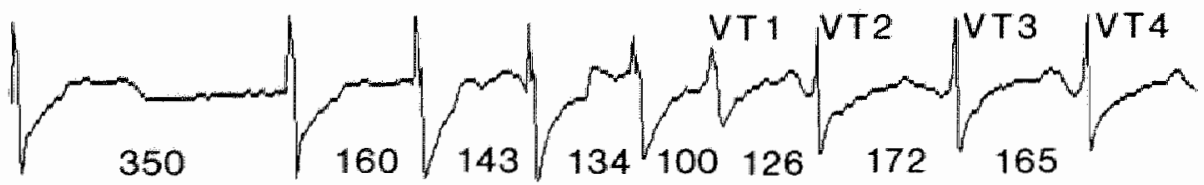

S1
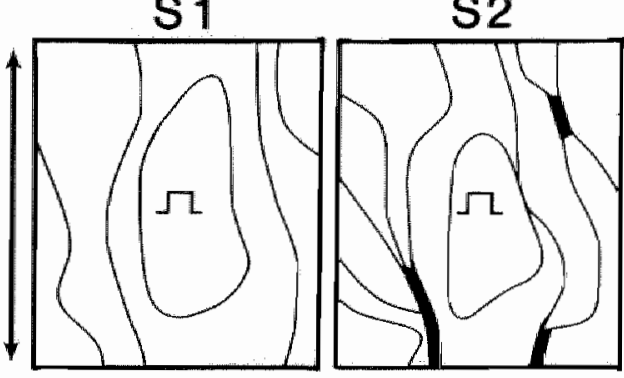

S2
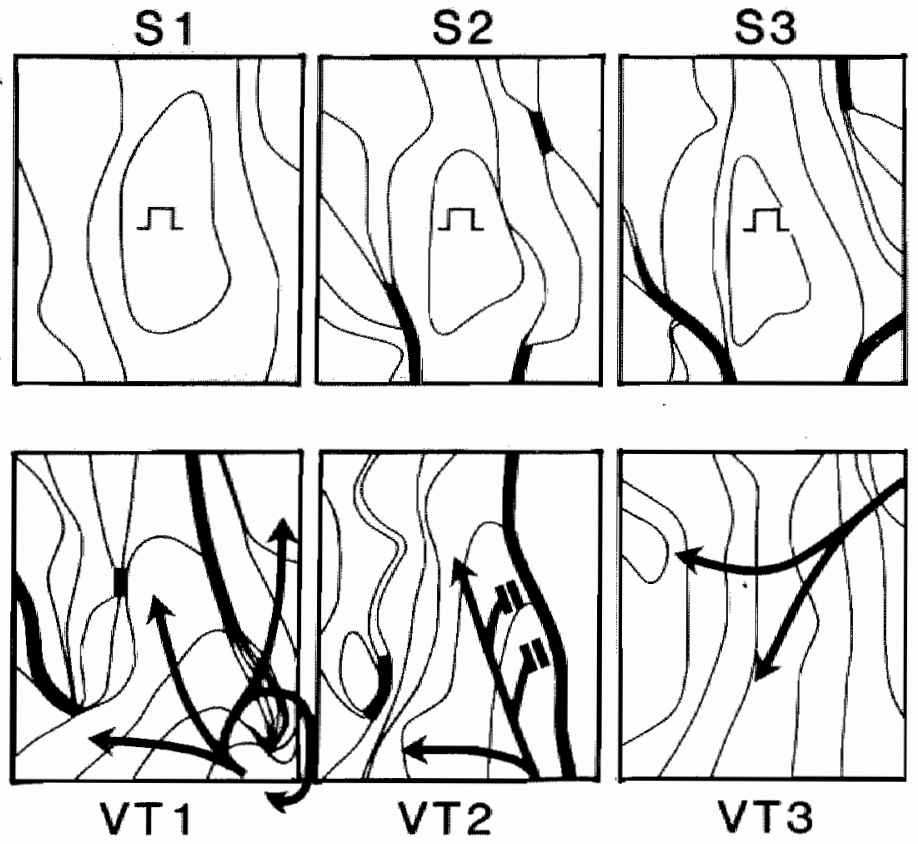
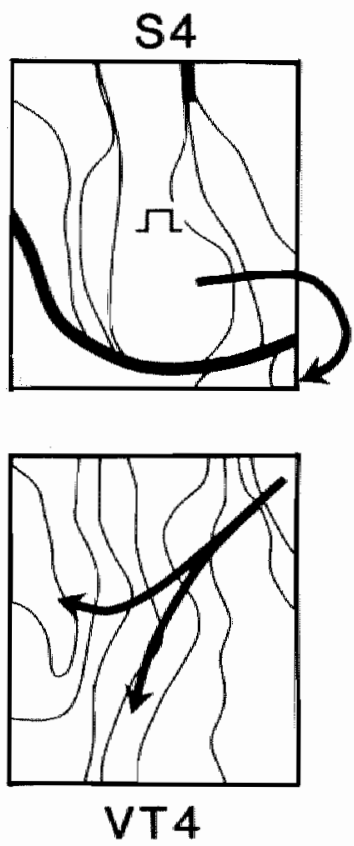

Elgure 3.13. Top: Initiation of ventricular tachycardia by three closely coupled premature stimuli (S1S4). The Intervals between the successive beats are indicated in ms.

Bottom: Isochirone maps during regular pacing (S1), premature stimull (S2-S4) and the first 4 beats of the ensuing ventricular tachycardia (VT1-VT4). The eplcardium was piaced through a pair of stimulating electrodes in the center of the mapping electrode. The vertical arrow to the left of the S1 map indicates the eplcardial fiber orientation; its length corresponds to a distance of $14 \mathrm{~mm}$. During the first and secand premature beats (S2 and S3) arcs of local transwerse conduotion block can be recognized. These transverse blocks did not lead to reentry. During the third premature limpulse (S4), block also occurred in a longitudinal direction. Fusion of the lines of transverse and longitudinal block resulted in a long $L$ shaped are of block. Ventricular tachycardia was initteted by reentry around this functional arc of block. During the first beats of the tachycardia the morphology of the electrograms and the isochrone maps varled from beat to beat, caused by changes in size and position of the reentrant pathways. During sustained tachycardia ${ }_{n}$ in this case the clrcult was located outside the mapping electrode. See text for further discussion. 
ranged from 110 to $165 \mathrm{~ms}$ (mean $130 \pm 11 \mathrm{~ms}$ ). Once initiated they could last for many hours without any change in cycle length or electrogram morphology.

Figure 3.13 shows the pattern of activation around the site of stimulation during the initiation of ventricular tachycardia by three consecutive premature stimuli. In this case local transverse conduction block occurred already during the first premature impulse (S2). Also during the second premature beat (S3) lines of transverse block can be distinguished. During the third premature impulse (S4) also longitudinal block occurred, resulting in a long L-shaped arc of block. The myocardium retrograde to this long line of block was activated after a long delay by an impulse turning clockwise around the right end of the line of block. In the first map of the tachycardla (VT1), it can be seen that the tissue proximal to the longitudinal line of block was reexcited by this turning impulse, resulting in an extra fast conducting wavefront propagating upwards parallel to the fiber direction. During this first reentrant beat, several regions of transverse conduction block were found. In the right lower corner an area of very slow transverse conduction (less than $5 \mathrm{~cm} / \mathrm{s}$ ) was present, glving rise to a single small reentrant circuit. During the second beat of the tachycardla (VT2), the spread of excitation changed completely. Except for a small line of block in the left part of the map, in the right part a long line of transverse conduction block extended from the lower to the upper border of the mapping electrode. The area of slow transverse conduction present during the first beat of the tachycardia now also participated in the line of block and reentry could no longer be found under the mapping electrode. However the tachycardia did not stop and as can be seen in the third and fourth map of the tachycardia (VT3 and VT4), the area under the electrode was now activated repeatedly by a broad wavefront propagating from the upper right to the lower left corner of the electrode. During the initiation of ventricular tachycardla the cycle length and electrogram morphology of the first three to four beats often change. Obviously before the tachycardia becomes sustained and monomorphic, the circulating impulse moves around (in this case away from the mapping area) before it finds a stable location somewhere else in the epicardium. 


\subsection{DISCUSSION}

The last decade it has become clear that anisotropic properties of the myocardium play an important role in impulse conduction and the genesis of cardiac arrhythmias (El-Sherif et al., 1977b, 1981, 1985, Fenoglio et al., 1983, Gardner et al., 1985, Wit et al ${ }_{\text {. }}$ 1982, 1987, Dillon et al., 1988). In the intact ventricle the myocardial fibers are orientated parallel to each other, with the longitudinal fiber axis gradually changing from epl- to endocardium over a total angle of about 120 degrees (Streeter 1979). By this rotation of the fiber axis the effect of anisotropy on impulse propagation is mitigated because slow transverse conduction is bypassed by impulses arriving earlier from the neighboring layers. This explains that in the ventricular wall, despite the presence of considerable anisotropy, the overall myocardial conduction velocity is governed by longitudinal propagation (Durrer and van Dam, 1957, Durrer et al., 1970). It also means that the local loss of myocardium resulting in survival of thin layers of cells, will lead to an Increased Influence of anisotropy on Impulse conduction.

Ventricular anisotropic conduction has been studied in isolated sheets of myocardium excised from the right or left ventricle and in papillary muscle preparatlons (Clerc, 1976, Spach et al., 1982b, 1986, Tsubol et al., 1985, Kadish et al., 1986, Delmar et al., $1987)$. To maintain stable conduction, such experiments had to be carried out at reduced temperatures $\left(25-30^{\circ} \mathrm{C}\right)$ or within a limited range of pacing frequencies. Under normothermic conditions the conduction velocity of in vitro preparations is strongly rate dependent and conduction block occurs at a lower pacing frequency than in the perfused heart (Spach et al., 1982b, Tsubol et al., 1985, Delmar et al., 1987). To avold some of the problems related to superfused preparations, we used an endocardial freezing technique to create a thin layer of perfused epicardium $(1.0 \pm 0.4 \mathrm{~mm})$. The electrophyslological properties like refractory period, conductlon velocity and maximal pacing rate were not different from control. The removal of the subepicardium however had an Important effect on the distance over which transverse epicardial conduction could proceed. In the intact ventricle transverse conduction was interrupted within 3-4 mm from the site of stimulation by epicardial breakthrough of an impulse from deeper layers. In the two-dimenslonal preparation slow transverse conduction continued undisturbed over a distance of more than $8 \mathrm{~mm}$. 
Anisotropic conduction and conduction block.

The theoretical and experimental studies of Spach and co-workers (1981, 1982b, $1983,1986,1987)$ have raised evidence that the continuous cable theory developed by Hodgkin and Huxdey for impulse transmission in nerve (1952) does not give an adequate description of impulse propagation in cardiac tissue. In the heart discontinuities of effective axial resistivity exist at several size levels and together with possible differences in membrane capacity this may be responsible for local differences in safety of propagation and a variety of cardiac conduction disturbances (Sommer and Dolber, 1979, Sommer, 1983, Joyner, 1982, Diaz et al., 1983, Spach et al., 1981, 1982a, $1986,1987)$. On the basis of the observed directional differences in propagation velocity and the inverse relationship between $V_{\max }$ and conduction velocity Spach et al. (1981) predicted that: "Propagation can become decremental and stop in one direction while it continues as uniform propagation in the other direction. In fact, uniform propagation ceases and becomes decremental first in the direction having the highest velocity, as the membrane activity is depressed. The low-velocity wavefront continues to propagate as the membrane is depressed still further. Thus, the "safety factor" is lower when the velocity is high and vice versa. Experimental support for thls concept was recently obtained by Tsubol et al. (1985) who found that in thin sections of canine right ventricular muscle superfused by a solution containing $10 \mathrm{mM}$ potassium, longitudinal propagation falled while conduction in a transverse direction continued. On the other hand, Van Capelle (1983) and Rudy et al. (1987) were unable to confirm the concept of preferential longitudinal conduction block. In computer simulations of impulse propagation in discrete cellular structures they found that $V_{\max }$ displayed a bi-phasic behavior as a function of increasing axial resistance. At a moderate increase of the coupling resistance $V_{\max }$ first increased, to drop sharply when the coupling resistance was further raised. The sudden decrease in upstroke veloclty of the action potential at high coupling resistances was explained by inactivation of the regenerative inward current during the foot of the slowly propagating action potentlal. Computer simulations of the propagation of early premature beats actually showed preferentlal block in a transverse direction and as stated by Van Capelle (1983): "Do not support the idea that transverse "slow" propagation is less susceptible to conduction block than is longitudlnal "fast" propagation". In a recent study Delmar et al. (1987) Investigated the effects of increasing intercellular resistance in Isolated sheep eplcardlal muscle by the cellu- 
lar uncoupler heptanol. Under these conditions they found that in all cases block occurred more promptly for transverse than for longitudinal propagation. Transverse conduction block was accompanied by "foot potentials" resulting in partially inactivating the sodium channels (Van Capelle, 1983, Delmar 1987, Rudy et al., 1987).

Our mapping studies of perfused rabbit eplcardium showed that when the stimulating efficacy of the depolarization wave is decreased, either by premature beats, rapid pacing or elevating extracellular potassium, transverse conduction block always occurs before propagation in a longitudinal direction fails. This is in agreement with the experimental studies of Delmar et al. (1987) and the computer simulations of Van Capelle (1983) and Rudy et al. (1987). Obviously, when conduction becomes critical, the higher $V_{\max }$ of transverse conduction does not compensate for the higher transverse axial resistance and a smaller amount of electrotonic current is delivered to the cells downstream of the crest of the depolarization wave.

\section{Anisotrople conduction and reentrant arrhythmilas.}

Anisotroplc conduction may play an Important role In the pathogenesis of atrial and ventricular arrhythmias (El-Sherif et al., 1981, Mehra et al. 1985, Wit et al., 1982, 1985, Dillon et al., 1987). The greater incidence of atrial fibrillation with age may be caused by a redistribution of collagen and progressive electrical uncoupling of myocardlal fibers, the resulting higher degree of nonuniform anisotropy enabling the occurrence of unidlrectional conduction block and providing small areas of slow conduction for Intramyocardlal micro-reentry (Spach et al., 1986). Since atrial fibrillation is based on the presence of multiple wandering wavelets the fibrillatory process will tend to be more stable if more reentering impulses are present (Moe, 1962, Allessie et al., 1985). Spear et al. (1983a, 1983b) showed that after myocardial infarction the degree of anisotropy is enhanced by collageneous septa dividing the myocardial fibers. In the studies of Wit et al. $(1982,1987)$ and El-Sherif et al. (1983) on ventricular tachycardia 3-4 days after myocardlal infarction, reentrant circuits were found in the thin epicardial layer overlying the Infarcted area. The conduction properties of this layer of cells exhiblted greatly enhanced (nonunlform) anisotropy (Spear et al., 1983a, 1983b, Richards et al., 1984, Fenoglio et al., 1983, Gardner et al., 1985, Dillon et al., 1988). In our experiments the effects of enhanced effective anisotropy were studied by the remo- 
val of deeper layers without the additional morphological and electrophysiological changes caused by myocardial infarction (Spear et al., 1983a, 1983b).

One of the interesting findings was that, after removal of the subepicardial layers sustained episodes of ventricular tachycardla could be induced by rapid pacing or induction of one or more premature beats. Epicardial mapping during rapid pacing and premature beats frequently showed long lines of transverse block whlch however dld not lead to reentry. The apparent benign nature of transverse block in relation to initiation of reentry is explained by the rapld activation of the area distal to the line of block by longitudinal propagation. On the other hand, If longitudinal block occured, the region behind the block was activated by slow transverse conduction providing more time for the fibers proximal to the block to restore their excitability. For reentry to occur, the minimal length of a line of longitudinal block can be much shorter than a line of transverse block. The higher the degree of anisotropy, the smaller the line of longitudlnal block necessary for initlatlon of intramyocardial reentry. Enhanced anisotropy thus amplifies the role of existing spatial inhomogeneities in conduction propertles. Small areas of depressed conduction, which under normal clrcumstances will not lead to arrhythmias, may then start to act as pivoting points for reentry. Also during sustained tachycardia anisotropy may play an important role because during its roundtrip the impulse has to propagate twice perpendlcular to the fiber orientation. The resulting slowing of conduction during transverse propagation will make the dimensions of the circuit smaller than they would be in isotropic myocardium. The presence of areas of nonunlform anisotropy (Spach et al., 1982a, 1986) might further diminish the size of intramyocardial circuits and influence the properties of sustalned ventrlcular tachycardla. 
$-72$. 


\section{CHAPTER IV}

\section{ANISOTROPIC REENTRY AS A MECHANISM OF SUSTAINED VENTRICULAR TACHYCARDIA}

\subsection{INTRODUCTION}

Ventricular tachycardia is a frequent and life threatening event in patients recovering from myocardial infarction Wellens et al., 1972, 1974, 1975a, Josephson et al., $1978,1986)$. Normal and abnormal automaticity, triggered activity, and reentry may cause ventricular tachycardia , however from extensive eplcardial and endocardial mapping studies performed in these patients, reentry emerged to be the most likely mechanism of sustained ventricular tachycardia (Josephson et al., 1978, 1986, De Bakker et al., 1983, Josephson and Wellens, 1984). Prerequisites for the initiation of reentry are local unidirectional conduction block and slow conduction. Once trapped in a circuituous pathway, the Impulse can circulate around a gross anatomical obstacle (Mines, 1914, Lewls et al., Rosenblueth and Garcla Ramos, 1947, Frame et al., 1986) or around a functionally determined area of conduction block (Allessie et al.,1973, 1977, 1984, 1987, Wit et al.,1987, Dillon et al., 1988). Conduction block and slow conduction were long thought to be caused by local differences in excitablity (Mines et al.,1914, Schmitt and Erlanger, 1928, Han and Moe, 1964 „Merx et al., 1977, Allessie et al.,1976). Later studies have suggested that it also may be caused by geometrical factors influencing the safety factor for conduction (Mendez et al., 1969, 1970, De la Fuente, 1971, Spach et, 1981, 1982a, 1982b, 1987). Results of experimental studies using canine models, either with permanent or translent occlusion of the coronary artery, suggest that surviving myocardial cell layers in the border zone of the infarct are involved in the pathogenesis of sustained tachycardia (EI Sherif et al.,1977, 1981, 1985, Mehra et al., 1983, Wit et al, 1982, 1987, Dillon et al., 1988). Although anatomical barriers sometimes may be present, Wit et al. (1987) and Dillon et al.(1988) demonstrated that sustained ventricular tachycardia initiated in the canine left ventricle 3-4 days after 
myocardial infarction, was caused by reentrant excitation involving a functionally determined area of conduction block. They showed that the anisotropic propertles of the epicardium overlying the infarct area were greatly enhanced. This enhanced nonuniform anisotropy facilitated the initiation of local conduction block and reentry (Wit et al., 1987, Dillon et al., 1988). However in post infarct ventricles ischemic alterations of the borderzone cells may also contribute to the initiation of reentry by enhancing the inhomogeneity in excitability and the stimulating efficacy of the cells (Spear et al., 1983a, 1983b, Richards et al., 1984, Janse, 1986, Wit et al., 1987, Dillon et al., 1988). In the previous chapter we demonstrated that when the effective area anisotropy of the left ventricle was enhanced by removal of the intramural and endocardial layers, local conduction block and reentry could be initiated by elther premature stimulation or rapid pacing. To study the effects of enhanced tissue anisotropy on the characteristics and mechanisms of ventricular tachycardla the two dimensional model of anisotropy presented in the previous chapter was used. The results of this study demonstrated that sustained ventricular tachycardia could be initiated in the epicardial layer. Reentry was the underlying mechanism of these tachycardias. The impulse circulated mostly around a line of conduction block orientated parallel to the epicardial fiber direction. This line of conduction block was functionally determined. However despite the functlional nature of "anisotropic" reentry an excitable gap was present. Due to the presence of an excitable gap anisotroplic reentry was stable and longlasting.

\subsection{METHODS}

\section{Becording and stimulation}

Detailed activation maps were reconstructed during sustained tachycardia, using either a high resolution rectangular mapping electrode (192 leads, silver wires diameter $0.3 \mathrm{~mm}$, interelectrode distance $1 \mathrm{~mm}$ ) or a "spoon" shaped electrode covering the apex and the free wall of the left ventricle, containing 384 leads (silver wires diameter $0.3 \mathrm{~mm}$, interelectrode distance $2 \mathrm{~mm}$ ).

The "spoon" electrode covered the entire free wall of the left ventricle and the apex. The left boundary of the mapping electrode was at the anterior interventricular groove 
and the right boundary at the posterior interventricular groove. Because the apex is a more or less circular structure the lower six rows of the spoon electrode are continuous. The activation maps recorded with the "spoon" electrode are displayed into a twodimensional matrix. The interelectrode dilstance was $2 \mathrm{~mm}$ when all 384 electrograms were recorded. It was also possible to record from half of the number of electrodes but then the interelectrode dlstance along the $X$-axis was $4 \mathrm{~mm}$ and along the $Y$-axis $2 \mathrm{~mm}$.

To study the properties of the central line of conduction block during anisotropic reentry in detall a high density mapping electrode was used, contalning two rows of 48 electrodes (silver wires, diameter $0.05 \mathrm{~mm}$ ) with a spatiall resolution of $0.185 \mathrm{~mm}$. After localization of the circuit this electrode was moved across the line of conduction block.

Programmed electrical stimulation was performed with a programmable constant current stimulator delivering square pulses of $2 \mathrm{msec}$ duration and 2-4 times diastolic threshold. Stimull could be applied to any pair of electrodes of the mapping electrode. The inducibility of ventricular arrhythmias was tested before and after freezing by programmed ventricular pacing. The pacing protocol consisted of incremental pacing upto a maximal pacing frequency and the application of single or multiple shortly coupled premature stimuli during regular pacing with a cycle length of $350 \mathrm{~ms}$.

Unipolar electrograms were recorded using the stainless steel cannula in the aorta as an indifferent electrode. The recorded electrograms were fed into 192 individual ampliffiers (bandwidth $2-400 \mathrm{~Hz}$ ) and displayed in groups of elgth on two Textronlx $5103 \mathrm{~N}$ oscilloscopes. The outputs of the ampliflers were multiplexed and digitised by three multiplexers, each of which handled 64 signals (Kailser PCM system K1280-00). Each signal was sampled with a frequency of $2000 \mathrm{~Hz}$ and recorded on tape (Ampex PR 2230). After the experiment, data analysis was performed using a PDP 11-73 computer (Digital). An algorithm to detect the intrinsic negative deflection in the electrograms was used to mark local activation times. On basis of the local activation times Isochronic maps were displayed on the computer video display (VT240, Digital). Detalls of the recording system enabling simultaneous measurement of 192 electrodes have been described elsewhere (Allessie et al, 1984). 


\subsection{RESULTS}

\section{Characteristlics of sustained ventricular tachycardia.}

The Induclbility of ventricular arrhythmlas was tested both before and after freezing by programmed electrical stimulation (figure 4.1). The pacing protocol consisted of incremental pacing and multiple shortly coupled premature stimuli applied during regular pacing (350 ms cycle length). In the intact ventricles, fibrillatlon or ventricular tachycardia could not be initlated by premature stimuli (figure 4.1 A). Only after prolonged periods of pacing at a maxlmal pacing rate (90-110 ms pacing interval) ventricular fibrillation was induced (figure 4.1 B).

After the intramural and endocardlial layers were destroyed by freezing, sustained ventricular tachycardia could be intlated, in 30 out of 35 preparations, either by the induction of single or multiple premature beats or by incremental pacing (figure $4.1 \mathrm{C}$, D). These tachycardlas were very stable and longlasting (more than several hours in different hearts). The cycle length ranged from 105 to $160 \mathrm{~ms}$ (mean $130 \mathrm{~ms} \pm 11 \mathrm{~ms}$ ). Except for the initial 2-4 beats the cycle length and the electrogram morphology showed only small varlations in time. However an electrical alternans, both in the cycle length and shape of the recorded electrograms was found during most of the tachycardias. These rhythmic variations were related to the cycle length of the tachycardia. Almost no alternans was recorded when the cycle length was relatively long, while during tachycardla with a high intrinsic rate the alternans was more marked, resulting in a maximal beat to beat varlation of $10-15 \mathrm{~ms}$ (figure $4.1 \mathrm{C}, \mathrm{D}$ ). After freezing ventricular flbrillation could not be Initlated anymore In any of the preparations, not even by prolonged perlods of rapid pacing (90-110 ms cycle length). Functional reentrant excitatlon is considered to play a major role during atrlal or ventricular fibrillation (Moe et al., 1962, Allessle et al., 1985). Because functional reentry tends to terminate spontaneously (Allessie et al. $(1977,1985)$ a minimal number of simultaneously wandering

Eloure 4.1. Initiation of ventricular arrhythmlas in the intact heart and the two dimensional epicardial layer produced by freezing. In the intact ventricle no arrhythmias could be initiated by up to three shortly coupled premature beats. Only prolonged periods of rapid pacing eventually leads to initiation of ventricular fibrillation (A-B). After freezing it was not possible anymore to initiate ventricular fibrillation. Instead sustained ventricular tachycardla could now be initiated either by multiple shortly coupled premature stimuli or rapid pacing (C-D). 


\section{BEFORE FREEZING}

A. RAPID PACING

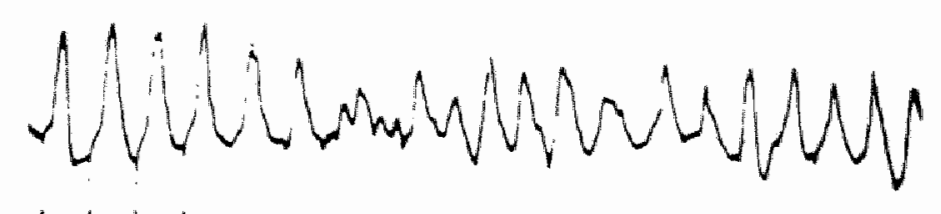

B. PREMATURE BEATS

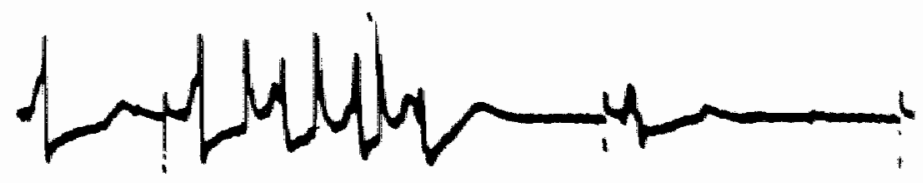

\section{AFTER FREEZING}

C. RAPID PACING

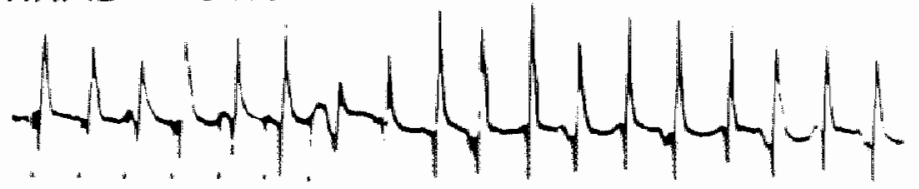

D. PREMATURE BEATS

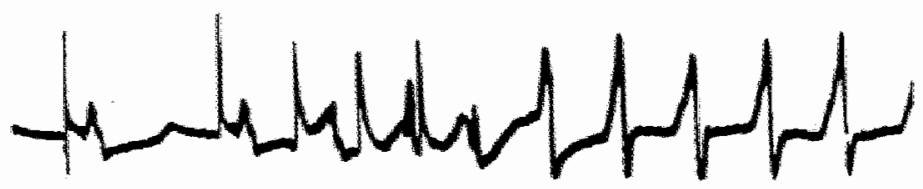

$100 \mathrm{~ms}$ 
wavelets is required for the maintainance of the fibrillatory process (Allessie et al., 1985, Rensma et al. 1988). When the average number decreases the chance of the synchronous inactivation of the wavelets increases and fibrillation will be terminated. The minimal number of wavelets simultaneously wandering through the myocardium depends on the tissue mass. The reduction of the tissue mass after freezing of the intramural and endocardial layers of the left ventricle might explain the fact that fibrillation could not be initiated anymore.

\section{The excitable gap.}

It is well known that during sustained ventricular tachycardia, initiated in the postmyocardial infarction perlod in patlents and in canine hearts, an excitable gap is present. During sustained tachycardia in the two dimenslonal layer a short but clear excitable gap was present. By comparing the cycle length during sustained tachycardla (105 to $160 \mathrm{~ms}$ ) with the functional refractory perlods measured during regular pacIng at the same cycle length, the duration of the excitable gap can be estimated to be 10 to $40 \mathrm{~ms}$. The relation between the measured functional refractory period and the cycle length of the tachycardia is given in figure 4.2. During pacing at a cycle length of $100 \mathrm{~ms}$ the refractory period was $94 \pm 3 \mathrm{~ms}$ which lengthened to about $109 \mathrm{~ms} \pm 9$ $\mathrm{ms}$ during pacing at a cycle length of $150 \mathrm{~ms}$. Due to the presence of an excitable gap it was possible to capture the myocardium during tachycardia with single or multiple premature stimuli, and to entrain or terminate the tachycardia by overdrive pacing. In flgure $4.3 \mathrm{~A}$ it is shown that a single premature stimulus (coupling interval $100 \mathrm{~ms}$ ) applied during sustained tachycardia with a cycle length of $120 \mathrm{~ms}$, captured the myocardium. The tachycardla was not terminated and resumed its intrinsic rate immediately after the premature beat. In figure $4.3 \mathrm{~B}$ an example of entrainment is shown. During a sustained tachycardia with a cycle length of $140 \mathrm{~ms}$ the ventricles were paced with a gradually shortened cycle length. As can be seen, during overdrive pacing, each stimulus is followed by a respons indicating entrainment of the tachycardia. When at a pacing interval of $130 \mathrm{~ms}$, pacing was suddenly interrupted, the rate immediately declined to the intrinsic rate of the tachycardia. Eventually, when the pacing frequency was further increased upto $100 \mathrm{~ms}$ the tachycardia was terminated (flgure $4.3 \mathrm{C}$ ). 


\section{REFRACTORY PERIOD (MS)}

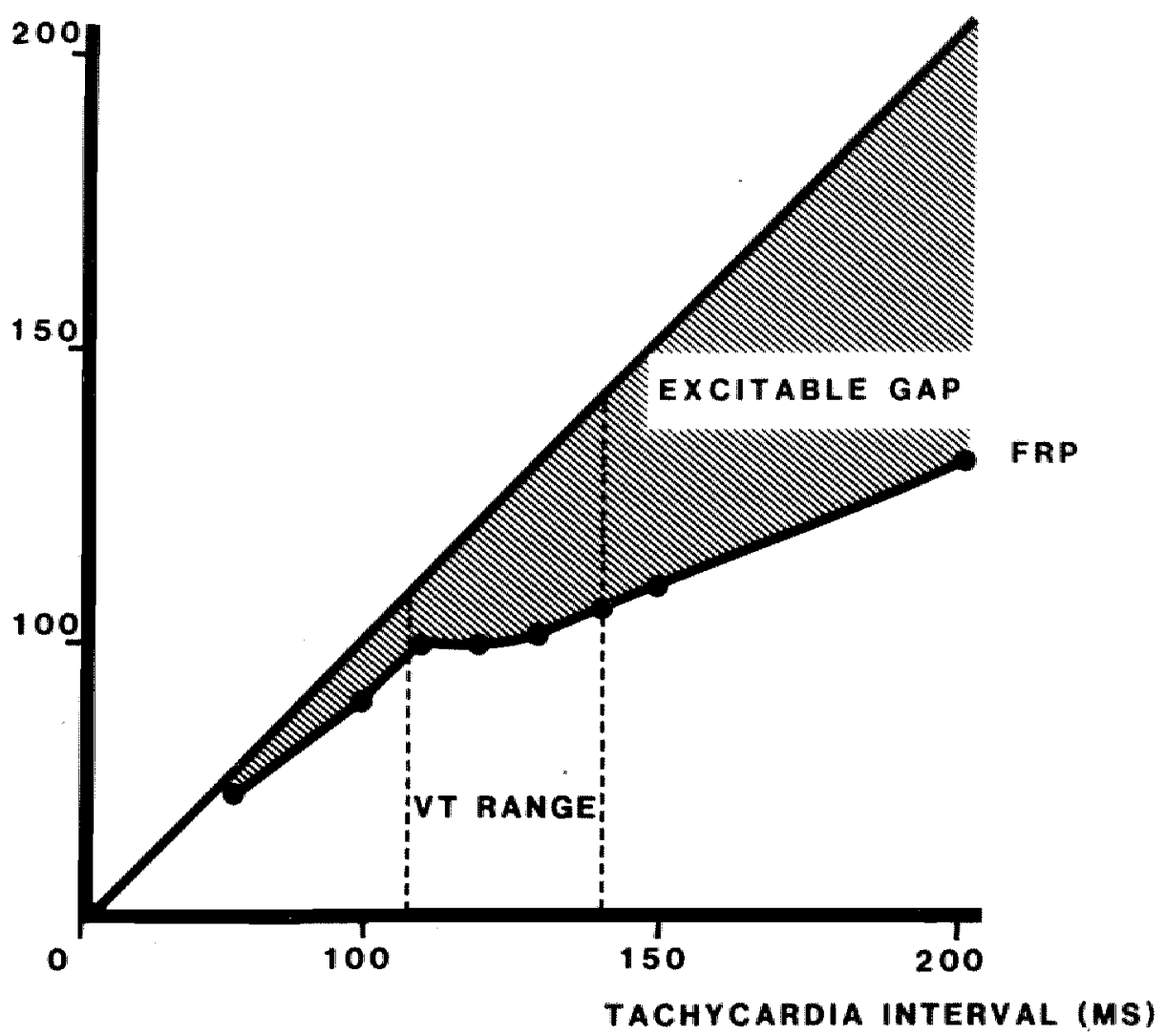

Fiqure 4.2. The relation between the functional refractory period and the cycle length during tachycardia. During regular pacing at a cycle length of $100 \mathrm{~ms}$ the refractory period was $94 \mathrm{~ms}$ gradually lengthening to about $110 \mathrm{~ms}$ during pacing at a cycle length of $150 \mathrm{~ms}$. The estimated excitable gap during tachycardia ranged from 10 to $40 \mathrm{~ms}$ depending on the cycle length of the tachycardia. 
Mapping of sustained ventricular tachycardia.

During sustained ventricular tachycardia different patterns of eplcardial activation were recorded. Reentrant excitation due to a circulating impulse around the cavitles of the ventricles was occasionally found but will not be discussed here. Thls type of tachycardla was extingulshed by freezing of the right ventricle, thereby interrupting the reentrant pathway.

Eplcardial reentrant excitation in a single loop was found in 28 out of 30 preparations. in the remaining two preparations a figure of elght type of reentrant excitation was recorded during tachycardia (figure $4.5 \mathrm{D}$ ).

The activation map shown in figure 4.4 was recorded during a tachycardia based on a single reentrant circuit. The cycle length of this tachycardia was $140 \mathrm{~ms}$. The isochrones were drawn at $10 \mathrm{~ms}$ time steps and only the central circuit area is displayed. The Impulse circulated in a clockwise manner around a long line of conduction block (thick line). The line of block is orientated parallel to the epicardial fiber direction. Due to the anisotropy of the ventricular myocardium the conduction velocity varied around the clircuit depending on the directlon of impulse propagation. During longitudinal impulse propagation, conduction velocity varied between 50 and $60 \mathrm{~cm} / \mathrm{s}$. At the pivotIng points, during transverse impulse propagation, conduction slowed down to less than $20 \mathrm{~cm} / \mathrm{s}$. The electrograms recorded around the line of block are given in the lower part of figure 4.4. The pattern of activation was regular and each of the recorded electrograms exhibited only minor variations in cycle length and morphology.

In figure 4.5, four activation maps are shown recorded during sustained tachycardia in different hearts.

The tachycardla shown in panel A was caused by a single reentrant loop (cycle length $120 \mathrm{~ms}$ ) circulating in a counter clockwise manner around a long line of transverse conduction block. The impulse conducted rapidly along both longitudinal limbs of the reentrant circult, while conduction was slower when the impulse propagated around the pivoting points in a transverse direction relative to the fiber orientation. The remaining part of the left ventricle was activated regularly and no other areas of conduction block were found.

Panel B shows the activation map during another tachycardia initiated in another experiment. Again a line of transverse conduction block was present around which the impulse circulated in a regular counter clockwise manner, 


\section{A single stimulus}

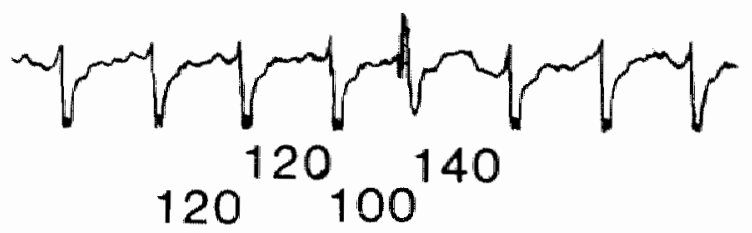

B entrainment

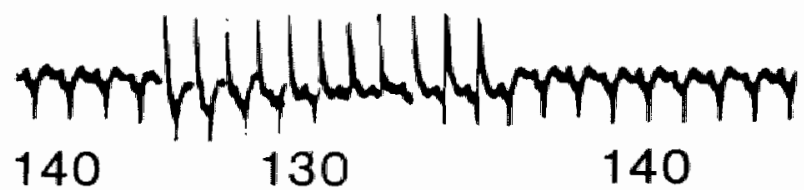

TERMINATION

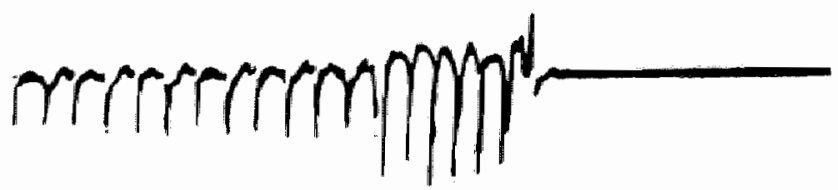

140

100

Eigure 4.3. Due to the presence of an excitable gap it was possible to capture the heart during sustained tachycardla (cycle length $120 \mathrm{~ms}$ ) with a single stimulus (coupling interval $100 \mathrm{~ms}$ ). The tachycardia was not terminated and resumed its intrinsle rate after a compensatory pauze (panel A). Entrainment of sustained tachycardia (panel B). During a sustained tachycardla wlth a cycle length of $140 \mathrm{~ms}$ the cycle length was increased to $130 \mathrm{~ms}$ by rapid pacing. After the cessation of pacing the rate immediately decreased again to resume the intrinsic rate of the tachycardla. Eventually, when the pacing interval was further increased to $100 \mathrm{~ms}$ the tachycardlia was terminated (panel C). 

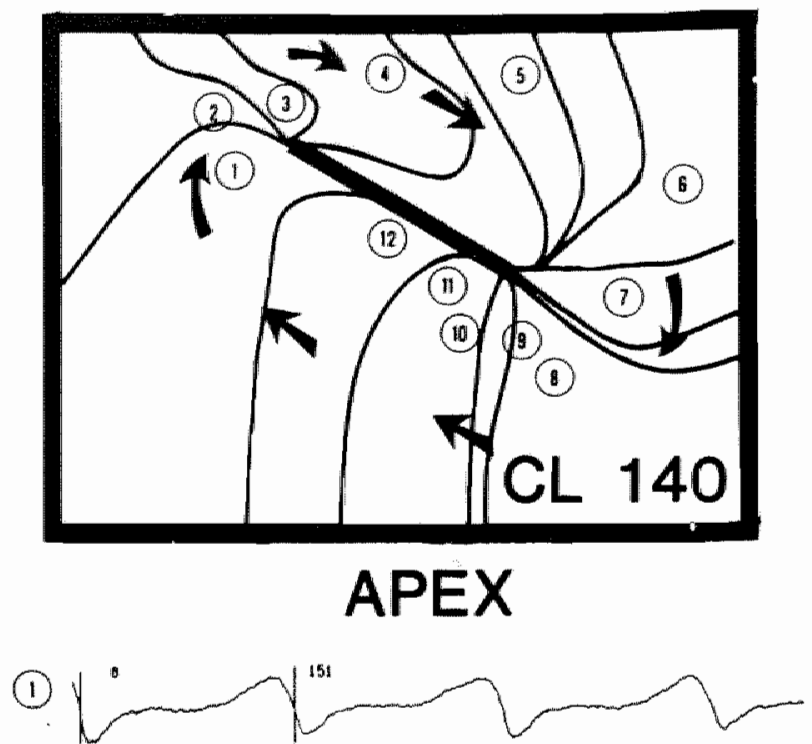

(2)

(3)

(1)

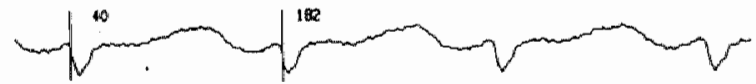

(5)

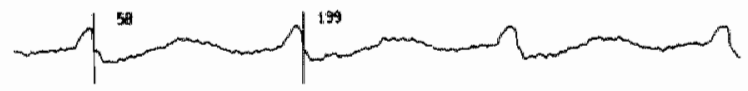

(B)

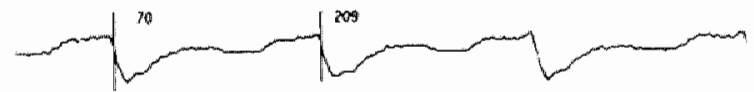

(1)

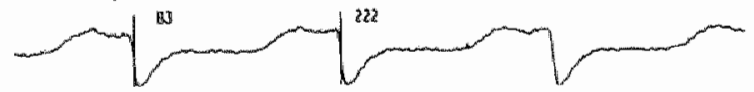

(1)

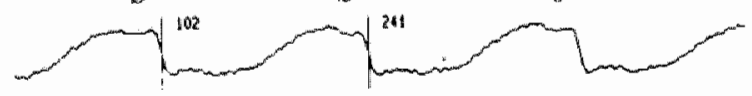

(a)

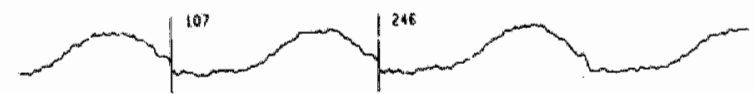

(10)

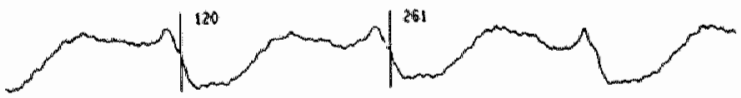

(11)

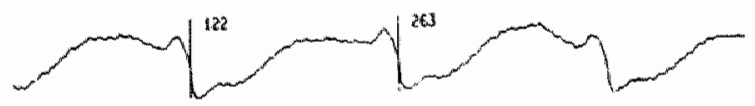

(12)<smiles>CCCCCCCCCCC(C)(C)CCCCCC(C)(C)CCCCCC</smiles> 
with a cycle length of $155 \mathrm{~ms}$. Conductlon velocity varled depending on the direction of propagation. Slow conduction was found during transverse conduction when the impulse pivoted around the line of block while fast conduction was found during longitudinal conduction, parallel to the line of block.

The tachycardila shown in panel $C$ was also caused by reentrant excitation. Again only one reentrant circuit (cycle length $120 \mathrm{~ms}$ ) was present, this time circulating in a clockwise direction around a short line of conduction block. This line of conduction block consisted of one segment orlentated parallel to the epicardial fiber direction and another segment orientated perpendicular to the fiber axis. Due to the presence of longitudinal block (orientated perpendicular to the fiber direction), the impulse was forced to propagate in a transverse direction over a considerable distance (reflected by the crowding of isochrones). A second line of conduction block was present in the upper right part of the activation map. This conduction block did not participate in the reentrant circuit.

A figure of elght like reentrant excitation pattern is shown in panel $D$. The cycle length of the tachycardia was $125 \mathrm{~ms}$. Two lines of conduction block were present, one line of block being orientated more or less perpendicular to the fiber directlon (upper left) while the second line was orientated parallel to the flber directlon (lower centre). The impulse conducted around the upper line of block in a clockwise manner. A counter clockwise activation was found around the lower line of block. A narrow common pathway was present between both lines of block through which the impulse conducted slowly.

In figure 4.6 the differences in conduction velocity during ventricular tachycardla are illustrated. Again a single reentrant loop was present, circulating in a clockwise manner around a line of transverse conduction block. Due to the striking anisotropy of the ventricular myocardium conduction velocity varied around the circult (panel B). During longitudinal conduction, the impulse propagated with a velocity of 52 to 62

Eigure 4.4. Electrograms recorded around the line of conduction block. One reentrant circult was present. The cycle length of this tachycardia was $140 \mathrm{~ms}$. The isochrones were drawn at $10 \mathrm{~ms}$ time steps and only the central circuit area is displayed. The electrograms demonstrated regular activation and only minor variations of cycle length and of the electrogram morphology were recorder. 
A

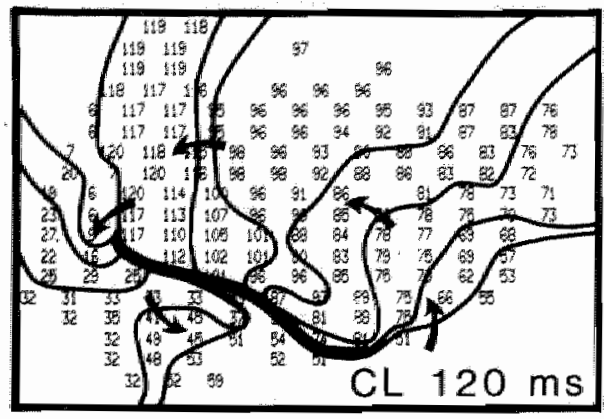

C

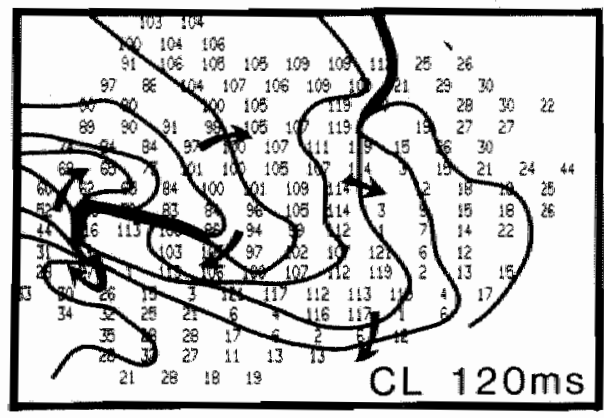

B

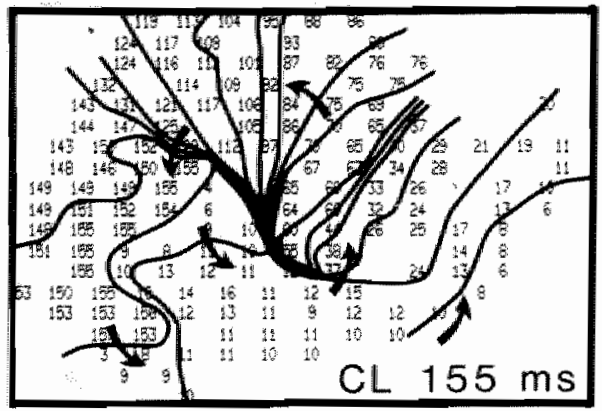

D

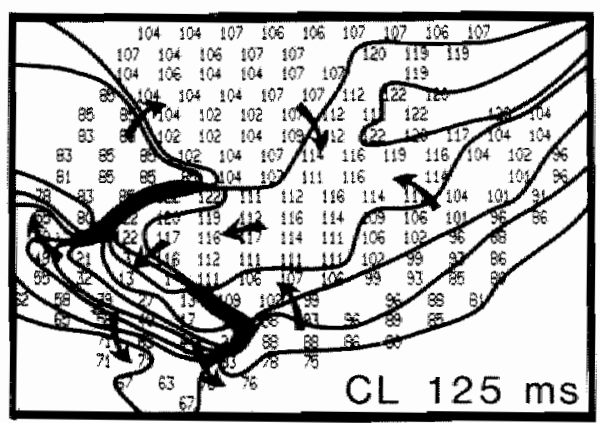

Elqure 4.5. Mappling of sustained ventricular tachycardia. Four activation maps ${ }_{4}$ recorded during sustained tachycardia in different hearts. See for explanation text.

$\mathrm{cm} / \mathrm{s}$. When the impulse pivoted around the line of block, transverse conduction occurred at a velocity of 14 to $16 \mathrm{~cm} / \mathrm{s}$.

The line of central conduction block.

The activation maps given in figure 4.4, 4.5 and 4.6 demonstrate that sustained tachycardia initlated in the normal epicardium of the rabbit ventricle was caused by reentrant excitation. In $75 \%$ of the experiments the impulse circulated around a line of block orientated parallel to the epicardial fiber direction (figure $4.7 \mathrm{~A}$ ). The length of these lines of conduction block was $20 \pm 5 \mathrm{~mm}$ and the mean cycle length of the tachy- 
cardias was $129 \pm 20 \mathrm{~ms}$. A different orientation of the line of block was found in $25 \%$ of the experiments (figure $4.7 \mathrm{~B}$ ). Sometimes a L-shaped line of block (figure $4.5 \mathrm{C}$ ) consisting of a longitudinal and a transverse part was present, while during some tachycardias the orientation of the line of block was found to be related to the orientation of an epicardial blood vessel. The length of these lines of block was $196 \mathrm{~mm}$ and the mean cycle length of the tachycardias was $123 \pm 4 \mathrm{~ms}$.

The central line of conduction block during anisotropic reentry may be caused by anatomical or functional properties of the myocardium. The results presented in chapter III demonstrated that no large anatomical barriers were present in the surviving epicardial layer and that functional anisotropic conduction block perpendicular to the fiber direction could be induced by high potassium, rapid pacing or the application of premature beats.

To study the properties of the line of conduction block, the electrograms recorded from the central area of the reentrant circuit were analysed.

In figure 4.8 the electrograms recorded from the central area of the clrcult and the region of conduction block are plotted. The electrograms recorded from the longitudinal limbs of the circult exhibited large biphasic deflectlons preceded by an R-wave. During transverse conduction at the pivoting points of the clicults the amplitude of the recorded electrograms was much smaller and no or only small R-waves preceeded the negative deflection. Electrograms recorded from the transverse line of block consisted of two distinct mainly positive deflections. These positive defections were caused by electrotonic current flow between the two opposing longlitudinal activation wavefronts. The double component electrograms did not show multiple low amplitude fragmented deflections which are seen during slow transverse conduction in nonunlform anisotropic tissue (Spach et al., 1986).

Additionally extracellular electrograms at the central line of block were recorded with a very high density mapplng electrode. This electrode consisting of two rows of 48 electrodes had a spatlal resolution of $0.185 \mathrm{~mm}$ (silver wires, $0.05 \mathrm{~mm}$ dlameter). After localization of the epicardial circuit with the "spoon" electrode, this high resolution electrode was positioned across the line of central block.

An example is given in figure 4.9. As can be seen from the activation map, the impulse circulated around a line of transverse block with a cycle length of $135 \mathrm{~ms}$. The electrograms recorded at different sites across the line of block are given in panels $A$, 

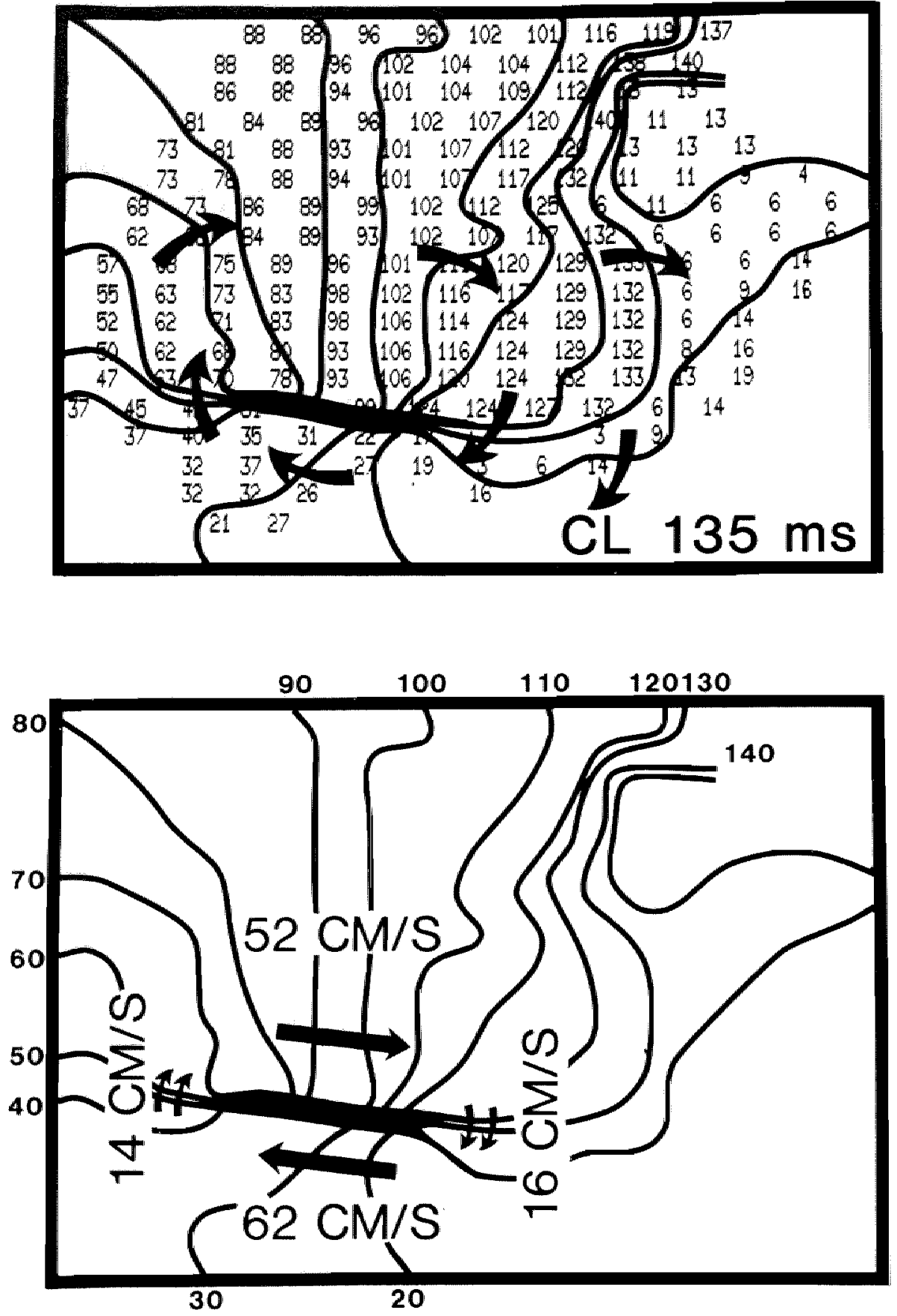
B, C. The family of electrograms displayed in panel B was recorded from the exact center of the circuit, where a difference of half the cycle length $(67 \mathrm{~ms})$ existed between the opposing longitudinal limbs of the circuit. A regular and single high amplitude biphasic deflection was recorded from each of the longitudinal limbs of the circuit. At the line of central conduction block the amplitude of the electrograms decreased and a second low amplitude positive deflection appeared. Electrograms recorded from the line of block showed two mainly positive deflections. Between these two deflections an isoelectrical segment was present and no multiple low amplitude deflections, indicating slow transverse conduction across the line of block were recorded. When the high resolution mapping electrode was shifted towards the pivoting points, the time difference between the double deflections shortened (panels $A$ and $C$ ). The electrical crosstalk between the opposing longitudinal limbs of the circuit , demonstrated by these waveplots show that electrical coupling was intact and that no insulating anatomicall barriers were present.

\section{Pseudoblock.}

In recent studies Wit et al. (1987) and Dillon et al.(1988) demonstrated that reentrant excitation within thin surviving epicardlal layers may be the source of sustained ventricular tachycardia in the healing phase after myocardlal infarctlon. They found that during sustailned tachycardla the impulse circulated around a line of functlonal conduction block, which was orientated parallel to the epicardial flber direction in most experiments. However sometimes, although the isochrones suggested the presence of a long line of block, actually slow discontinuous transverse impulse conduction (less than $5 \mathrm{~cm} / \mathrm{s}$ ) through the line of block occurred, as reflected by the occurrence of multiple low amplitude deflections in the extracellular electrograms. The slowing of the transverse conduction velocity was caused by the interposition of collageneous septa

Eioure 4.6. Conduction velocity around the line of conduction block. Due to the anisotropy of the ventricular myocardlum conduction vellocity varied around the circuit depending on the direction of the impulse. During longitudinal conduction, the veloclty of the Impullse varled between 52 and $62 \mathrm{~cm} / \mathrm{s}$. When the impulse pivated around the lline of block, during transverse impulse conduction, the conduction velocity was as slow as $14-16 \mathrm{~cm} / \mathrm{s}$. 
A

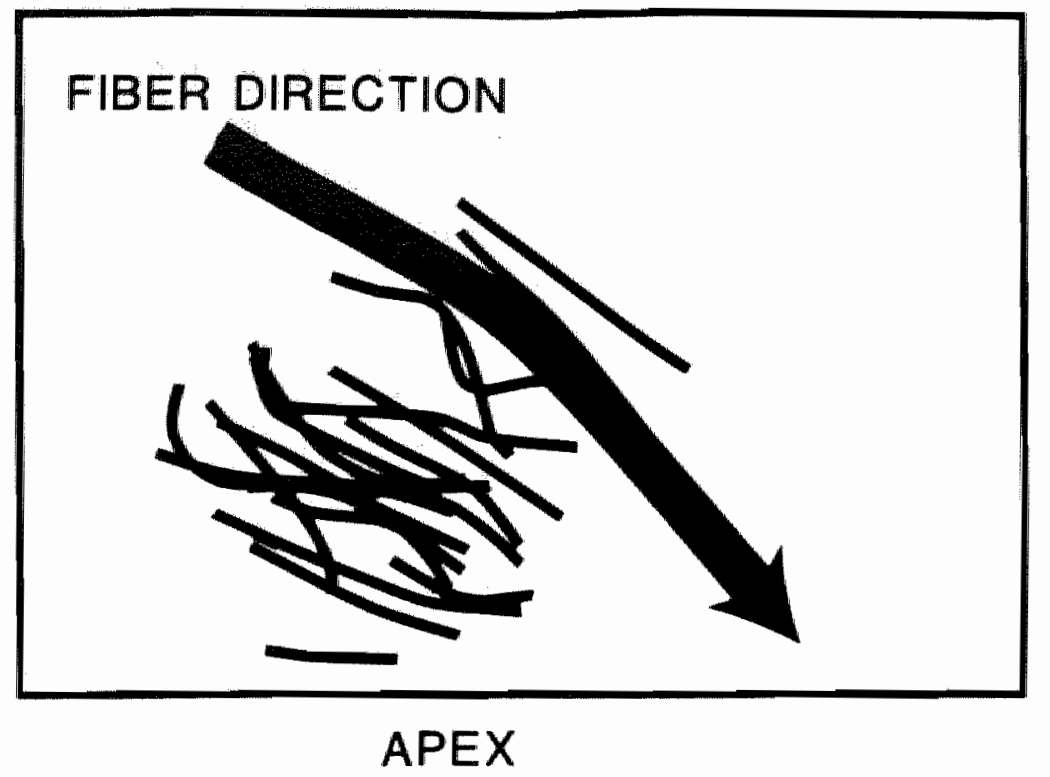

B

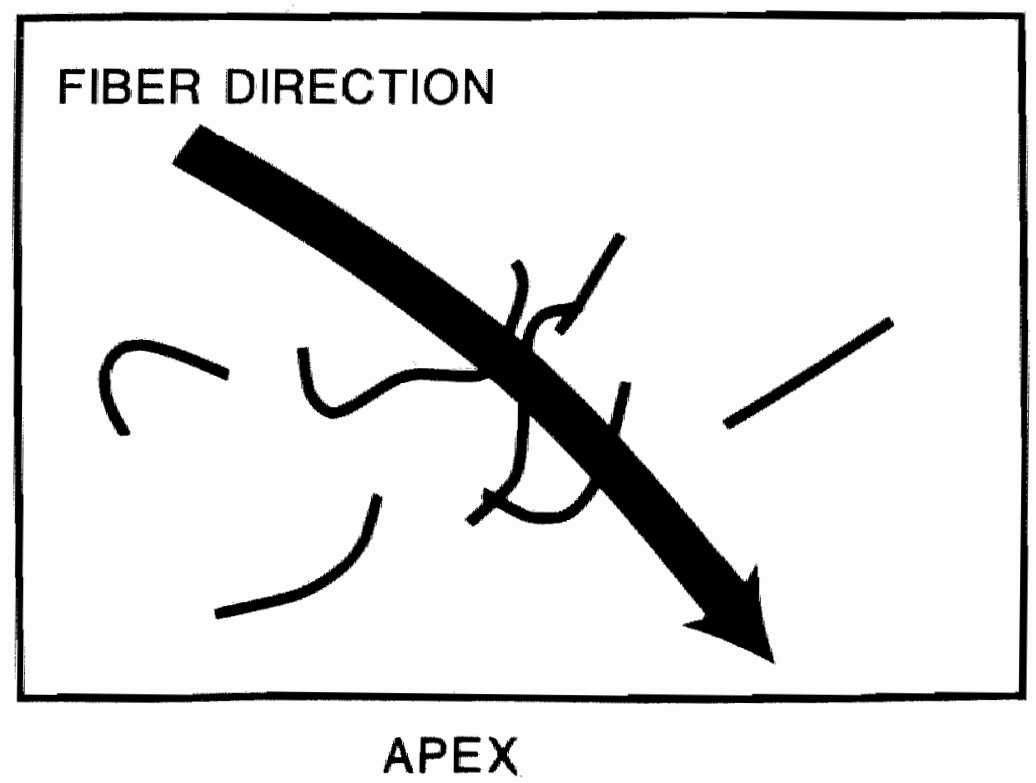


and destroyed cells between surviving myocardial fibers. (Wit et al., 1987, Dillon et al., 1988).

In the uniform epicardial layer a much faster transverse conduction was found (15$20 \mathrm{~cm} / \mathrm{s}$ ) and during most of the sustained tachycardias a reentrant circuit circulated around a true line of transverse conduction block. However in some preparations slow transverse impulse conduction across the line of apparent block could be detected. Figure 4.10 gives an example of such a "pseudoblock". The cycle length of the tachycardla was $122 \mathrm{~ms}$ and a single impulse circulated around a line of transverse conduction block. Fast conduction was present during longitudinal conduction while at the pivoting points the impulse propagated slowly in a transverse direction. However the tissue at one side of the line of block was activated nearly simultaneously. Consequently the 20,30 and $40 \mathrm{~ms}$ isochrones are orientated parallel to the line of block. This might be explained by very slow transverse conduction across the line of block.

\section{The spread of activation during the initiation of sustained tachycardla.}

Due to the enhanced anisotropic conduction properties of the two dimensional eplcardial layer, local conduction block and slow conductlon could be Induced by depressing the stimulating efficacy of the impulse (chapter III). Although conduction block occurred more promptly during transverse conduction, reentry was not initiated until eventually a short longitudinal line of conduction block appeared. This short line of longitudinal block forced the impulse to propagate in a transverse direction providing sufficient delay for reentry (chapter III, figure 3.13). After the initial beats the pattern of excitation changed completely however due to the limited size of the high resolution mapping electrode $(13 \times 15 \mathrm{~mm})$ it was not possible to map the total spread of epicardial excitatlon during initiatlon of tachycardia.

Elgure 4.7. Orientation of the lines of conduction block during sustalned tachycardla. In most of the experiments $(75 \%)$ the impulse circulated around a long line of conduction block orlentated parallel to the eplcardial fiber direction (panel A). The length of these lines of block was $20 \pm 5 \mathrm{~mm}$ and the cycle length of the tachycardias was $129 \pm 10 \mathrm{~ms}$. During $25 \%$ of the tachycardias a different orientation of the line of conduction block was recorded (panel B). The length of these lines of block was $19 \pm 6 \mathrm{~mm}$ and the mean cycle length of these tachycardias was $123 \pm 4 \mathrm{~ms}$. 

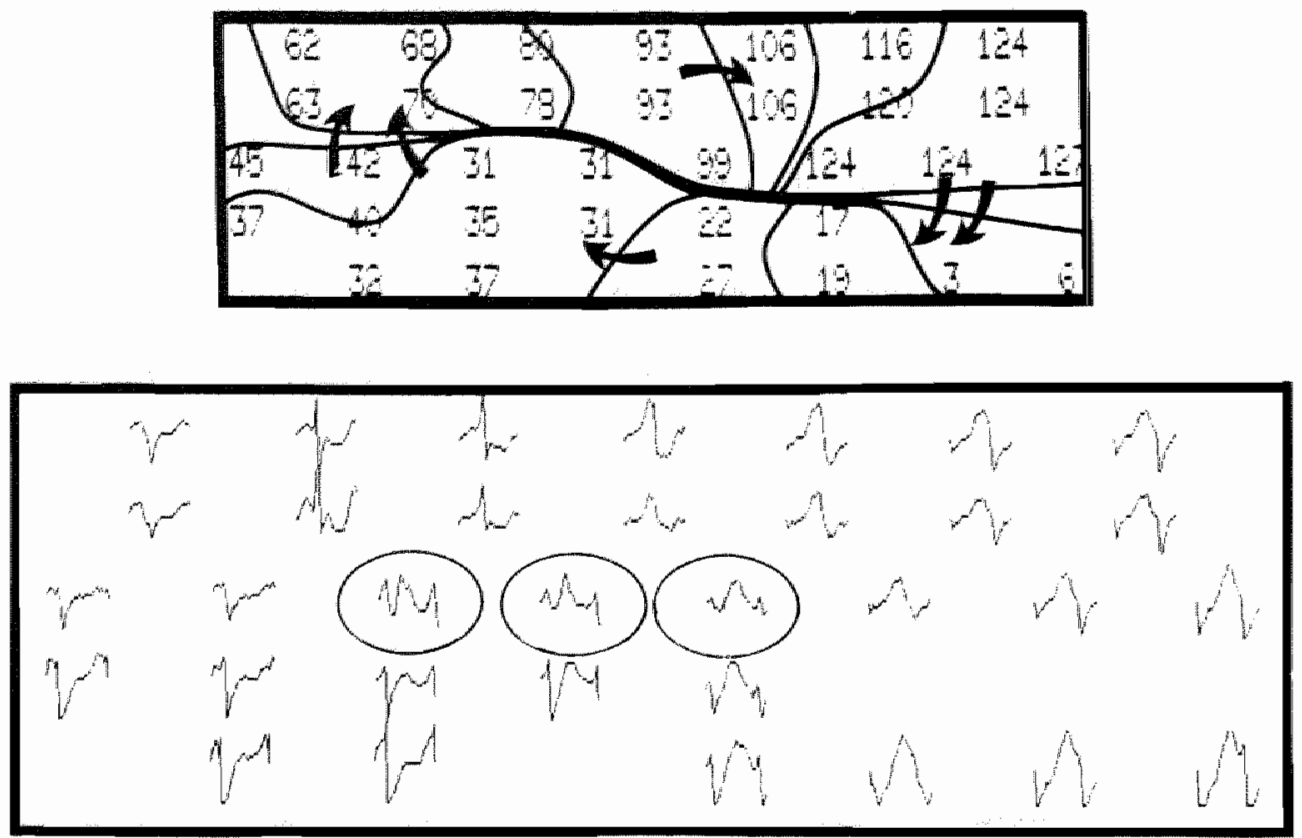

Eligure 4.8. Properties of the central line of conduction block during sustained tachycardia. A large reentrant loop clirculating around a long line of transwerse conduction block was present. The electrograms recorded from the central circuit region of the circuit and the are of conduction block are given. Electrograms recorded around the line of block exhibited a 1:1 response and either large biphasic deflectlons (during longitudinal conduction) or low amplitude deflections preceeded by a small R-wave (during transverse conduction, at the pivoting points) were recorded. The electrograms (encircled) recorded from the line of conduction block exhibited two deflections. The delay between both deflections is equal to the time difference between the adjacent limbs of the circult at each site of the line of block.

In this paragraph we will describe the initial phase of a sustained tachycardia. By mapping the epicardlal activation pattern with the "spoon" electrode, a detalled reconstruction could be made (figure 4.11).

The tachycardla was initlated by two shortly coupled premature stimuli applied during regular pacing with a cycle length of $350 \mathrm{~ms}$ (top tracing). In panels $\mathrm{S}_{1}$, S2, and S3 the activation maps recorded during regular pacing (S1) and the two premature beats $(\mathrm{S} 1-\mathrm{S} 2=155 \mathrm{~ms}, \mathrm{~S} 2-\mathrm{S} 3=135 \mathrm{~ms})$ are given. The heart was stimulated from a palr of electrodes located in the upper left part of the mapping electrode. During regular pacing an ellipsoid activation pattern was recorded. The impulse conducted rapidly parallel to the epicardial fibers and more slowly perpendicular to the fiber direction. No signs of impaired conduction or conduction block were found. During the first premature beat (\$2) longitudinal and transverse conduction were slowed down slightly. 

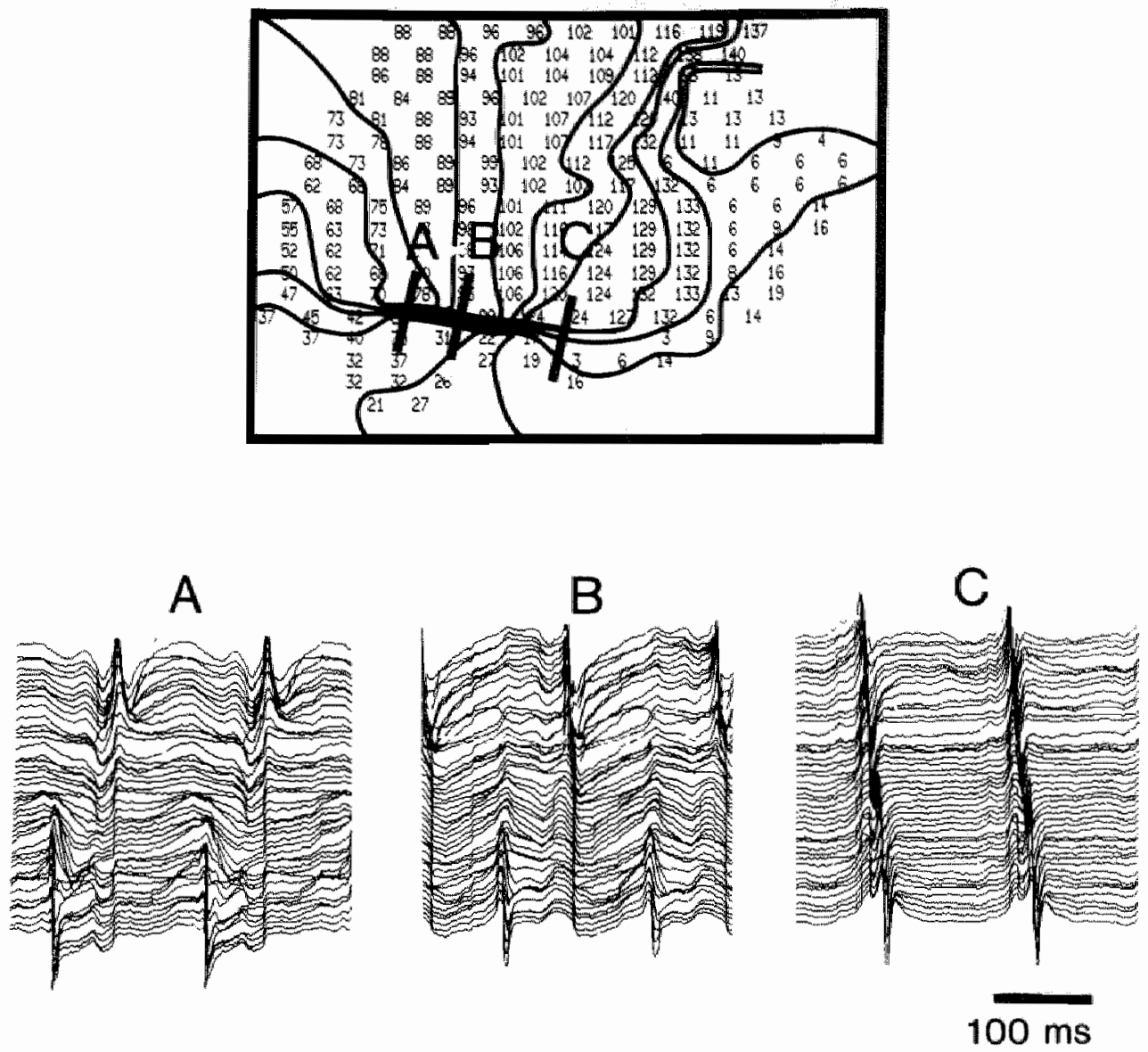

Elgure 4.9. Wave plots recorded during sustained tachycardia. The totivation map showed that the impulse circulated around a line of transwarse block with a cycle length of $135 \mathrm{~ms}$. The electrograms $r e$ corded at different sites across the line of block are given in panels $A, B, C$. See for explanation text

A short line of transverse conduction block emerged near the site of stimulation (fusion of isochrones). During the second premature beat (S3) conduction was further depressed, both in a longitudinal and transverse direction and a few lines of transverse and longitudinal conduction block appeared. About $140 \mathrm{~ms}$ after the second premature stimulus, a spontaneous beat originated near the orginal site of stimulation (VT1). Because of the relatively low spatial resolution of the "spoon" electrode it was not possible to decide whether this first spontaneous beat was initiated by spontaneous 


\section{PSEUDO BLOCK}

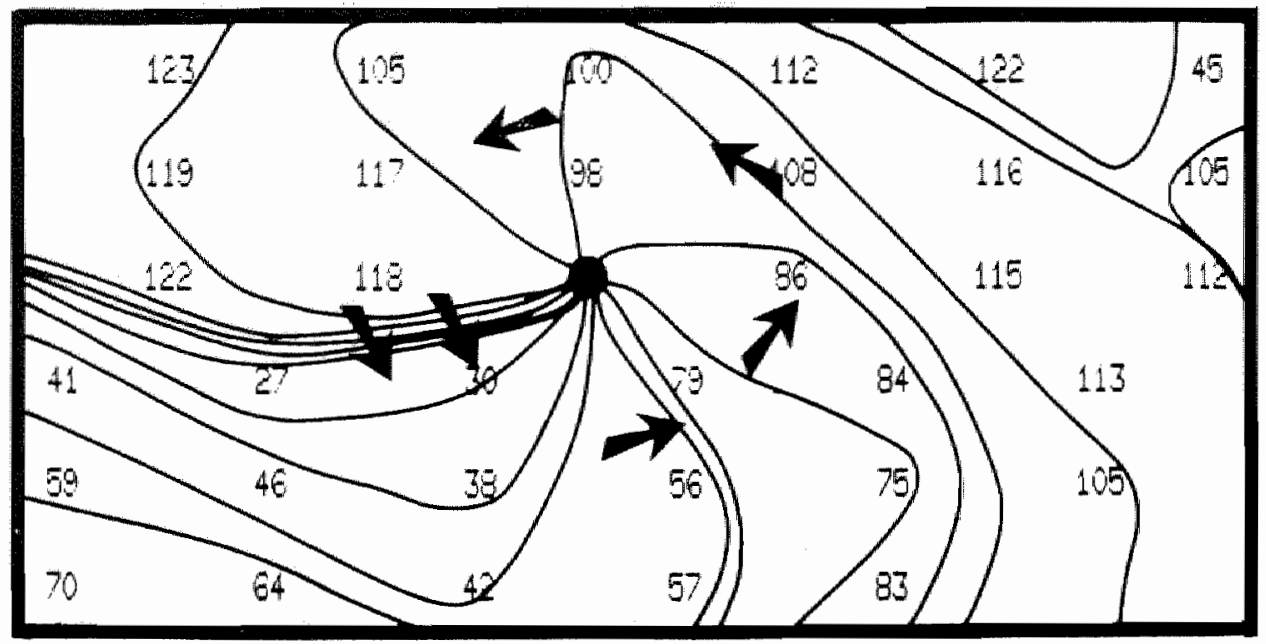

Figure 4.10. Pseudo blook. The activation map showed the central circult area during sustained tachycardia. The cycle length was $122 \mathrm{~ms}$ and the impulse conducted around an apparent line of transverse conduction block. Near the line of block large parts of the myocardium were actlvated nearly without any conduction delay. The 20,30 and $40 \mathrm{~ms}$ isochrones are orientated parallel to the line of block and extend along the line of block.

Impulse formation or by reentrant excitation within a small reglon near the site of stimulation. However the activation map of the first beat of the tachycardia showed that conduction became more depressed and that some lines of conduction block emerged. The impulse plvoted around both ends of a relatively long line of conduction block in the center of the map. After about $80 \mathrm{~ms}$ the second spontaneous beat originated when the impulse propagated retrogradely through the line of block near the left pivoting

Figure 4.11. The Initlation of sustalned tachycardia by two closely coupled premature beats. The isochrone maps during regular pacing (S1), premature stimuli (S2-S3) and the first flive beats of the ensulng ventricular tachycardlia are shown (VT1-VT5). See for further explanation text. 


\section{INITIATION OF TACHYCARDIA}

$\begin{array}{llllllllll}S_{1} & S 1 & S_{2} & S_{3} & V T_{1} & V T_{2} & V T_{3} V T_{4} & V T_{5}\end{array}$

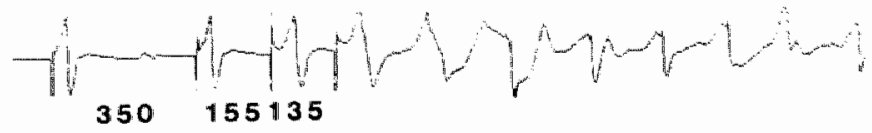

S1

S2
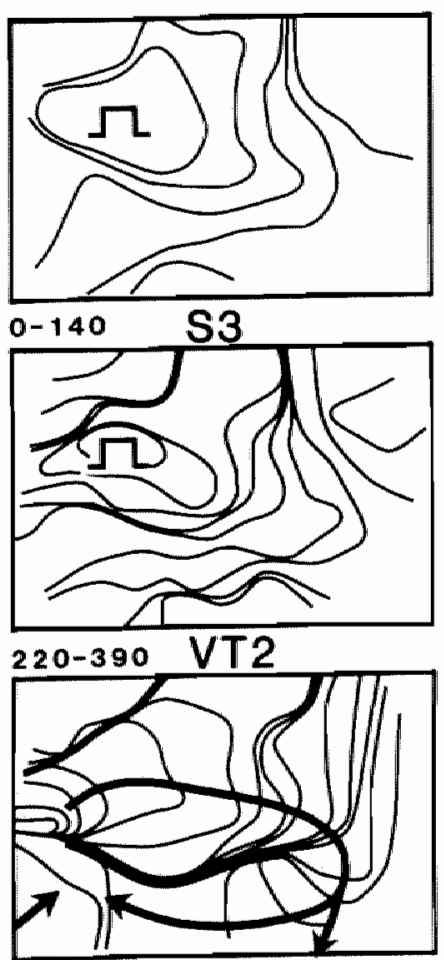

520-650 VT4
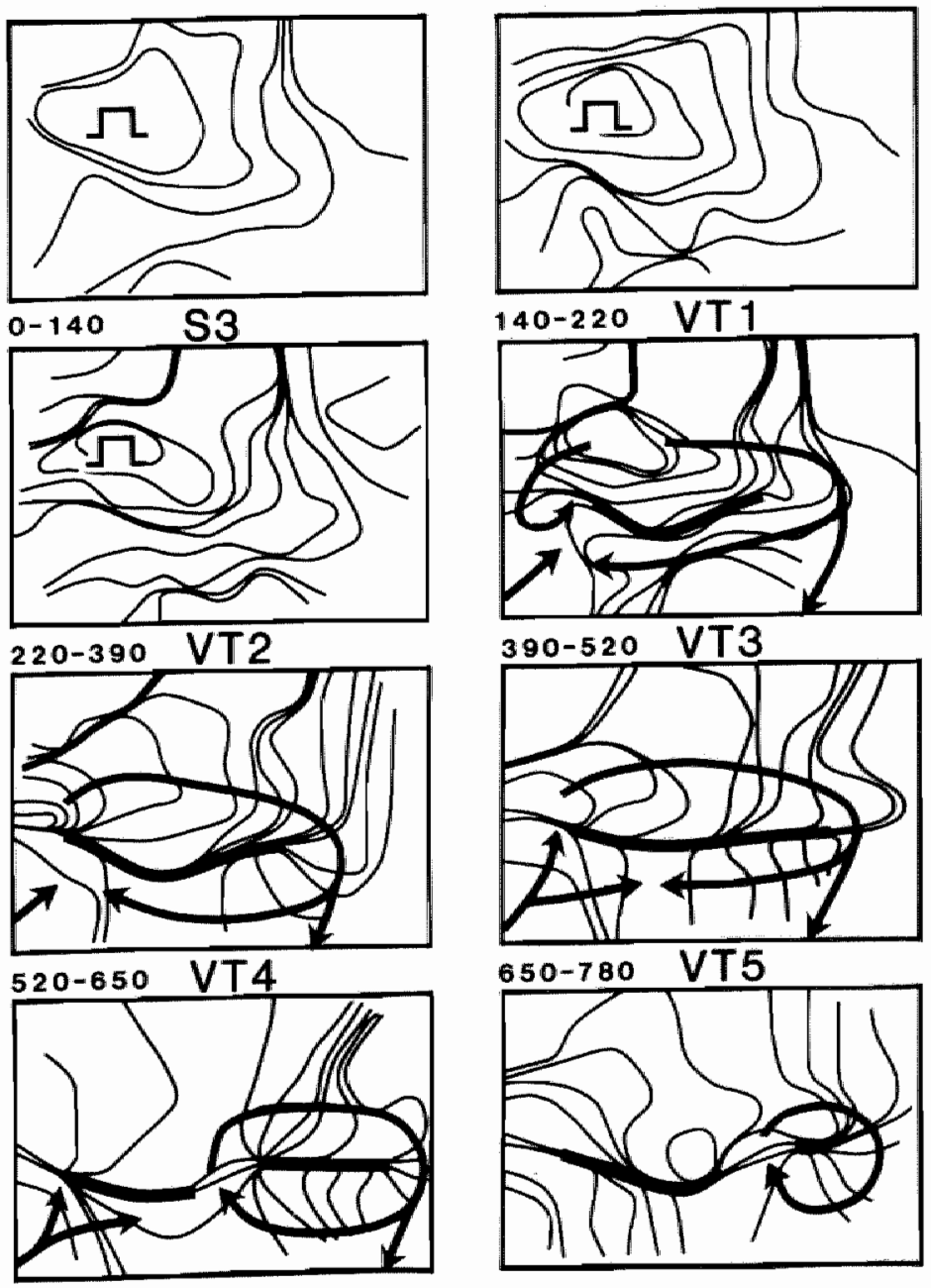
point (VT2). The impulse propagated in a clockwise direction around the long line of conduction block. Because the length of the line of block was increased the length of the excitation pathway increased also and as a result of this the next spontaneous beat (VT3) originated only after about $170 \mathrm{~ms}$ when the impulse conducted around the left end of the line of block. During this beat the impulse circulated again around the long line of conduction block, but was partially blocked by an impulse circulating around the apex. At the site of collision of these two wavefronts the impulse now succeeded to propagate up through the line of conduction block thus short circuiting the left part of the circuit. Consequently the circuit during the next beat (VT4) had smaller dimensions and shifted to the right. During the next beat the length of the line of conduction block was further shortened (VT5). This pattern of excitation found during the fifth beat of the tachycardia remained stable, during the whole period of the tachycardia. 


\section{CHAPTER V}

\section{GENERAL DISCUSSION}

Due to the anlsotropic morphology of the ventricles, conduction is about three times faster during impulse conduction parallel to the fiber axis, compared to transverse conduction. Consequently the wavelength of refractoriness, given by the product of conduction velocity and refractory period is three times longer during longitudinal conduction than during transverse conduction (chapter II). Due to the three dimensional geometry of the ventricles the arrhythmogenic effects of slow transverse conduction and the short transverse wavelength are masked by a fast and homogeneous impulse spread in nearly all different directions (chapter III). Because of this, in normal intact ventricles, ventricular tachycardlas do not occur. After removal of the intramural and endocardial layers of the rabbit ventricle the effectlive distance of slow transwerse impulse conduction Increased and local conductlon block could be easily Initiated (chapter III). It emerged that anisotropic conduction and conduction block played a key role in the initiation of sustained reentrant tachycardia in a thin epicardlal layer. During sustained tachycardla, the impulse circulated around a line of functional conduction block; no gross anatomical barriers were Involved In the reentrant circuit (chapter IV). However in contrast to the leading circle type of functional reentry (Allessle et al., 1977), In uniform anlsotroplc myocardlum a clear excltable gap was present. Due to the presence of an excitable gap, anisotroplc reentry was more stable and longlasting.

In this chapter the characteristics of "anisotroplc" reentry and the mechanisms contributing to the creation of an excitable gap will be discussed.

\subsection{INITIATION OF ANISOTROPIC REENTRY.}

Among other things the inducibility of reentrant arrhythmias is determined by the wavelength of refractoriness ('Smeets et al., 1986, Rensma et al., 1988, Lammers et al., 1988). Recently Rensma et al. (1988) demonstrated that the wavelength of refractoriness is a sensitive and specific index of the susceptibility of the heart to atrial arrhyth- 
mias. A short wavelength was found to be a risk factor for the initiation of reentry. A long wavelength on the other hand, could prevent the induction of reentry. In agreement with this we demonstrated that in the intact ventricle, due to the fast three dimenslonal Impulse spread, the wavelength was long and no ventricular fibrillation or tachycardia could be Initiated by the application of shortly coupled premature stimuII. Only after prolonged periods of maximal pacing, when conductlion has become seriously depressed and consequently the wavelength was shortened, ventricular fibrillation was initiated. In the two dimensional epicardial layer slow transverse impulse conduction was no longer bypassed via faster conducting deeper layers and as a result the area of effective anisotropy increased. When the stimulating efficacy of the impulse was lowered and conductlon block developed, sustained ventricular tachycardia could be Initiated after the application of two or more shortly coupled premature stimuII (chapter III and IV). Ventricular tachycardia was never observed after induction of only one premature beat. This is explained by the fact that the wavelength of a single premature beat was only slightly shorter than during regular pacing and no conduction block occurred.

The minimal length of the line of conduction block required to initiate reentry has to be at least half the length of the excitation wave. When the line of block is orientated perpendicular to the fiber direction (e.g. longitudinal conduction block) the impulse activates the myocardium distal to the line of block in a slow transverse manner at a conduction velocity of about $20 \mathrm{~cm} / \mathrm{s}$. During fast pacing (for instance $100 \mathrm{~ms}$ cycle length) the transverse wavelength is $2 \mathrm{~cm}$ and a block of $1-2 \mathrm{~cm}$ will be required to inItlate reentry. In nonunlform anisotroplc myocardium, when transverse conduction may be slowed to less than $5 \mathrm{~cm} / \mathrm{s}$, the minimal length of the line of block might be even less than $0.5 \mathrm{~cm}$ (Spach et al. 1981, 1986). However when the line of block is positioned parallel to the epicardial fiber direction (transverse conduction block) the myocardlum distal to the line of block will be actlvated by fast longitudinal conduction $(60 \mathrm{~cm} / \mathrm{s})$, and the minimal length of the line of block for reentry will be about $6 \mathrm{~cm}$. The initiation of reentry thus will be facilitated by both the occurrence of longitudinal conduction block and slow transverse impulse conduction. In agreement with this we demonstrated (chapter III) that although conduction block occurred more promptly during transverse conduction, reentry was rarely initiated unless also an area of longitudinal block occurred. 


\subsection{SUSTAINED "ANISOTROPIC" REENTRY}

The cycle length of sustained ventricular tachycardia ranged from $105 \mathrm{~ms}$ to 160 $\mathrm{ms}$ (mean $13011 \mathrm{~ms}$ ) with an excitable gap of 10 to $40 \mathrm{~ms}$. Reentrant excitation was found to be the underlying mechanism of sustained tachycardia. Due to the anisotropy of the ventricular myocardium (Clerc, 1977 , Spach et al., 1981, 1982) the conduction velocity of the circulating impulse around the circuit varied from about $60 \mathrm{~cm} / \mathrm{s} \mathrm{during}$ longitudinal conduction to less than $20 \mathrm{~cm} / \mathrm{s}$ during slow transverse conduction. The presence of an excitable gap explained the stability and long duration of the tachycardias.

At the line of block no insulating anatomical barriers could be found and the slze of the circuit will thus be determined by the electro-physlologlcal propertles of the myocardium (chapter IM). The length of the circular pathway is determined by the product of the average conduction velocity and the cycle length of the arrhythmla. When the line of conduction block is orientated parallel to the eplcardial fiber direction, the mean conduction velocity around the circuit is about $40 \mathrm{~cm} / \mathrm{s}$. During a tachycardia with a cycle length of $130 \mathrm{~ms}$, the length of the circular pathway will then be $5.2 \mathrm{~cm}$. The surface area required for the perpetuation of a reentrant tachycardia will be 2.3 $\mathrm{cm}^{2}$. In nonuniform anisotropic myocardium transverse conduction may slow down to less than $5 \mathrm{~cm} / \mathrm{s}$ (Spach et al., 1981, 1982a, 1986). Thls can decrease the mean conduction velocity to less than $19 \mathrm{~cm} / \mathrm{s}$ and the circumference of the circuit to less than $2.5 \mathrm{~cm}$, under these circumstances a surface area of only $0.5 \mathrm{~cm}^{2}$ would sufflce for a circus movement of the impulse.

When the line of block is orientated perpendicular to the flber direction in uniform anisotropic myocardlum, the mean conduction velocity is estimated to be $25 \mathrm{~cm} / \mathrm{s}$. In this situation the minimal clircumference of the circult will be $3.3 \mathrm{~cm}$, resulting in a surface area of only $0.9 \mathrm{~cm}^{2}$. In addition, when transverse impulse conduction is further slowed down in nonunlform anisotroplc myocardium, to less than $5 \mathrm{~cm} / \mathrm{s}$, the clrcumference of the circuit may shorten to less than $1 \mathrm{~cm}$, resulting in a minimal surface area of only $0.08 \mathrm{~cm}^{2}$.

The minimal surface area necessary for the maintaince of anisotroplc reentry thus varies from about $2.3 \mathrm{~cm}^{2}$ when the impulse circulates around a transverse line of conduction block to less than $0.08 \mathrm{~cm}^{2}$ when the impulse circulates around a longitudinal conduction block in nonuniform anisotropic myocardium. This is in accordance with 
the suggestion of Spach et al. (1981) that in nonuniform anisotropic myocardium micro reentrant circuits may be confined within only a few square millimeters. Experimental results of Wit et al. (1987) and Dillon et al. (1988) demonstrated that reentrant circuits within the borderzone of the infarct may cause sustalned ventricular tachycardias. Due to slow discontinuous transverse impulse conduction some of these circults were extremely small.

The rate of circus movement excitation depends on the length of the circular pathway and the average conduction velocity around the circult. During functional reentry the circulating impulse follows the shortest possible pathway and the circuit length is equal to the length of the excitation wave (Allessie et al., 1977). Consequently the revolution time will be determined by the functional refractory period. During anisotropic reentry however, due to the presence of an excitable gap, the circuit length is not equal to the length of the excitation wave. As a consequence, the rate of anisotropic reentry will be determined by the functional refractory period add to the duration of the exclitable gap.

In conclusion the characteristics of "anisotroplc" reentry are:

1. A central line of functional conduction block mostly paraliel to the fiber orlentation.

2. Varying conduction velocities of the circulating impulse caused by changes in direction relative to the fiber direction.

4. The presence of an excltable gap.

5. A cycle length proportional to (but longer than) the refractory period of the myocardlum.

6. A high degree of stability.

Anatomlcall, functional and anisotroplc reentry.

A number of Important differences exists between anisotropic reentry and either anatomical or leading circle reentrant arrhythmias. 1 . In contrast with anatomical reentry no insulating barrier is present and the line of block consists of normal cells during leading circle and anisotropic reentry. 2 . Whereas the size of an anatomical circuit is determined by the size of the anatomical barrier, during leading circle reentry and during anisotropic reentry the length of the circular pathway is determined by the electrophysiologic propertles of the myocardium. 3. Durlng leading circle reentry and dur- 
ing anisotropic reentry the circuit length changes with variations in conduction velocity and refractory period, while during anatomlcal reentry the length of the circular pathway is fixed. 4. During anatomical and anisotropic reentry an excitable gap is present, while during leading circle reentry no excitable gap is present because there exists a tight fit between the crest and the tail of the impulse. Consequently anatomical and anisotropic reentry are stable and longlasting whereas leading circle reentry tends to terminate spontaneously. 5 . The rate of a leading circle reentry is equal to the refractory period whereas due to the presence of an excitable gap the rate of anisotropic reentry is proportional to the refractory period of the myocardium and the duration of the excitable gap. During anatomical reentry the rate of the tachycardia is inversely related to the conduction velocity.

Characteristics of anatomical, functional and anisotropic reentry.

Anatomical

1.Impulse circulating around an anatomical barrier.

2.Large dimensions

3.Fixed pathway
Leading circle

1.Functional conduction block

2.Smallest possible dimensions

3.Size of the circuit may change with alterations of electrophysiologic properties
4. Excitable gap
4.No excitable gap
5.Stable and longlasting
5.Tends to terminate spontaneously
6.The revolution time inversely related to conduction velocity
6. Revolution time proportional to refractory period

\section{Anisotropic}

1.Functional conduction block

2.Intermediate dimensions

3. Size of the circult may change with alterations of electrophysiologic properties
4. Excitable gap
5.Stable and longlasting

6. Revolution time proportional to refractory perlod and excitable gap 


\subsection{THE EXCITABLE GAP}

The presence of an excitable gap during anisotropic reentry is the most important difference compared to leading circle reentrant excitation (Allessie et al., 1977). The existence of an excitable gap of $10-40 \mathrm{~ms}$ in a functionally determined circuit, might be explained by three possible mechanisms (figure 5.1 ).

Microanatomical barriers at the pivoting points.

Although no gross anatomical barriers are involved, the presence of microanatomlcal obstacles at the pivoting points of the circuit may enlarge the central, functionally determined line of block of the circuit. It will also stabilize the position of the reentrant loop at a fixed location in the myocardium. Small conduction barriers may exist when, due to the interposition of collageneous septa, adjacant myocardial fibers become separated (Sommer and Dolber, 1979, Sommer, 1983). Such microanatomlcal barriers at the pivoting points of the circuit lengthen the functional conduction block, thus creating an excitable gap during tachycardia. The dimensions of such a reentrant circult are determined by the distance between these barrlers.

Block at the pivoting points because of increased electrotonic current load.

Spatial differences of the stimulating efficacy of the impulse, due to the effects of tissue anlsotropy, may contribute to the creation of an excitable gap. The stimulating efflcacy of a propagating action potential is influenced by sudden changes in the axial current load (Spach et al., 1981, 1982a, 1986, 1987). Such a sudden increase of the current load occurs during branching of myocardlal fibers or when an abrupt change In the direction of impulse propagation occurs. A depression of the stimulating efficacy

Egure 5.1. Three possible mechanisms contrlbuting to the creation of an excitable gap are schematically summarized.

1: Microanatomical barriers at the piwoting points may lengthen the line of functional conduction black.

2: A sudden depression of the stimulating efficacy of the impulse at the pivoting points due to a sucdien increase of the axial current.

3: Action potential prolongation at the pivoting points prevents the impulse from short circulting the circuit. 


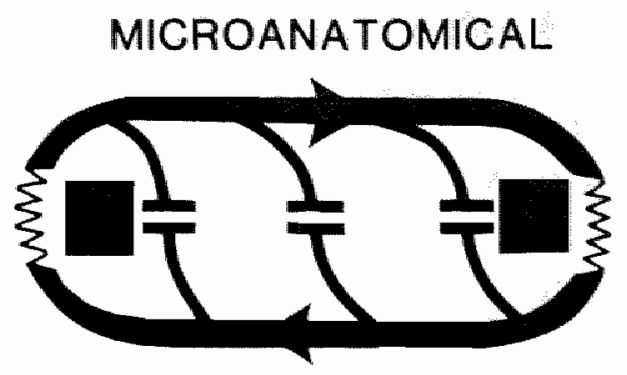

DOWNLOAD PHENOMENON

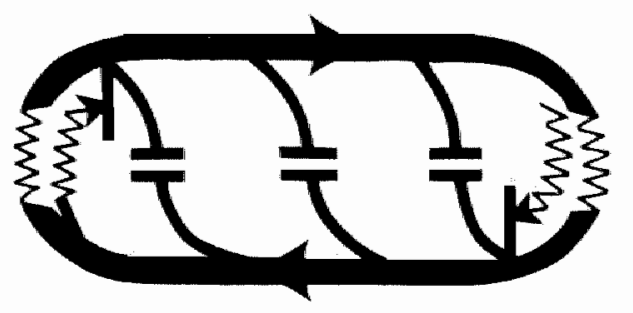

ACTION POTENTIAL PROLONGATION

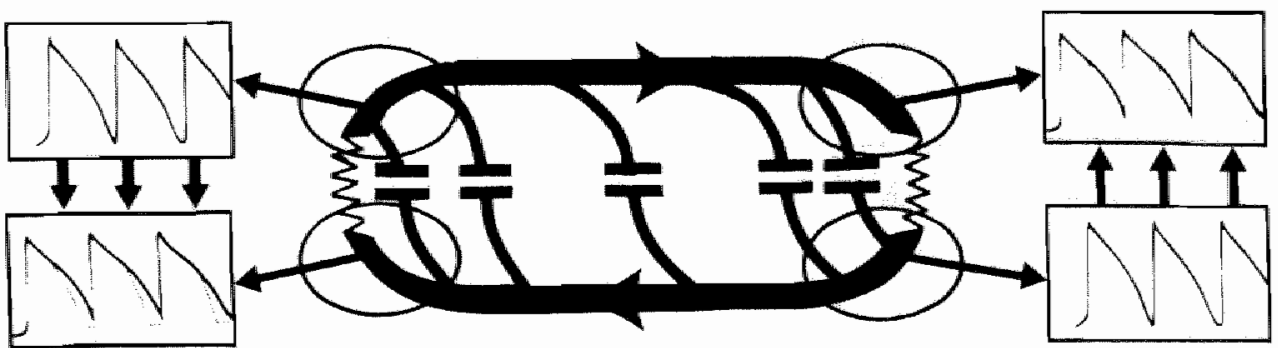


may lead to decremental conduction or conductlon block despite the fact that the cells are excitable.

At the pivoting points of anisotropic reentry, the slowly conducting transverse wavefront encounters a sudden Increase of axlal current load when the returning longitudinal limb has to be activated. It is possible that at the transition from transverse to longitudinal conduction the sudden increase of electrotonic load leads to temporary conduction block. The returning longlitudinal limb of the clrcult will not be activated until a larger part of the wavefront has rotated around the pivoting point. This temporal halt of the Impulse at the pivoting points may create an excitable gap because it results in a functional lengthening of the central line of conduction block and consequently in a prolongation of the cycle length of the tachycardia.

\section{Electrotonic.prolongation of actlon potential duration at the plvoting points.}

Spatial differences of the action potential duration might also contribute to the creation of an excitable gap. It is known that during regular pacing the action potential duration near the stimulation site is prolonged by electrotonic Interaction with more remote cells which are actlvated later in time (Hoffman and Cranefield, 1960, Osaka et al., 1987).

Recently Osaka et al. (1987) demonstrated that the amount of prolongation of the action potential duration depends on the conduction time between the cells and the axlal resistance. During centrifugal impulse spread In anisotropic myocardium the proIongation of the action potentlall duration was most marked. The prolongation of the actlon potential duration lengthened the local refractory period.

During anisotroplc reentry considerable differences in activation time are present around the plvoting points. Because electrical coupling is intact, these differences in activation time over only a few millimeters may result in action potential prolongation of the cells proximal to the pivoting point and consequently in a lengthening of the local refractory perlod. This selective prolongation of refractoriness at the pivoting points will delay the moment the impulse can turn around, thus lengthening the central IIne of conduction block. Because of local prolongation of refractoriness, at the pivoting points there is a tlght fit between the crest of the depolarization wave and its tail of refractoriness. However in all other parts of the heart an excitable gap will exist durIng anisotroplc tachycardia. 


\subsection{CELLULAR CHARACTERISTICS OF ANISOTROPIC REENTRY.}

Preliminary results of a study of the cellular characteristics of anisotropic reentry show clear electrotonic interaction across the central line of conduction block and at the pivoting points. Standard microelectrode techniques were used and in figures 5.25.4 action potentials recorded from different parts of the circuit are given. During sustained ventricular tachycardia a regular 1 to 1 activation response and normal action potentials were recorded from different sites outside the line of conduction block. An alternans in action potential duration and in action potential amplitude was frequently observed. In the central area of the circuit variable degrees of conduction block were recorded. In figure 5.3 an example of 2 to 1 conduction block is given. As can be seen the action potential duration In the center of block was clearly prolonged by a electrotonic interaction between the two longitudinall limbs of the circuit. Not only 2 to 1 block but also local 3 to 2 conduction block was sometimes observed. The possible mechanism of 3 to 2 conduction block is explained in figure 5.4. Due to a slight prolongation of the action potential duration, the cells were activated every other cycle by one of the opposing longitudinal wavefronts. The strong electrotonic interactlon found between the adjacent limbs of the circuit may also prolong the action potential duration at the pivoting points and contribute to the creation of an excitable gap during functional reentry in anisotropic myocardium.

\subsection{COMPUTER SIMULATION OF ANISOTROPIC REENTRY.}

Computer simulation studies may contribute to the elucidation of the role of tissue anisotropy in determining the characteristics of functional reentrant excitatlon and the creation of an excitable gap. Recently Lammers et al. (1987) demonstrated, that when In a simple computer simulation modell, consisting of 900 cells, arranged in a regular matrix of $30 \times 30$ elements, the properties of the sheet were changed from isotropic to anisotropic, during clrcus movement excitation, an excitable gap appeared. However In this model, the actual transmembrane currents could not be calculated. Therefore a more suitable model was used to simulate the effects of tissue anisotropy on conduction and action potential configuratlons. Thls model, based on actual transmembrane currents, was developed by Dr F.J.L. Van Capelle, department of experimental 


\section{NORMAL}
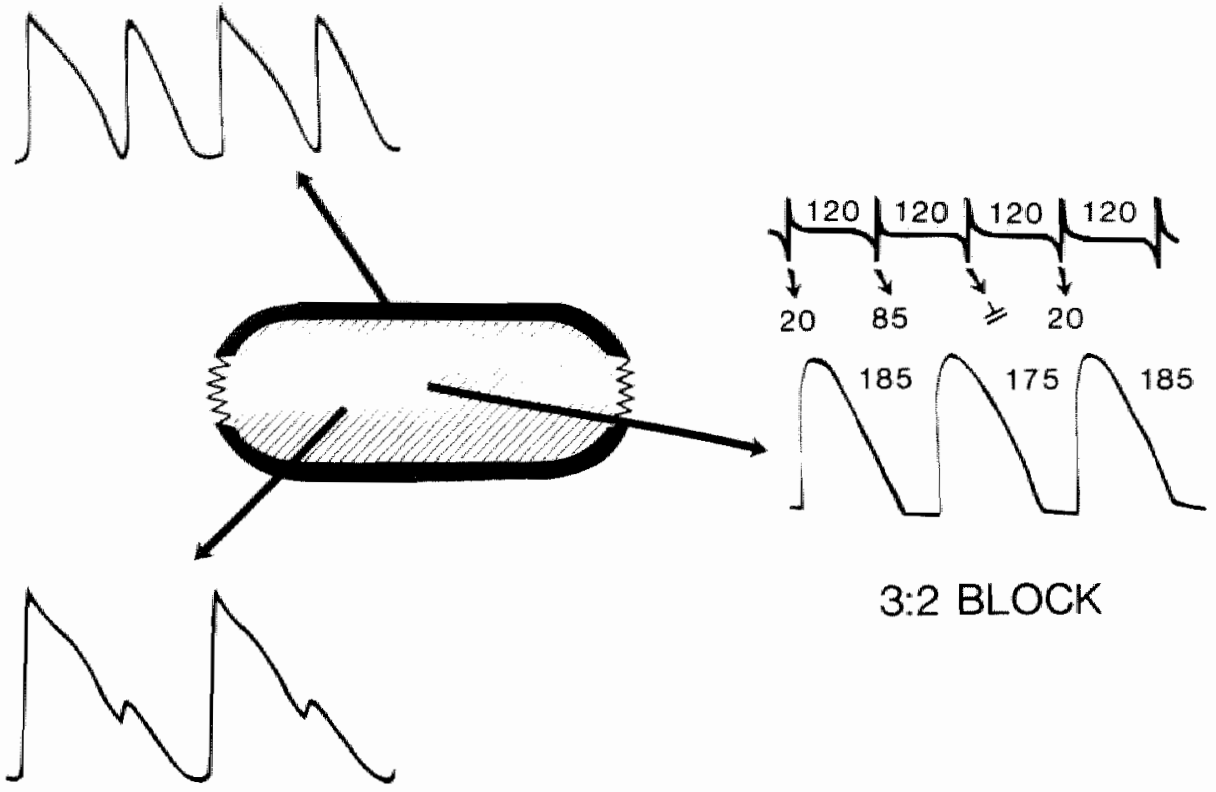

\section{2:1 BLOCK}

Eloure 5.2. Cellular characterlstics of anlsotropic reentry. Actlon potentials recorded from different parts of the ciroult area are shown. Normal action potentials were recorded from different sides around the clrcult. Actlon potentlals recorded from the central clrcult area reflected varlable degrees of functional conduction black. 


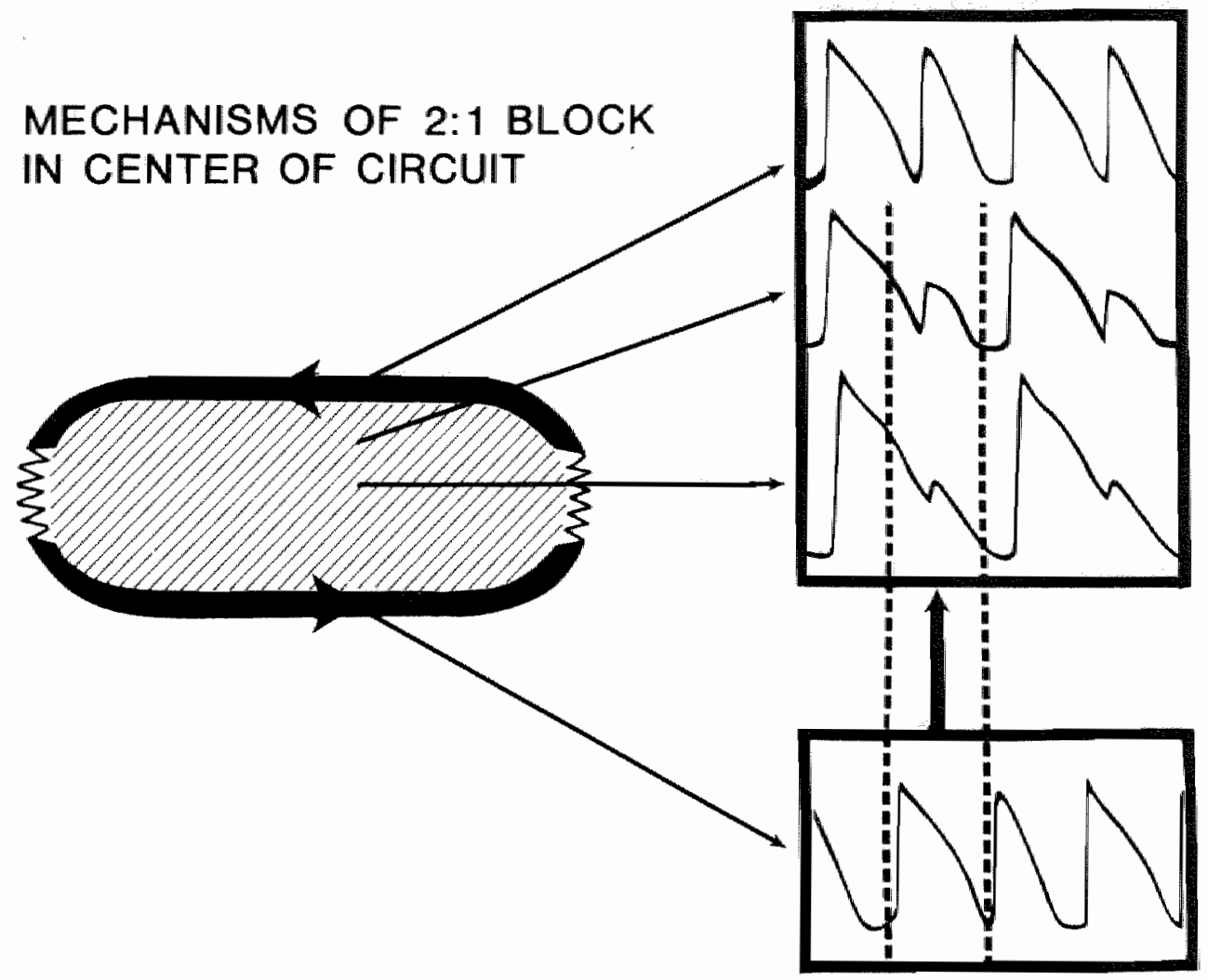

Elgure 5.3. In the center of the clrculit due to electrotonlic Interaction between the longltudinal limbs of the circult the plateau phase of the action potentials was prolonged. This electrotonio prolongation of the action potentials caused conduction block in the center of the circuit. As a result in the center 2 to 1 conduction block was found, and the same mechanism may cause action potentlal prolongation at the pivoting points of the circuit, thereby creating an excitable gap (see text for further explanation). 


\section{3:2 BLOCK IN CENTER OF CIRCUIT}
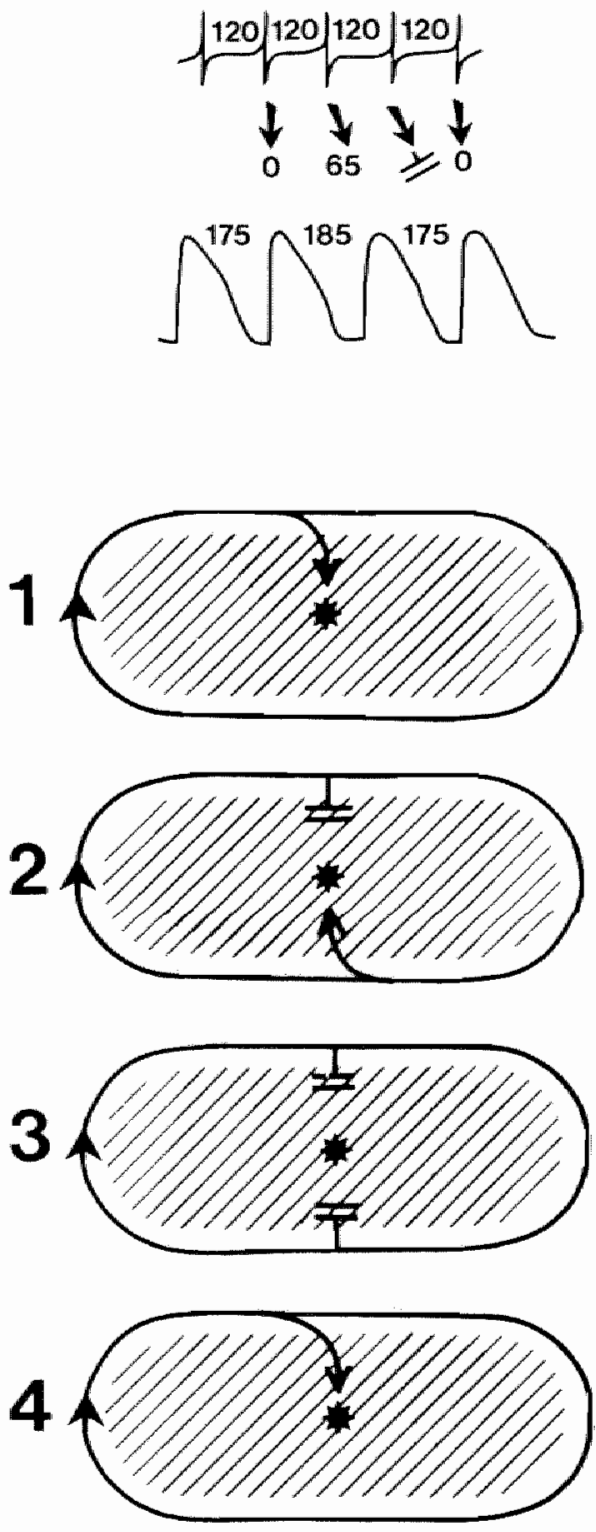
cardiology, University of Amsterdam. The simulation study was performed in co-operation with Dr Van Capelle.

Before presenting the results of this study, first a short summary of the essential characteristics of the computer simulation as described by Dr van Capelle (Van Capelle and Durrer, 1980) model will be given.

"The model consists of up to 650 excitable elements, arranged in a geometry which is to be specified at the start and which may be changed during execution of the simulation. As an example, a square lattice geometry is illustrated in figure 5.5. The elements are coupled through passive resistances, which may be set individually to arbitrary values (although no more than five different values are accepted by the program). The elements need not be all identical. Elements may be deleted or changed at any time during simulation, and coupling resistances may be deleted, changed, or added between any two elements. The network of resistors overlying the elements in figure 5.5 may be thought of as representing the Intracellular space. The lower side of the ellements is connected to the extracellular space, which is assumed to be zero potential at all times.

From the instantaneous transmembrane potentlals of the elements and from the values of coupling resistances, the currents through the intracellular maze are known. Thus the currents emerging from the elements at the nodes of the network can be calculated. Subtraction of the lonic currents flowing through the same elements at that point in time then yields the capacitive current flowing through that particular element. In this way the rate of rise of the action potentials of the elements can be calculated, and integration of this quantity ylelds the time course of the transmembrane voltage of all elements.

Before starting a simulation, it is necessary to define the types of elements to be used. In our simulation, this was done by specification of two membrane voltage-current relations, a steady state inactivation function, and a few parameters. An adequate choice of these quantities could result in elements possessing the desired electrophysiological characteristics. A separate interactive program which displays the relevant functions and parameters, together with the resultant action potentlals and voltage

Figure 5.4. Sometimes 3 to 2 conduction block may be present in the center of the circuit. Due to a prolongation of the action potent alls, the cells in the center could only be activated after one and an half cycle length. The mechanism of 3 to 2 conduction block is shown (see text for further explanation). 


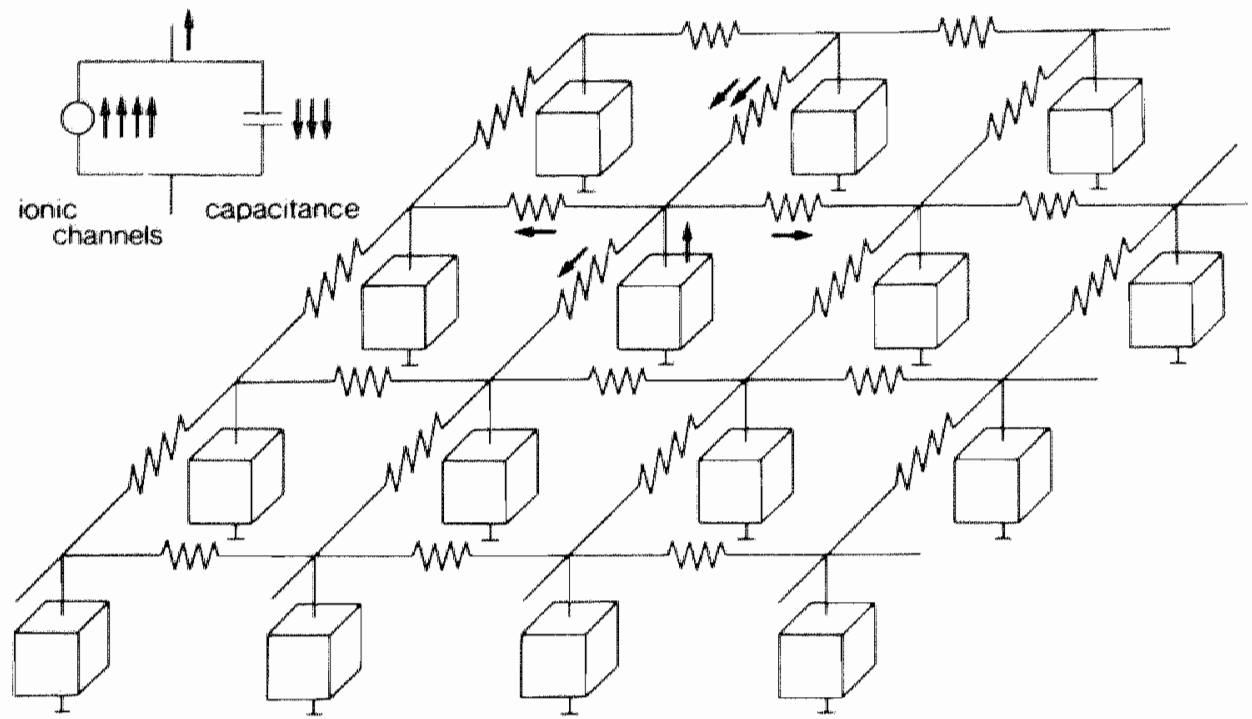

Elaure 5.5. Example of arrangement of excitable elements. The bottom side of the individual elements (extracellular space) is always at zero potentlal. The top side is connected by a resistive network, which repiesents the intracellular space. The current emerging from an element consists of an ionic and a capacitive component (inset). This current matches the sum of the currents flowing to the element through the intracellular space.

clamp currents, facilitates adjustments of the properties of the ellements. In this way, a library of excitable elements was created from which a selection could be made when a simulation was performed.

Next the arrangements of the elements must be specified. After specification of the dimensions of the sheet, the graphic terminal will initially display in a square lattice containing the elements. Now, polinting at the elements with a Joystick, individual cells may be deleted, leaving a "hole" in the sheet. In the same way, existing cell connections may be deleted, and new ones installed, resulting in a network of arbitrary complexity. Using the same technique, the cell type of individual elements and the resistance of individual cell connections may be changed. Since it is confusing to display more than 10 traces simultaneously on the terminal, a selection of elements to be 
monitored on the terminal is made. This is equivalent to the procedure of positioning of the recording electrodes in an actual experiment. In the same way, the stimulating sites are selected with the joystick.

After specification of the stimulus sequence, the simulation can be started. While the simulation progresses, the action potentials of the selected elements are displayed on the graphic terminal and stored on a disk. Whenever an element is activated, the activation time also is written on a separate disk file, yilelding a complete survey of the activation sequence." A more detailed description of the current voltage relationships used in this model can be found in the paper of Van Capelle and Durrer (1980).

\section{Results.}

To simulate the effects of tissue anisotropy In a sheet of 400 (40x10) excitable elements, the resistance between the elements was changed in such a manner that a longitudinal and transverse axis were created with a ratio of 4 to 1 between the transverse and longitudinal resistance. The active properties of all 400 excltable elements were identical. In the center of this sheet of excitable elements a long line of "anatomical" conduction block parallel to the longitudinal axis ("transverse" conduction block) was created by deleting the transverse connections between 40 opposite elements. Reentry was initiated by the application of a single stimulus near the upper left edge of the line of conduction block. The line of block was temporarily extended to the left border of the sheet resulting in unidirectional conduction block. As a result of this, the impulse propagated in a clockwise fashlon around the long line of conduction block in the center of the sheet. Just before the "returning" wavefront reached the left plvoting point of the line of block, the extended line of conduction block was removed by connecting the cells again, and as a result of this, the elements distal to the temporarlly line of conduction block were reactivated. The impulse continued to circulate around the "anatomical" line of block and stable sustalned tachycardla was Initlated. The Impulse propagated rapidly along the longltudinal axis of the clrcult, whereas at the plvoting points, conduction velocity slowed down because of transverse propagation. The simulated action potentlals recorded from different sites in the simulated anatomlcal circuit are given in figure 5.6. Normal action potential configurations were recorded during longitudinal impulse conduction. Because the length of the clircular pathway exceeded the wavelength an excitable gap was present, and the excitability of the cells 

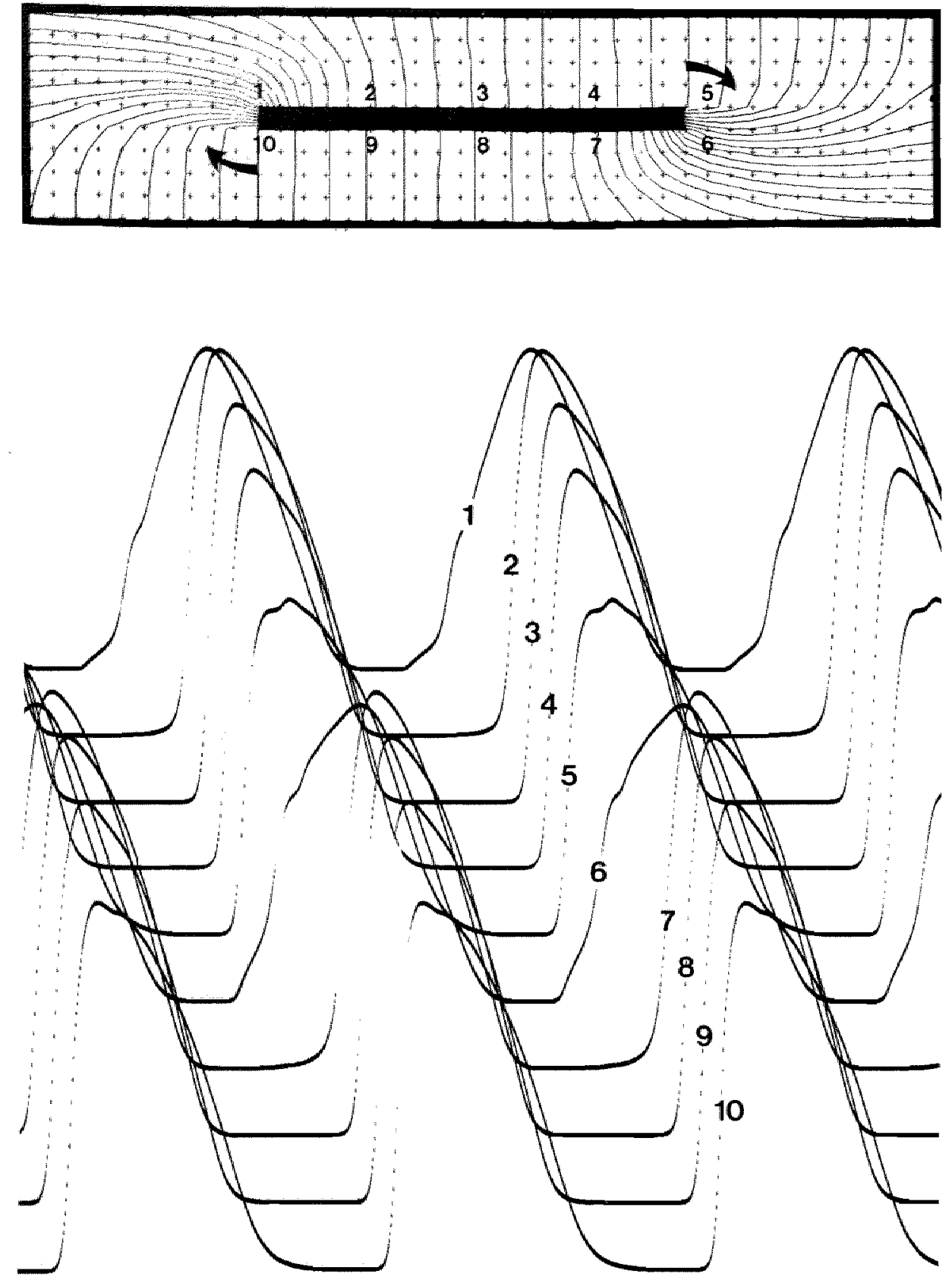
was restored before the next impulse arrived. At both pivoting points a notch was found in the upstroke of the action potentials and the upstroke velocity of the action potentials was depressed. These effects can be explained by the sudden increase of the axial current load occurring when the impulse turned circulated the pivoting points. To simulate functional reentrant excitation, the anatomical line of block was shortened at one side (right), by connecting 10 opposite cells again when the impulse rotated around the other plvoting point. In the resulting circuit one plvoting point was anatomically defined, while the right turning point was completely determined by the functional properties of the excitable elements. Figure 5.7 gives the Isochronic map recorded during the resulting stable tachycardia. Compared to the fully anatomically defined circuit (fig 5.6) the length of the line of block was decreased significantly and the cycle length of the tachycardia shortened. As can be seen the action potentials recorded from the anatomical part of the circult (elements 1,2 ) were not changed compared to those recorded during anatomical reentry. However a more complex action potential configuration was recorded from the functionall pivoting point (element 8). Because the electrical coupling between the cells was restored, the Impulse was able to conduct through the line of block and as a result, the length of the line of block was markedly shortened. However no full blown action potentlals were recorded from that site and conduction block still occurred. The occurrence of conduction block at the functional pivoting point can be explained by the sudden increase of the current load due to the transition from transverse to longitudinal conductlon. Such functional lengthening of an anatomical line of conduction block contributes to the creation of an excitable gap in the resulting circus movement. Due to the long duration of the action potential distal to the pivoting point (element 8) the action potentlal duration proximal to the pivoting point was prolonged (element 3 ). This prolongation may also contribute to the creation of the excitable gap in a functlonal reentrant circuit in anisotropic myocardium.

Figure 5.6. Computer simulation of anatomical reentry in a two-dimensional sheet of anisotropio "tissue". The impulse propagated rapidly along the longitudinal axis of the clrcuit, whereas at the plvoting points, conduction velocity slowed down. The numbers given in the activation map correspond to the "recorded" action potentials. At both plvotling points (elements 1 and 6) a notch was found in the upstroke of the action potentials and the upstroke velocity of the action potentials was slowed down. This is caused by a sudden increase of the axial current load when at the plvoting points the impulse suddienly changes: from transwerse to longitudinal conduction. 

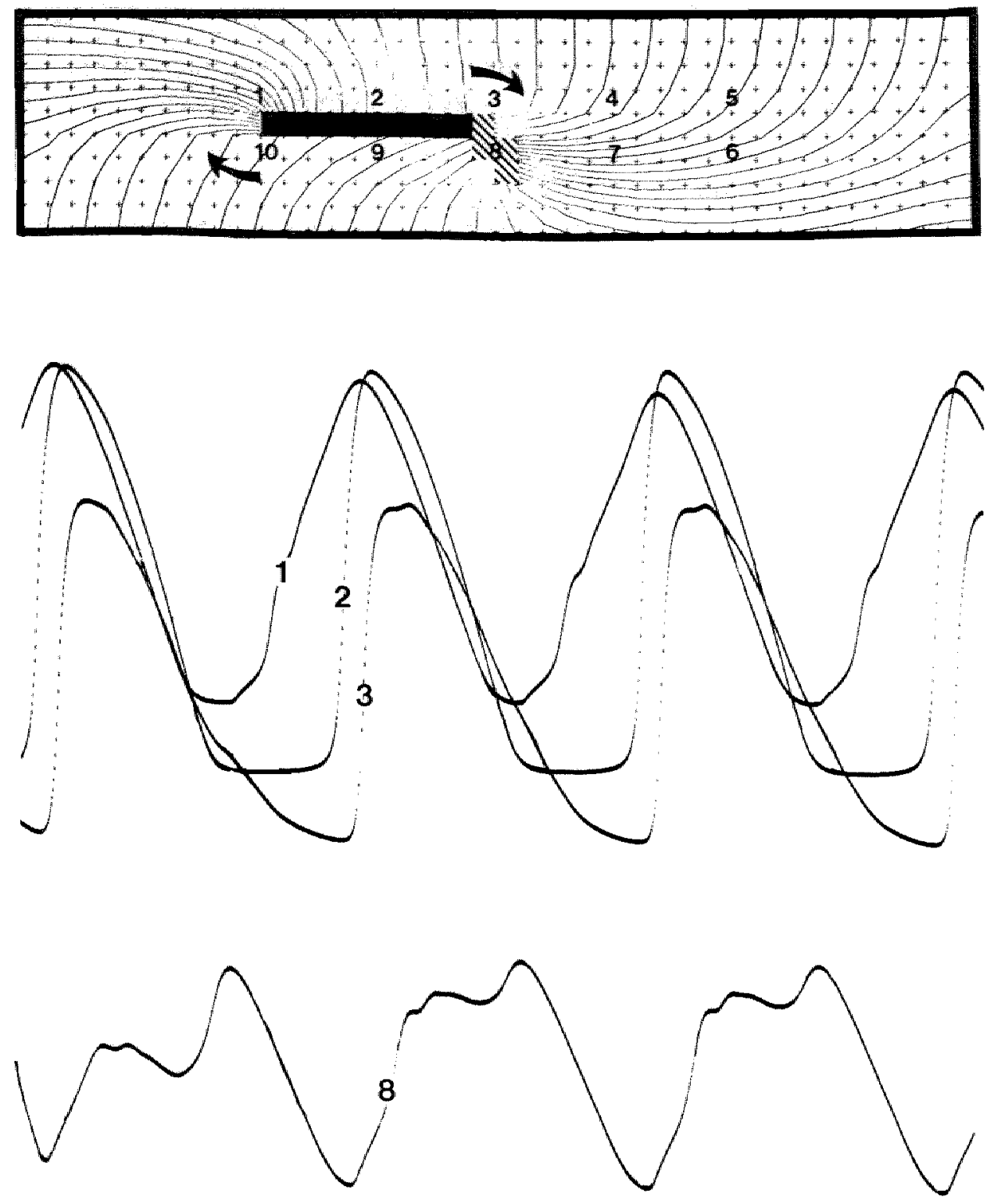
The results of both experimental microelectrode studies and computer simulation studies emphasize the importance of passive electrotonic interaction at the pivoting points of a reentrant clrcult. The results of the computer simulatlon studles also demonstrated, that electrotonic action potential prolongation at the pivoting points, during circus movement arrhythmias may create an excitable gap.

\subsection{ANISOTROPIC REENTRY AS A MECHANISM OF SUSTAINED VENTRICULAR TACHYCARDIA IN THE POST MYOCARDIAL INFARCTION PERIOD.}

Sustained ventricular tachycardla is a frequent and life threatening event in patients recovering from myocardlal infarction. Ventricular tachycardla may be caused by reentry, abnormal automaticity, or triggered activity. Both clinical and experimental studies indicate that the majority of the tachycardias is based on a reentrant mechanism (Wellens et al., 1976, Wellens and Josephson, 1984, Almendral et al., 1986).

Leading circle reentrant excitation is not a likely mechanism of sustained ventricular tachycardia in the postmyocardlal infarction period. Sustained ventricular tachycardia is stable and longlasting due to the presence of an excitable gap (Josephson and Wellens, 1984), whereas during leading circle reentry no excitable gap is present. (Allessie et al, 1984). During the acute phase of a myocardial Infarction however, increased inhomogeneity in conduction and refractoriness may cause reentrant arrhythmilas based on leading circle reentry. Anatomlcally determined reentrant excitation Involving either scar tissue or myocardlal fibers or Purklnje tlssue separated by collageneous septa may cause sustained ventricular tachycardlas.

In recent years it has been demonstrated by a number of Investigators that in canine hearts three to four days after myocardlal infarction thin surviving eplcardial layers are present. (Wit et al., 1982, 1987, Dillon et al., 1988, El-Sherif et al., 1977a, 1977b, 1981, 1985, Mehra et al.,1983, Gough et al., 1985, Spear et al., 1983a, 1983b)

Eigure 5.7. Computer simulation of anisotropic reentry. In this situation one pivating point (lleft) was anatomically defined, while the other (right) was determined by the functional properties of the excitable elements. Compared to the anatomically defined circuit (fig 5.5) the length of the line of block had decreased significantly and the cycle length was shortened. Although the excitability of the cells (nr 8) was restored, decremental conduction and conduction block occurred. 
These layers, interdigitating with destroyed myocardial fibers and collageneous tissue may play an important role in the pathogenesis of sustained ventricular tachycardias. The resting membrane potential of these surviving cells are shifted to less negative values and the refractory periods may be prolonged, causing unidirectional conduction block and reentry, or may give rise to dlastollic depolarization or delayed after depolarizations. (Spear et al., 1983a, 1983b, Wit et al., 1987, Dillon et al., 1988). Spear et al. (1983a, 1983b) demonstrated that within the infarcted region, local continuous activity can be recorded, which can be related to the occurrence of ventricular tachycardia. Local continuous activity caused by slow nonuniform conduction may reflect areas of enhanced tissue anisotropy (Spear et al., 1983a, 1983b, Wit et al., 1987). DilIon et al. (1988) demonstrated that sustained ventricular tachycardias, initlated 3-4 days after myocardial infarction in canine hearts were caused by reentrant excitation within these thin surviving epicardial layers. Although sometimes the central area of conduction block was caused by an anatomical obstacle, in other cases the apparant line of conduction block was determined by the functional properties of the tissue. (figure 5.8A). Although the activation maps showed lines of block orientated parallel to the fiber direction, detailed analysis of the recorded electrograms revealed the presence of slow transverse conduction across the line of conduction block and only a small vortex of circulatingc excitatiiornc was present (figure 5.8B). During anisotropic reentry, initlated in our twodimensional model of anisotropy, the line of conduction block was also orientated parallel to the eplcardlal flber direction (chapter 4). However except for a few cases no evidence for slow transverse conduction perpendicular to the line of conduction block was found. This difference is explained by the fact that in healthy myocardium transverse conduction is 3 times faster $(20 \mathrm{~cm} / \mathrm{s})$ than in the infarcted eplcardlum (less than $7 \mathrm{~cm} / \mathrm{s}$ ). (Spach et al., 1981, 1986) Further evidence that infarct structure plays an important role in the initiation of sustained ventricular tachycardias was provided by the studies of Kramer et al. (1985) and Pogwizd and Corr

Elqure 5.8. Characteristics of electrograms recorded along the line of apperent black. At the top, isochrones from the activation map are shown. The letters indicate recording sites of ellectrograms shown in panels $\mathrm{A}, \mathrm{B}$ and $\mathrm{C}$. Below each letter is a number indicating the designated activation time at that site. Panel A shows electrograms recorded at sites $A$ to $I_{s}$ along the line of the block. The arrows indicate the point on the electrogram taken at the moment of activation plotted on the map (see text). Panels B and C show electrograms recorded on elther side of the line of block.

(From: Dillon et al., 1988, with permission.) 

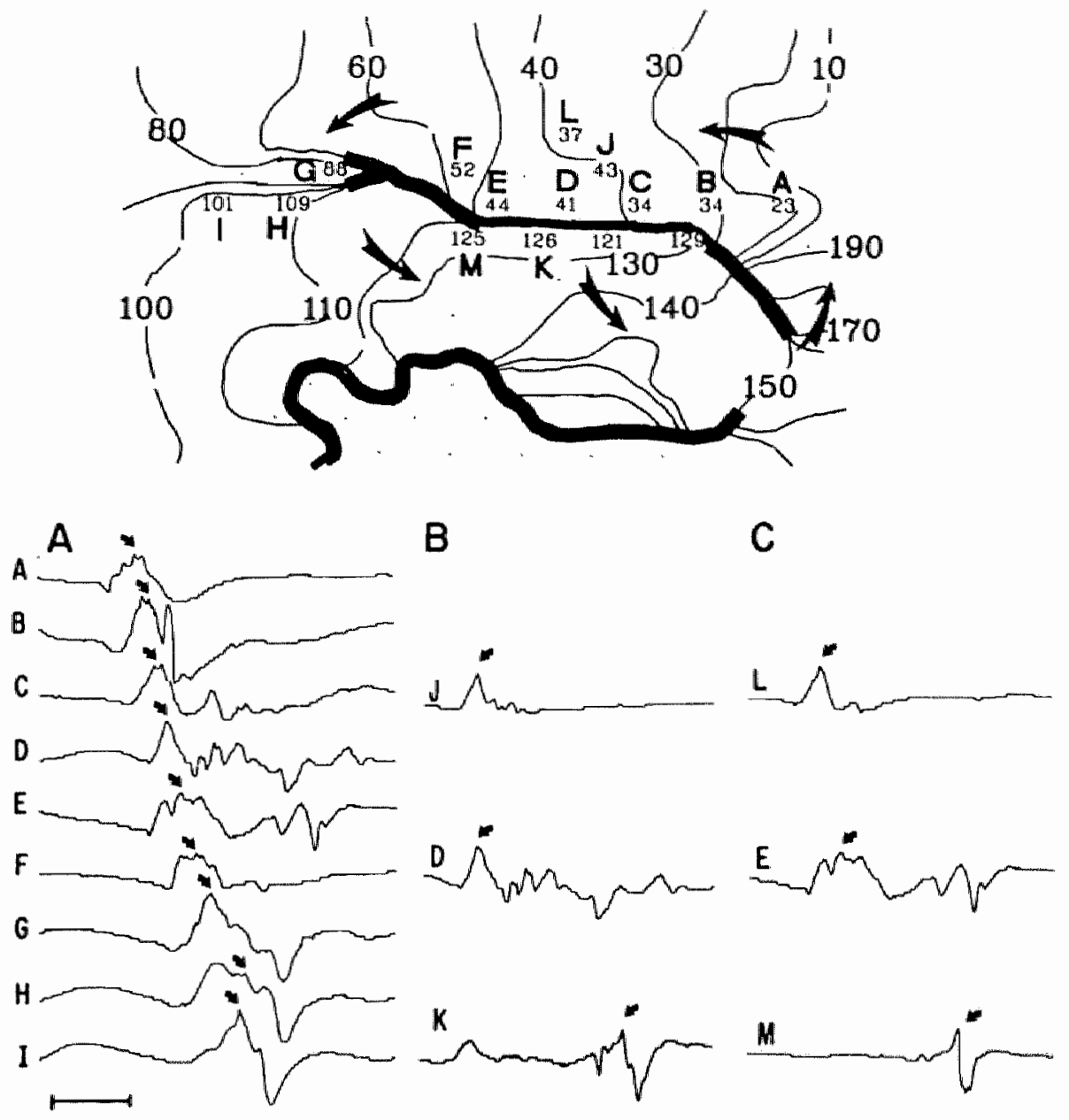
(1987) who demonstrated that small intramural reentrant circuits may cause sustained ventricular tachycardlas in the healing phase after myocardlal infarction.

The cycle length of the reentrant tachycardlas initiated in canine hearts, ranged from 140 to $240 \mathrm{~ms}$ (Dillon et al., 1988), which is somewhat longer than anisotroplc reentry in the twodlmenslonal model of anisotropy (105 to $160 \mathrm{~ms}$, mean $130 \pm 11 \mathrm{~ms}$ ). This may be explained by ischemic alterations of the cells depressing conduction velocity and lengthening refractory periods.,

In patlents with healed infarction and ventricular aneurysms endocavitary mapping studies often reveal extremely broad or fractionated electrograms. These fracthonated electrograms are similar to those recorded during ventricular tachycardla near the infarcted region in canine hearts (Josephson et al., 1978, Horowitz et al., 1980, Josephson and Wit, 1984). Although the time course of the anatomic and electrophysiological changes in clinical and experimental studies may be different the pathophyslological basis of arrhythmias is analogous (Fenoglio et all., 1983, Gardner et al., 1985). However In contrast with experimental results, the earliest activation during ventricular tachycardlas in patlents often originates in the subendocardium of the infarcted reglon instead of in the epicardlum during sustalned tachycardias in canine hearts.

The presence of continuous local actlvity, which reflect sites of altered myocardlal structure, however does not implicate that reentrant circuits are located within these reglons or that patients are of risk of ventricular tachycardla (Brugada et al., 1985). Direct demonstration that durlng sustalned tachycardla cooling, compression or resectlon of these reglons leads to the termination of the tachycardia is necessary to proove the presence of reentry within these areas (Josephson and Wit, 1984).

The occurrence of sustained ventrlcular tachycardlas diminishes in the course of the healing process. In a recent study however Brugada et al. (1985) demonstrated that in about $40 \%$ of the patients perlods of ventricular tachycardla could be initiated by programmed electrical stimulation, which indicated that the anatomical substrate for reentrant excitation was still present. The occurrence of "late" tachycardias is related to the presence of ventricular aneurysm and impaired ventricular performance (Jospehson and Wellens, 1984). Despite the fact that in these patlents the tachycardia is probably caused by either macro or micro anatomical reentrant circuits enhanced tissue anisotropy of surviving cell layers near the infarcted region, may play an Important role in the pathogenesis of these "late" sustained reentrant ventricular tachycardlas. 
Reentrant excitation can be terminated by locally blocking the conduction of the circulating impulse. The administration of Class I antiarrhythmic drugs may, by depressing the fast sodium inward current result in such a conduction block and termination of reentry.

From the results of Kadish et al. (1986) and the results presented in chapter two, it became clear that class I antiarrhythmic drugs diminish the degree of anisotropy by depressing the longitudinal conduction velocity to a greater extent than the transverse conduction velocity. Another theoretical way class I antlarrhythmic drugs may result in termination of reentrant arrhythmlas is preferentlal conduction block in a transverse directionn. Because transverse conduction in the infarcted region is extremely slow (3-5 cm/s) any further slowing of conduction induced by drug administration may lead to conduction block. Despite the high safety factor for conduction, due to a high Initial Vmax of the action potentials, conduction may be critical during these low velocities (Van Capelle, 1983, Rudy et al, 1987).

Apart from changes in active membrane properties also the passive membrane properties play a key role in conduction and conduction disturbances in the anisotropic myocardium. Although the structure of infarcted regions will be different and more complex, the model of anisotropy presented in this study may be useful to study the mechanisms of sustained ventricular tachycardia to evaluate the effects of antiarrhythmic drugs. 
$-118$. 


\section{LIST OF REFERENCES}

Alessi $R$, Nusynowitz $M$, Abildskov JA, Moe GK: Nonuniform distribution of vagal effects on the atrial refractory period. Am J Physiol 194:406-410, 1958.

Allessie MA, Bonke FIM, Schopman FJG: Circus movement in rabbit atrial muscle as a mechanism of tachycardia. Circ Res 32:54-62, 1973.

Allessie MA, Bonke FIM, Schopman FJG: Circus movement in rabbit atrlal muscle as a mechanism of tachycardia. II. The role of nonuniform recovery of excitabillty in the occurrence of unidirectlonal block,as studled with multiple microelectrodes. Clrc Res 39:168-177, 1976.

Allessle MA, Bonke FIM, Schopman FJG: Circus movement in rabbit atrlal muscle as a mechanism of tachycardia. III. The "leading clrcle" concept: A new model of circus movement in cardiac tissue without the involvement of an anatomic obstacle. Circ Res $41: 9-18,1977$.

Allessie MA, Lammers WJEP, Bonke FIM, Hollen J: Intra-atrial reentry as a mechanIsm for atrial flutter induced by acetylcholline and rapld pacing in the dog. Circulation $70: 123-135,1984$.

Allessle MA, Lammers WJEP, Bonke FIM, Hollen J: Experlmental evaluation of Moe's multiple wavelet hypothesis of atrial fibrillation. In: Cardiac Electrophysiology and Arrhythmias. Ed: Zipes DP and Jalife J, Grune \& Stratton, Orlando 1985.

Allessie MA, Schali] MJ, Wit AL, Lammers WJEP, August||n CH: Does anisotropy play a role in the creation of an excitable gap in reentrant ventricular tachycardia? In: NonPharmacological therapy of tachyarrythmlas. Ed: Breithardt G, Futura Publishing Company, New York, 1987.

Almendral JM, Stamato NJ, Rosenthal ME, Marchlinskl FE, Miller JM, Josephson ME. Resetting response during sustained ventricular tachycardla: relationship to the excitable gap. Circulation 74:722-720, 1986.

Anderson $\mathrm{GJ}_{\|}$Greenspan K, Bandura JP, Fisch C: Asynchrony of conduction within the canine specialized Purkinje fiber system. Circ Res 27:691-703, 1970. 
Antoni $H_{\text {}}$ Zerweck $T$ : Besitzen die sympatischen Ubertragerstoffe einen direkten Einflusz auf die Leitungsgeschwindighkeit des Saugetiermyokards? Elektrophysiologische Untersuchungen an isollerten Papillarmuskeln und Purkinjefaden des Rhesusaffen. Pflügers Arch 293:310-330, 1967.

Arnsdorf MF and Bigger JT: The effect of procaine amide on components of excitabllity In long mammallan cardiac purkinje fibers. Circ Res 38: 115-122, 1976

Arnsdorf MF and Wasserstrom JA: Mechanisms of antiarrythmic drugs: a matrical approach. In: The heart and cardlovascular system, edt H.A.Fozzard et al. Raven Press, New York, 1986.

Barr $\mathrm{L}$, Dewey $\mathrm{MM}$, Berger W: Propagation of action potentials and the structure of the nexus in cardiac muscle. J Gen Physiol 48:797-823, 1965.

Barr RC: Finding the site of origin and velocity of propagation in a short one-dimensional strand from two extracellular waveforms. IEEE trans biom eng. 31:546-550, 1984.

Beeler GW, Reuter $\mathrm{H}$ : Reconstruction of the actlon potential of ventricular myocardial fibres. J Physiol. 268: 177-210, 1977.

Boineau JP, Schuessler RB, Mooney CR, Miller CB, Wylds AC, Hudson RD, Borremans $\mathrm{JM}$, Brockus CW: Natural and evoked atrial flutter due to circus movement in dogs. Am J Cardiol 45:1167-1181,1980.

Bredikis J, Bukauskas F, Vetelkis R: Decreased intercellular coupling after prolonged rapid stimulation in rabbit atrial muscle. Circ Res 49:815-820, 1981.

Buchanan JW, Saito T, Gettes LS: The effects of antiarrhytmic drugs, stimulation frequency and potassium induced resting membrane potential changes on conduction velocity and dV/dtmax in quinea pig myocardium. Clrc Res 56: 696, 1985

Burdon-Sanderson J, Page FJM: On the time-relations of the excitatory process in the ventricle of the heart of the frog. J Physiol 2:384-435,1879.

Brugada $\mathrm{P}$, Abdollah $\mathrm{H}$, Wellens $\mathrm{HJJ}$. Continuous local activity during sustained monomorphic ventricular tachycardla. Am J Cardliol 55:402-411,1985.

Cardinal R, Savard P, Carson DL, Page P: Mappling of ventrlcular tachycardla induced by programmed stimulation in canlne preparations of myocardial infarction. Circulation 70:136-148, 1984. 
Clerc L: Directional differences of impulse spread in trabecular muscle from mammallan heart. d Physlol (London) 255:335-346,1976.

Cohen CJ and Strichartz GR: On the voltage dependent action of tetrodotoxin. Biophys J 17:275-279, 1977.

Cohen CJ, Fozzard HA, Sheu SS: Increase in intracellular sodium ion activity during stimulation in mammallan cardiac muscle. Circ Res 50:651-662, 1982.

Cohen CJ, Bean BP vien RW: Maximal upstroke velocity as an index of available sodium conductance. Comparison of maximal upstroke velocity and voltage clamp measurements of sodium current in rabbit Purkinje fibres. Circ Res 54:636-651, 1984.

Cranefleld PF: The conduction of the Cardlac impulse. The Slow Response and Cardiac Arrhythmias. Futura, Mount Kisko, New York, 1975.

Cranefield PF, Klein HO, Hoffman BF: Conduction of the cardiac impulse. I. Delay, block, and one-way block in depressed Purkinje fibers. Clrc Res 28:199-219,1971.

Cranefleld PF, Hoffman BF: Conduction of the cardlac impulse. II. Summation and inhibition. Circ Res 28:220-233,1971.

Daniel EE, Daniel VP, Duchon G, Garfleld RE, Nichols M, Malhotra SK, OkI M: Is the nexus necessary for cell to cell coupling of the smooth muscle. J Memb Biol 28:201239, 1976.

De Bakker JMT, Janse MJ, Van Capelle FJL, Durrer D: Endocardlal mapping by simultaneous recording of endocardial electrograms during cardlac surgery for ventricular aneurysm. J. Am. Coll Cardlol 2:947-953, 1983.

De la Fuente $\mathrm{D}$, Sasyniuk $\mathrm{BI}$, Moe GK: Conduction through a narrow isthmus in isolated canine atrial tissue. A model of the WPW syndrome. Circulation 44:803-809, 1971.

De Mello WC, Motta G, Chapeau M: A study of healing over of myocardial cells of toads. Circ Res 24:475-487, 1969.

De Mello WC: The healing process Incardlac and other muscle fibers. In: Electrical Phenomena in the Heart, edited by WC De Mello. New York, Academic Press, 323$351,1972$. 
De Mello WC: Influence of the sodium pump on intercellular communication in heart fibres: effect of intracellular injection of sodium lon on electrical coupling. J Physiol 263:171-197, 1976.

De Mello WC: Intercellular communications in cardiac muscle. Circ Res 55:1-9, 1982

Deleze $\mathrm{J}$ : Calcium lons and the healing over of heart fibers. In: Electrophysiology of the Heart, edited by B TaccardI, G Marchetti. London, Pergamon Press, 147-148, 1965

Delmar $\mathrm{M}$ Michaels $\mathrm{DC}$, Johnson $\mathrm{T}$, Jalife $\mathrm{J}$ : Effects of increasing intercellular resistance on transverse and longitud inal propagation in sheep epicardial muscle. Circ Res 60: $780-785,1987$.

Dewey and Barr: A study of structure and distribution of the nexus. J Cell Biol 23:553585,1964

Diaz PJ, Rudy Y, Plonsey R: Intercalated discs as a cause for discontinuous propagatlon In cardlac muscle: A theoretical simulation. Ann Blomed Eng 11:177-189, 1983.

Dillon S, Allessie MA, Ursell PC, Wit AL: Influences of anisotropic tissue structure on reentrant clrcuits in the eplcardlal border zone of subacute canine infarcts. Accepted for publication in Circ Res, 1988.

Dominguez G, Fozzard HA: Influence of extracellular $\mathrm{K}+$-concentration on cable propertles and excitabllity of sheep cardlac Purkinje fibers. Circ Res 26:565-574, 1970.

Dräper $\mathrm{MH}$, Mya-Tu M: A comparison of the conduction velocity in cardlac tissues of various mammals. Quart J Exptl Physiol 44:91-109,1959.

Durrer D, van der Tweel LH: Excitation of the left ventricular wall of the dog and goat. Ann of the NY Acad of Sclences 65:779-803, 1957.

Durrer D, Roos JP: Epicardial excltation of the ventricles in a patient with Woff-Parkinson-White syndrome (type B). Circulatlon 35:15-21,1967a.

Durrer $D$, Schoo L, Schuillenburg RM, Wellens HJJ: The role of premature beats in the Initiation and the termination of supraventricular tachycardia in the Wolff-ParkinsonWhite syndrome. Circulation 36:644-662,1967b.

Durrer D, van Dam RT, Freud GE, Janse MJ, Meijler FL, Arzbaecher RC: Total excitatlon of the isolated human heart. Clrculation 41:899-912, 1970. 
Durrer D, Wellens HJJ: The Wolff-Parkinson-White syndrome: anno 1973. Eur J Cardiol $1 / 4: 347-367,1974$.

Elnthoven W: Un nouveau galvanometre: Arch N Sc Ex Nat 6:625-633,1901.

El-Sherif N, Scherlag BJ, Scherlag R, Hope RR: Reentrant arrhythmilas in the late myocardial infarction period. I Conduction characteristics in the infarct zone. Circula tion 55: 686-701, 1977a.

El-Sherif N, Hope RR, Scherlag BJ, Lazzara R: Re-entrant ventricular arrhythmias in the late myocardial infarction period. II. Patterns of initiation and termination of reentry. Circulation 55:702-719, 1977b.

El-Sherif N, Smith A, Evans K: Canine ventricular arrhythmias in the late myocardial infarction period. 8. Epicardial mapping of reentrant circuits. Circ Res 49:255-265, 1981.

El-Sherif N, Gough WB, Zeiler RH, Hanman R: Reentrant ventricular arrhythmlas in the late myocardial infarction period. 12. Spontaneous versus induced reentry and intramural versus epicardial circuits. J Am Coll Cardiol 6: 124-132, 1985.

Engelmann ThW: Over de geleiding der irritatie in de spierzelfstandigheid van het hart. Kon Acad v Wetenschap, Amsterdam. Proces Verbaal 15:12, 1874.

Engelmann ThW: Ueber die leitung der Erregung im Herzmuskel. Pflüg Arch ges Physiol $11: 465-480,1875$.

Engelmann ThW: Vergleichende Untersuchungen zur Lehre von der Muskel-und Nervenelektricitat. Pluegers Arch 15: 116-148, 1877.

Fenoglio JJ. Pham TD, Harken AH, Horowitz LN, Josephson ME, Wit AL: Recurrent sustained ventricular tachycardla: structure and ultrastructure of subendocardial regions in which tachycardia originates. Circulation 68 3: 518-533, 1983.

Fisch $\mathrm{C}$, Felgenbaum $\mathrm{H}$, Bowers JA: The effect potassium on atrioventricular conduction of normal dogs. Am J Cardiol 487-492, 1963.

Fishbein MC, Meerbaum S, Rit J, Lando U, Kanmatsuse, Mercier JC, Corday E, Ganz W: Early phase acute myocardial infarctsize quantification: validation of the triphenyl tetrazolium chloride tissue enzyme stalning techniqu. Am Heart J 101: 593-600, 1981. 
Fozzard HA: Conduction of the action potential. In: handbook of physiology, section 2. vol 1, The Heart, pp 335-356, edited by RM Berne, N Sperilakis, SR Geiger. Bethesda, American Physiological Society, 1979.

Frame $\mathrm{LH}$, Page RL, Hoffman BF: Atrial reentry around an anatomic barrier with a partially refractory excitable gap. Circ Res 58:495-511,1986.

Garan H, Fallon JT, Rosenthal S, Ruskin JN: Endocardial, Intramural, and epicardial activation patterns during sustained monomorphic ventricular tachycardia in late canine myocardlal infarction. Circ Res 60: 879, 1987.

Gardner PI, Ursell PC, Fenoglio JJ, WIt AL: Electrophyslologic and anatomic basis for fractionated electrograms recorded from healed myocardial infarcts. Circulation 723 : 596-611, 1985.

Garrey WE: The nature of fibrillary contractlon of the heart. Its relation to tissue mass and form. Am J Physiol 33:397-414, 1914.

Garrey WE: Auricular fibrillation. Physiol.Rev. 4:215-250, 1924.

Gough WB, Mehra R, Restlvo $M$, Zeller $R \mathrm{H}$, El-Sherlf N: Reentrant ventricular arrhythmias in the late myocardial infarction period in the dog. 13. Correlation of activation and refractory maps. Circ Res 57:432-442, 1985.

Grumbach $L_{n}$ Howard $J$, Merill J: Factors related to the initiation of ventricular fibrillation in the isolated heart: Effect of calcium and potassium. Circ Res 2:452-459, 1954.

Han J, Moe GK: Nonuniform recovery of excitability in ventricular muscle. Circ Res $14: 44-60,1964$.

Han J, Millet D, Chlzzonittl B, Moe GK: Temporal dispersion of recovery of excitablity in atrilum and ventricle as a function of heart rate. Am Heart $\mathrm{J} 1: 481-487,1966 \mathrm{a}$.

Harvey W: Exertatlo anatomica de motu cordis et sanguinis in animalibus. Sumptibus Guillelmo Fitzerl, Francofurtl, 1628. Translation by KJ Franklin. Movement of heart and blood In animals. Oxford: Blackwell, Oxford, 1957.

Hayden WG, Hurley EJ, Rytand DA: The mechanism of canine atrlal flutter. Circ Res 10:496-505,1967.

Hodgkin AL and Rushton WAH: The electrical constants of a crustean nerve fibre. Proc R Soc London Ser B133:444-479, 1949. 
Hodgkin AL and Huxley AF: A quantative description of the membrane current and its apllication to conduction and excitation in nerve. J Physiol (London) 117: 500-544, 1952

Hodgkin AL: A note on conduction velocity. J Physiol (London) 125: 221-224, 1954.

Hoffman BF, Cranefield PF: Electrophysiology of the heart. McGraw-Hill, New York, 1960.

Hoffman BF, Rosen MR: Cellular mechanisms for cardlac arrhythmias. Circ Res 49:115,1981 .

Horowitz LN, Josephson ME, Farshidi A, Spielman SR, Mlchelson EL, Greenspan AM: Recurrent sustained ventricular tachycardia. 3. Role of the electrophyslologlc study in selection of antlarrhythmic regimens. Circulation 58:986-997, 1978.

Jack JJB, Noble D, Tslen RW: Electrcl current flow in excitable cells. Clarendon Press, Oxford, 1975.

Janse MJ: Reentry rhythms. In: The Heart and Cardiovascular System. Scientific Foundations. Ed: HA Fozzard, E Haber, RB Jennings, AM Katz, HE Morgan. Raven Press, New York, 1986.

Janse MJ, Downar E: The effect of acute ischemla on transmembrane potentlals in the intact heart. The relation to re-entrant arrhythmias. In: Reentrant Arrhythmias, Ed: Kulbertus HE, MTP Press, Lancaster, 1977.

Janse MJ, van Capelle FJL, Morsink H, Kleber AG, Wilms-Schopman E, Cardinal R, Naumann d'Alvoncout $C_{\text {, }}$ Durrer $D$ : Flow of "Injury current" and patterns of excitation during early ventricular arrhythmlas in acute reglonal myocardial Ischemla in Isolated porcine and canlne hearts: evldence for 2 dlfferent arrhythmogenic mechanlsms. Clrc Res 47:151-165, 1980.

January $\mathrm{CT}$, Fozzard HA: The effects of membrane potentlal, extracellular potasslum, and tetrodotoxin on the intracellular sodium lon activity of sheep cardiac muscle. Circ Res 54:652-665, 1984.

Jewett PH, Sommer JR, Johnson EA: Cardiac muscle. Its ultrastructure in the finch and humming bird with special reference to the sarcoplasmic retlculum. J Cell Biol 49:50-65, 1971. 
Johnson EA and Sommer JR: A strand of cardiac muscle. Its ultrastructure and the electrophyslological implicatlons of its geometry. J of Cell Biol 33: 103-129, 1967.

Josephson ME, Caracta AR, Lau SH, Gallagher JJ, Damato AN: Effects of lidocaine on refractory perlods in man. Am Heart J 84:778-786, 1972.

Josephson ME, Horowitz LN, Farshidi A: Continuous local electrical activity. A mechanism of recurrent ventricular tachycardla. Circulation 57:659-665,1978.

Josephson ME, Harken AH, Horowitz LN: Endocardial excision: a new surgical technique for the treatment of recurrent ventricular tachycardia. Circulation 60:1430$1439,1979$.

Josephson ME, Simson MB, Harken AH, Horowitz LN, Falcone RA: The incidence and clinical significance of eplcardial late potentials in patients with recurrent sustained ventricular tachycardla and coronary artery disease. Circulation 66:1199-1204,1982.

Josephson ME, Wit AL: Fractionated activity and continuous electrical activity: fact or artifact? Circulation 70:529-532,1984.

Josephson ME and Wellens HJJ: Tachycardias: Mechanisms, Diagnosis, Treatment. Phlladelphla, Lea \& Febinger, 1984.

Josephson ME: Treatment of ventricular arrhythmias after myocardial Infarction. Circulation 74:653-658, 1986.

Joyner RW: Effects of the discrete pattern of electrical coupling on propagation through an electrical syncytium. Circ Res 50: 192-200, 1982.

Joyner RW, Overholt ED, Ramza B, Veenstra RD: Propagation through electrically coupled cells: Two Inhomogeneously coupled cardiac tissue layers. Am J Physiol 247:596-609,1984.

Kadish AH, Spear JF, Levine JH, Moore EN: The effects of procainamide on conduction In ansitropic canine ventricular myocardlum. Cliculation 74: 616-625, 1986.

Kent AFS: Observations on the auriculo-ventricular junction of the mammalian heart. Q J Exp Physiol 7:193-195,1913.

Kimura E, Kato K, Murao $S$, Ajisaka $H$, Koyama S, Omiya Z: Experimental studies on the mechanlsm of the auricular flutter. Tohoku J Exp Med 60:197-207,1954. 
Kimura S, Bassett AL, Kohya T, Kozlovskis PL, Myerburg RJ: Simultaneous recordings of action potentials from endocardium and epicardium during ischemia in the isolated cat ventricle: relation of temporal electrophysiologic heterogeneities to arrhythmias. Circulation $74: 401-409,1986$.

Kishida H, Surawicz B, Fu LT: Effects of K and K-induced polarization on (dV/dT)max, threshold potentlal, and membrane input resistance In guinea pig and cat ventricular myocardium: Circ Res 44:800-814, 1979.

Kleber AG, Janse MJ, Wilms-Schopman FJG, Wilde de AAM, Coronel R. Changes in coduction velocity during acute ischemia in ventricular myocardium of the isolated porcine heart. Circ Res 73:189-198, 1986.

Kramer JB, Saffitz JE, Witkowski FX, Corr PB: Intramural reentry a a mechanism of ventricular tachycardia during evolving canine myocardial infarction. Circ Res 56: 736, 1985.

Kuo CS, Munakata K, Reddy P, Surawicz B: Characteristics and possible mechanism of ventrlcular arrhythmla dependent on the dlspersion of action potentlal durations. Circulation 67:1356-1367,1983.

Lammers WJEP, Wit AL, Allessie MA. Effects of anisotropy on functional reentrant circults: priliminary results of computer simulation studies. In: Activation, metabollsm and perfusion of the heart. Ed. by S. Sideman and R. Beyar. Martinus Nijhof Publishers, Dordrecht, 1987.

Lammers WJEP: Inhomogenelty in conduction and reentrant arrhythmlas. Thesis, university of Maastricht, 1987.

Lammers WJEP, Allessle MA, Schall] MJ, August||[n CH: Quant/fication of spatial Inhomogeneity in conduction and initlation of reentrant arrhythmias in the isolated rabbit atrium. (Submitted for publication in circulation research)

Lazzara R, Hope RR, El-Sherif N, Scherlag BJ: Effects of lidocaine on hypoxic and ischemic cardiac cells. Am J Card 41:872-879, 1978.

Lewis T, Rothschild MA: The excitatory process in the dog's heart. Part Il. The ventricles. Philos Trans A Soc London 206:181-226,1915.

Lewis T, Feill HS, Stroud WD: Observations upon flutter and fibrillation. Part II. The nature of auricular flutter. Heart VII:191-246,1920. 
Lewis T, Drury AN, Bulger HA: Observations upon flutter and fibrillation. Part VI. The refractory period and rate of propagation in the auricle: Their relation to block in the auricular walls and to flutter, etc. Heart 8,83-140,1921.

Lewis T: The mechanism and graphic registration of the heart beat. 3rd ed., Shaw and Sons, London 1925.

Lewis T: Mechanism and graphic registration of the heart beat. Chicago, IL:Chicago Medical , 83-98, 1924.

Lle KI, Wellens HJJ, Downar E, Durrer D: Observations on patients with primary ventricular fibrillation complicating acute myocardial infarction. Circulation 52: 755-759, 1975.

Loewenstein WR: Junctional intercellular communication: the cell to cell membrane channel. Physiol Rev 61:829-913, 1981.

Lown B, Verrler RL: Neural activity and ventricular fibrillation. N Eng J Med 294:1165, 1971.

MacWilliam JA: Fibrillar contraction of the heart. J Physiol 8:296-310,1887.

Mayer AG: Rhythmical pulsation in scyphomedusae. Carnegie Institution Pubication No. 47:1,1906.

Mayer AG: Rhythmical pulsation in scyphomedusae.-II. Papers from the Tortugas Laboratory of the Carnegie Institution of Washington. Publication no. 102:115,1908.

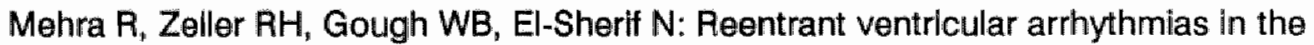
late myocardial infarction period. 9. Electrophysiologic anatomic correlation of reentrant circults. Circulation 67:11-24,1983.

Mendez C, Mueller WJ, Merldeth J, Moe GK: Interactlon of transmembrane potentials in canine Purkinje fibers and at Purkinje fiber-muscle junctions. Circ Res 24:361-372, 1969.

Mendez C, Mueller WJ, Urgulaga X: Propagation of impulses across the Purkinje fibermuscle junctions in the dog heart. Circ Res 26:135-150,1970.

Merx W, Yoon MS, Han JN: The role of disparity in conduction and recovery time on ventricular vulnerability to fibrillation. Am Heart $J \mathbf{J} 94: 603-610,1977$. 
Millar CK, Kralios FA, Lux RL: Correlation between refractory periods and activation recovery intervals from electrograms: effects of rate and adrenergic interventions. Circulation 72:1372-1379, 1985 .

Mines GR: On dynamic equilibrium in the heart. J Physiol 46:349-383,1913.

Mines GR: On circulating excitations in heart muscles and their possible relation to tachycardia and fibrillation. Trans R Soc of Canada, Section V:43-53,1914.

Moe G.K: On the multiple wavelet hypothesis of atrial fibrillation. Arch Int Pharmacodyn Ther 140:183-188, 1962 .

Moe GK, Rheinboldt WC, Abildskov JA: A computer model of atrial fibrillatlon. Am Heart J 67:200-220,1964.

Moss AJ, DeCamilla J, Davis $\mathrm{H}$ : Cardiac death in the first 6 months after myocardial infarction: Potentlal for mortality reduction in the early posthospltal period. Am J Cardlol 39: 816-820, 1977.

Moss AJ: Clinical significance of ventricular arrhythmis in patients with and without coronary artery. Prog Cardiovasc Dis 23:33-52, 1980.

Myerburg RJ, Nilsson K, Befeler B, Castellanos A, Gelband H: Transverse spread and longitudinal dissociation in the distal $A-V$ conducting system. J Clin Invest 52:885$895,1973$.

Nachlas MM and Shnitka TK: Macroscopical identificatlon of early myocardial infarcts by alteration in dehydrogenase activity. Am J Pathol 4: 379-405, 1963

Noble D: A modification of the Hodgkin-Huxley equations applicable to Purkinje fibre action and pace-maker potentials. J Physiol, 160:317-352, 1962.

Noble D: Applications of Hodgkin-Huxley equatlons to excitable tissues. Physlol Rev 46:1-50, 1966.

Noble D: The initiation of the heart beat. Oxford UK, Clarendon Press, 1975.

Osaka T, Kodama I, Tsubol $\mathrm{N}_{\text {, }}$ Toyama J, Yamada K: Effects of activation sequence and anisotropic geometry on the repolarization phase of action potential of dog ventricular muscles. Circulation 76: 226-236, 1987. 
Page P, Plumb V, Waldo AL: Total epicardlal mapping of atrial flutter in a new animal model (abstract). J Am Coll Cardiol 1:716A,1983.

Peracchia C: Low resistance junctions in crayfish. I. Two arrays of globules in junctional membranes. J Cell Blology 57:54-65, 1973.

Pogwizd SM, Corr PB: Reentrant and nonreentrant mechanisms contribute to arrhythmogenesis during early myocardlal ischemia: results using three dimensional mapping. Circ Res 61:352-371, 1987.

Rall W: distribution of potential in cylindrical coordinates and time constants for a membrane cylinder. Biophys J 9:1509-1541, 1969.

Rawling DA, Joyner RW, Overholt ED: Variations in the functional electrical coupling between the subendocardial purkinje and ventricular layers of the canine left ventricl. Circ Res 57: 252-261, 1985.

Rensma PL: Atrlal arrhythmlas and measurement of the wavelength in a chronlc dog model. Thesis. University of Limburg 1987.

Rensma PL, Allessle MA, Lammers WJEP, Bonke FIM, Schali] MJ: The lengh of the excitatlon wave as an index for the susceptibility to reentrant atrial arrhythmlas.Circ Res, 62:395, 1988

Richards DA, Blake GJ, Spear JF, Moore EN: Electrophysiologic substrate for ventricular tachycardia: correlation of properties in vivo and vitro. Circ Res 69:369-381, 1984.

Roberts DE, Hersh LT, Scher AM: Influence of cardlac fiber orientation on wavefront voltage, conduction velocity and tissue resistivity in the dog. Circ Res 44: 701-712, 1979

Rosenblueth A, Garcia Ramos J: Studles on flutter and fibrillaton. II. The Influence of artlficlal obstacles on experlmental auricular flutter. Am Heart J 33:677-684,1947.

Rudy Y and Quan WL: A model study of the effects of the discrete cellular structure on electrical propagation in cardlac tissue. Circ Res, 61:815-823, 1987.

Salto T, Otoguro $M_{n}$ Matsubara T: Electrophysiological studies on the mechanism of electrically induced sustained rhythmic activity in the rabbit right atrium. Circ Res 42:199-206, 1978. 
Sano T, Takayama N, Shimamoto T: Directional difference of conduction velocity in the cardiac ventricular syncytium studied by microelectrodes. Circ Res:262-267, 1959.

Schalij MJ, Allessie MA, Lammers WJEP, Rensma PL. The role of anisotropy in the reentrant mechanism of ventricular tachycardia.

Circulation $74: 11-482,1986$

Schalij MJ, Allessie MA, Lammers WJEP, van Kaam F. Reentry in anisotropic ventricular myocardium. Circulation 76:IV-113,1987

Schalij Mل, Allessie MA, Lammers WJEP, van Kaam F. Effects of frequency, lldocaine, potassium and epinephrine on ventricular anlsotropy. Clrculation 76:IV-431,1987

Schalij MJ, Lammers WJEP, Rensma PL, Allessie MA. Anlsotropic conduction and reentrant ventricular tachycardla in the epicardial layer of the left rabbit ventricle. submitted for publication :, 1988

Schall] MJ, Boersma LVA, Musch EJ, Lammers WJEP, Allessle MA. Anisotropic conduction and reentrant ventricular tachycardia. FASEB :,1988

Schmitt FO, Erlanger J: Directional differences in the conduction of the impulse through heart muscle and thelr possible relation to extrasystolic and fibrillary contractions. Am J Physiol 87:326-347,1928.

Schmitt FO and Schmitt $\mathrm{OH}$ : Partial excitation and variable conduction in the squid giant axon. J Physiol (London) 98:26-46, 1940.

Sheu SS, Blaustein MP: Sodium calcium exchange and regulation of cell calcium and contractility in cardiac muscle, with a note about vascular smooth muscle. In: The Heart and Cardiovascular System. Scientific Foundations. Ed: HA Fozzard, E Haber, RB Jennings, AM Katz, HE Morgan. Raven Press, New York, 1986.

Sheung WY: Calmodulin plays a pivotal rolle in cellular regulation. Science, 207, 19-27. 1980.

Sjöstrand FS, Andersson E: Electron microscopy of the Intercalated discs of cardiac muscle tissue. Experientia (Basel) 10:369-370,1954.

Smeets JLRM, Allessie MA, Lammers WJEP, Bonke FIM, Hollen J: The wavelength of the cardiac impulse and reentrant arrhythmias in isolated rabbit atrium. The role of heart rate, autonomic transmitters, temperature, and potassium. Circ Res 58:96-108, 1986. 
Sommer JR and Dolber PC: Ultrastructure of cardiac muscle. In: handbook of physiology, sectlon 2, voll, The Heart, pp 113-186,

edlted by RM Berne, N Sperilakis, SR Gelger. Bethesda, American Physiological Society, 1979.

Sommer JR: Implications of structure and geometry on cardiac electrical activity. Ann of Blomed Eng 11:149-157, 1983.

Spach MS, Barr RC, Serwer GA, Kootsey JM, Johnson EA: Extracellular potentlals related to intracellular action potentials in the dog Purkinje system. Circ Res 30:505-519, 1972.

Spach MS, Barr RC, Johnson EA: Cardlac extracellular potentials. Analysis of complex wave forms about the purkinje networks in dogs. Circ Res 33:465-473, 1973.

Spach MS, Barr RC: Ventricular intramural and epicardial potential distributions durIng ventrlcular actlvation and repolarization in the Intact dog. Circ Res 37:243-257, 1975.

Spach MS, Miller WT, Miller-Jones E, Warren RB, Barr RC: Extracellular potentials related to intracellular actlon potentials during impulse conduction in anisotropic canine cardlac muscle. Circ Res 45:188-204, 1979.

Spach MS, Miller WT Jr, Geselowitz DB, Barr RC, Kootsey JM, Johnson EA: The discontinuous nature of propagation in normal canine cardiac musicle. Evidence for recurrent discontinuitles of intracellular resistance that affect the membrane currents. Clic Res 48:39-54, 1981.

Spach MS, Miller WT, Dolber PC, Kootsey JM, Sommer JR, Mosher CE: The functlonal role of structural complexities in the propagation depolarization in the atrium of the dog. Cardlac conduction disturbances due to discontinuities of effective axial resistivIty. Clrc Res 50: 175-191, 1982a.

Spach MS, Kootsey JM and Sloan JD: Active modulation of electrical coupling between cardlac celss of the dog. A mechanism for transient and steady state variations in conduction velocity. Circ Res 51:347-362, $1982 \mathrm{~b}$.

Spach MS, Kootsey JM: The nature of electrical propagation in cardiac muscle. Am J Physiol 244:H3-H22, 1983. 
Spach MS: The discontinuous nature of electrical propagation in cardiac muscle. Consideration of a quantative model incorparating the membrane lonic properties and structural complexities. Ann Biom Eng 11:209-261, 1983.

Spach MS and Kootsey JM: Relating the sodium current and conductance to the shape of the tranmembrane and extracellular potentials by simulation: effects of propagation bounderaries. IEEE Blomed Eng 32:743-755, 1985.

Spach MS and Dolber P: Relating extracellular potentlals and their derivatives to anlsotropic propagation at a microscopic level in human cardlax muscle: evidence for electricla uncoupling of side to side fiber connections with increasing age. Circ Res 58:356-371, 1986.

Spach MS, Dolber PC, Heidlage JF, Kootsey JM, Johnson EA. Propagating depolarization in ansitropic human and canine cardiac muscle: apparant directional differences in membrane capacitance. A simplified model for selective directional effects of modifying the sodium conductance on Vmac, tfoot, and the propagation safety factor. Circ Res 60:206-219, 1987

Spear JF, Moore EN: Supernormal excitability and conduction in the His-Purkinje system of the dog. Circ Res 35:782-792,1974a.

Spear JF, Moore EN: The effets of changes in rate and rhythm on supernormal excitability in the isolated Purkinje system of the dog. A possible role in reentrant arrhythmias. Clrculation 50:1144-1149,1974b.

Spear JF, Michelson, Moore NE: Cellular electrophysiologic characteristics of chronically infarcted myocardlum in dogs suceptible to sustained ventrlcular tachyarrhythmias. J Am Coll Cardiol 1: 1099-1110, 1983a.

Spear JF, Michelson EL and Moore EN: Reduced space constants in slowly conduction regions of chronically infarcted canine myocardlum. Clrc Res 53: 176-185, 1983b.

Sperelakis $\mathrm{N}$ and MacDonald $\mathrm{R}$ : Ratio of transverse to longitudinal resistivities of isolated cardiac muscle fiber bundles. J Electrocardlol 7:301-314, 1974.

Streeter DD: Gross morphology and fiber geometry of the heart. In: Handbook of physiology, section 2, vol 1, chapter 4. edlted by RM Berne, N Sperilakls, SR Geiger. Bethesda, Amerlican Physlological Soclety, 1979. 
Tsuboi N, Kodlama I. Toyama J, Yamada K: Anisotropic conduction properties of canine ventricular muscles. Influence of high extracellular $\mathrm{K}^{+}$concentration and stimulation frequency. Jap Circ J. 49:487-498, 1985.

Van Capelle FJL, Janse MJ: Influence of geometry on the shape of the propagated action potential. In: The Conduction System of the Heart. Ed: Wellens HJJ, Lie KI, Janse MJ, Stenfert Kroese, Lelden, 1976.

Van Capelle FJL, Durrer D: Computer simulation of arrhythmias in in a network of of coupled excitable elements. Circ Res, 47:454-466, 1980.

Van Capelle FJL: Slow conduction and cardiac arrhythmias. Thesis, university of Amsterdam, 1983.

Vivaldi MT, Kloner RA, Schoen FJ: Triphenyltatrazolium staining of irreversible Ischemic injury following coronary artery occlusion in rats: Am J Pathol 121: 522-530, 1985

Waldo AL, Olshansky B, Okumura K, Henthorn RW: Current perspective on entrainment of tachycardias. In: Cardlac Arrhythmlas: Where to go from here. Edited by Brugada P, Wellens HJJ, Mount Kisco, NY, Futura Publishing Company, 1987.

Walton MK, Fozzard HA: Experimental study of the conducted action potentlal in cardiac purkinje strands. Blophys $\mathrm{J} 44: 1-8,1983 \mathrm{a}$.

Walton MK, Fozzard HA: The conducted action potentlal. Models and comparison to experiments. Blophys $\rfloor$ 44:9-26, $1983 \mathrm{~b}$.

Weldman S: The electrical constant of purkinje fibres. J. Physiol 118:348-360,1952.

Weldman S: The diffusion of radiopotasslum across intercalated discs of mammalian cardlac muscle. J Physiol (London) 187:323-342, 1966.

Weldman S: Electrical constants of trabecular muscle from mammalian heart. J Physiof (London) 210:1041-1054, 1970.

Wellens HJJ: Electrical stimulation of the heart in the study and treatment of tachycardlas. Stenfert Kroese, Leiden, 1971.

Wellens HJJ, Schullenburg RM, Durrer D: Electrical stimulation of the heart in patients with ventricular tachycardia. Circulation 46,216-226, 1972. 
Wellens HJJ, Lie KI, Durrer D: Further observations on ventricular tachycardia as studied by electrical stimulation of the heart. Chronlc recurrent ventricular tachycardla and ventricular tachycardia during acute myocardial infarction. Circulation 49:647653,1974 .

Wellens HJJ: Pathophysiology of ventricular tachycardia in man. Arch Intern Med 135:473-479,1975a.

Wellens $\mathrm{H} J \mathrm{~J}$ : Contribution of cardiac pacing to our understanding of the Wolff-Parkinson-White syndrome. Br Heart J 37:231-241, 1975b.

Wellens HJJ, Durrer $\mathrm{D}$ : The role of an accessory atrioventricular pathway in reciprocal tachycardia. Circulation 52:58-72,1975c.

Wellens $\mathrm{HJJ}$, Durrer $\mathrm{D}$, Lle KI. Observations on mechanisms of ventricular tachycardia in man. Circulation 54:237-244, 1976.

Wellens HJJ: Value and limitations of programmed electrical stimulation of the heart in the study and treatment of tachycardlas. Circulation 57:845-853, 1978.

Wellens HJJ, Farre J, Bar FW: The Wolff-Parkinson-White syndrome. In: Cardlac Arrhythmlas. Their Mechanisms, Dlagnosis and Management. Ed: Mandel. JB Lippincott, Philadelphla, 1980.

Wellens $\mathrm{HJJ}$, Brugada P: Value of programmed stimulation of the heart in patients with the Wolff-Parkinson-White syndrome. In: Tachycardlas-Mechanisms, diagnosis and treatment. Ed: Josephson ME, Wellens HJJ. Lea and Febiger, Philadelphia, 1984.

Wiggers CJ: Defibrillation of the ventricles. Editorial. Circ Res 1: 191-199, 1953.

Wit AL, Allessie MA, Bonke FIM, Lammers WJEP, Smeets JILRM, Fenoglio Jr JJ: Electrophysiologic mapping to determine the mechanism of experimental ventricular tachycardia initiated by premature impulses. Experimental approach and initial results demonstrating reentrant excitation. Am J Card 49:166-185,1982.

Wit AL, Dillon S, Ursell PC: Influences of anisotropic tissue structure on reentrant ventricular tachycardla. In:Cardiac Arrhythmias: Where to go from here. Edited by Brugada P, Wellens HJJ, Mount Kisco, NY, Futura Publishing Company, 1987.

Wojtczak J: Contractures and increase in internal longitudinal resistance of cow ventricular muscle induced by hypoxia. Circ Res 44:88-95,1979. 
Woodburry JW , Crill WE: On the problem of impulse conduction in the atrium. In: Nervous Inhibition, edited by E. Florey. New York: Pergamon, 1961, p. 124-135.

Zipes DP, Mihalick MJ, Robbins GT: Effects of selective vagal and stellate ganglion stimulation on atrial refractoriness. Cardiovasc Res 8:647-655, 1974. 


\section{SUMMARY}

The aim of the study presented in this thesis was to investigate the role of tissue anisotropy on conduction and conduction disturbances in the Langendorff perfused rabbit left ventricle.

In chapter one, a short introduction concerning impulse conduction and conduction disturbances is given. The possible role of tissue anisotropy in the pathogenesis of reentrant arrhythmias is discussed and the varlous electrophysiological parameters involved in the initiation of cardiac arrhythmlas are evaluated.

In chapter two the effects of heart rate, premature beats, potasslum, temperature, epinephrine and lidocaine an conduction velocity, refractory period, and the wavelength of the cardiac impulse are described. Due to the anisotropic morphology of the left ventricle, conduction velocity of the cardlac impulse depends on the direction of impulse propagation. Parallel to the fiber direction, impulse conduction is about three times faster than perpendicular to the fiber direction. Consequently the wavelength of refractoriness depends on the direction of impulse propagation. The degree of anisotropy (the ratio between the longitudinal and tranverse conduction velocity) may vary from less than 1.5 (during high extracellular potassium) to more than 3.4 (during cooling). However in the intact rabbit ventricle it is difficult to correlate the wavelength with the risk of the initiation of reentrant arrhythmias. This is due to the fact, that the three dimensional architecture of the ventricles effectively counteracts the arrhythmogenic effects of slow transverse conduction.

To study the effects of tissue anisotropy on conduction of the cardiac impulse a new experimental model of anisotropy was developed to create a thin epicardial layer of normal ventricular myocardium (chapter three). A Langendorff perfused rabbit heart was immersed in a warm tissue bath and a cryoprobe inserted in the left ventricular cavity. By endocardial freezing the total interventricular septum and $4 / 5$ th of the free wall of the left ventricle were destructed. Only a $1 \mathrm{~mm}$ thick eplcardial layer, protected by the warm perfusion fluid in the surrounding tissue bath, survived. This survlving layer of epicardium showed the same electrophysiologic properties as before freezing, both refractory periods and conduction velocity being the same as during control. Epicardial conduction was mapped with a 192 fold mapping electrode (Spatial resolution $1 \mathrm{~mm}$ ). It was found that in the intact ventricle slow transverse conduction 
was interrupted within 3-4 mm from the site of stimulation by epicardial breakthrough from a faster propagating intramural wavefront. However in the thin epicardial layer slow transverse conduction could proceed undisturbed resulting in an extension of the area of effective anisotropy. Longltudinal and transverse conduction were studied during high extracellular potassium, induction of premature beats and rapid pacing. Under all these circumstances local conduction block occurred more readily in a transverse direction than in a longitudinal direction. However, although arcs of transverse conduction block occurred more frequently, they rarely led to intramyocardial reentry because the tissue distal to the line of conduction block was activated with little delay by fast longitudinal propagation. In contrast, the area distal to a longitudinal block was activated with more delay by a slow transwerse wavefront, creating a higher chance of reentry of the fibers proximal to the line of block. Induction of intramyocardlal reentry by (multiple) premature beats or rapid pacing resulted in eplsodes of sustained monomorphic ventricular tachycardia. This led to the conclusion that the removal of the subepicardlum enlarges the effective area of anisotropy in the overlying epicardium facilitating the induction and perpetuation of reentrant ventricular tachycardia.

In chapter four, the characteristics and mechanisms of sustained ventricular tachycardias initiated in the two dimensional model of anisotropy are presented. The tachycardias could be initiated by either incremental pacing or programmed electrical stimulation, aplying upto three shortly coupled premature beats. From the reconstructed epicardlal actlvation maps it became clear that the tachycardias were caused by circusmovement excitation, during which the impulse was circulating around a long. functionally determined line of conduction block which was orientated parallel to the epicardlal fiber direction. Desplte the fact that the line of block was functionally determined, an excitable gap was present. Due to the presence of an excitable gap tachycardias were stable and longlasting.

In chapter five the effects of enhanced tissue anisotropy on conduction disturbances and reentrant ventricular tachycardlas is discussed. The characteristics of "antsotropic" reentry "as a new type of circusmovement, are summarlized and compared with the properties of anatomically determined reentrant excitation and leading circle reentry. The possible mechanisms of the creation of an excitable gap during "anisotropic" reentry are analysed and the preliminary results of a computer simulation study are presented. Furthermore, the possible clinical significance of "anisotropic" reentry 
as a mechanism of sustained ventricular tachycardia in the healing phase after a myocardial infarction in patients is discussed.

We conclude that:

1. The three dimensional geometry of the ventricles prevents the initiation of reentrant arrhythmias in the intact heart.

2. Enhanced tissue anisotropy facilitates the induction of reentrant ventricular arrhythmias.

3. "Anisotropic" reentry may be a likely mechanism of sustained ventricular tachycardia in the healing phase after a myocardlal infarction.

4. The two dimensional model of anisotropy, presented in this thesis, is a useful tool to study the mechanisms of ventricular tachycardlas and to evaluate the effects of antlarrhythmic drugs. 
- 140 - 


\section{SAMENVATTING}

Afwijkingen van het normale slagritme van het hart kunnen verschillende consequenties hebben, varierend van een slechts minimaal verminderde pompfunctie tijdens extrasystoles tot een volledig falen van de pompfunctie tijdens kamerfibrilleren, leidend tot acute hartdood.

In het gezonde hart, wordt ongeveer 70 maal per minuut een electrische impuls gevormd door de cellen in de sinusknoop. Deze impuls verspreidt zich snel over de beide boezems en bereikt na een fractie van een seconde de atrioventriculaire knoop gelegen op de scheiding tussen boezems en ventrikels. Na een geleidingsvertraging in deze structuur versnelt de impuls weer en verspreidt zich via een speciaal geleidingssysteem (het Purkinje systeem) snel over beide kamers, waarna de kamercellen worden bereikt. Na electrische prikkeling van de kamercellen zullen deze min of meer synchroon samen trekken. De volgorde van activatie en contractle van de kamercellen is van belang voor een normale pompfunctie. Er ziln echter verschillende zlektebeelden waarbij de normale impulsgeleiding gestoord is en de pompfunctie van het hart is verminderd. Met name na een myocardinfarct wanneer een deel van de hartspier is afgestorven kan dit leiden tot ernstige afwijkingen van het normale hartritme.

Hartritmestoornissen kunnen worden veroorzaakt door drie verschillendle mechanismen; 1 . Aritmieën veroorzaakt door abnormale impulsvormingl, 2. Aritmleën veroorzaakt door abnormale impulsgeleiding, 3. Aritmieën veroorzaakt door een combinatie van abnormale impulsgeleiding en impulsformatie.

In dit proefschrift worden de eigenschappen bestudeerd van aritmleën dle veroorzaakt worden door abnormale impulsgeleiding.

Abnormale impulsgeleiding in het kamermyocard kan, indien geleidingsblok optreedt In een richting en de impuls traag geleid wordt in de andere richting, leiden tot ritmestoornissen, waarbil de impuls "gevangen" raakt in een cirkelvormig activatiepad. Alhoewel locaal geleidingsblok en trage geleiding kunnen optreden als gevolg van locale verschillen in prikkelbaarheild van de cellen, blijkt uit recente studies, dat deze geleidingsstoornissen ook kunnen optreden als gevolg van verschillen In geleidingselgenschappen afhankelijk van de richting van impulsgelelding. In tegenstelling tot in de boezems, zijn de cellen in de ventrikels min of meer parallel aan elkaar gerangschikt. De cellen zijn aan elkaar gekoppeld door middel van een aantal "weer- 
stands"- bruggen. Omdat hartsplercellen langer zijn dan breed, worden er veel meer "weerstands"- bruggen in de dwarse richting gevonden. Als gevolg hiervan, is de weerstand dwars op de vezelrichting een factor 9-11 hoger dan de weerstand parallel aan de vezelrichting. Omdat de geleidingssnelheid van de impuls omgekeerd evenredig is aan de wortel van de weerstand, is de geleidingssnelheid parallel aan de vezelrichting ongeveer 3 maal zo snel als de geleldingssnelheid in transversale richting (Anisotrople). Gelelidingsnelheld, refractaire periode, en de golflengte van de impuls ziljn belangrilike electrofyslologlsche parameters, die de gevoeligheld van het myocard voor het optreden van hartritmestoornissen gebaseerd op cirkel gelelding bepalen.

In hoofdstuk twee wordt het effect van weefselanisotropie op deze parameters en de effecten van snel drijven, extrasystoles, hoog kalium, hypothermie, adrenaline en lidocaine beschreven. Het was echter nlet mogelljk de kans op het optreden van ritmestoornissen te correleren met bovengenoemde parameters omdat het in het intacte geperfundeerde konijnenhart zeer moeilijk was om hartritmestoornissen op te wekken. Alleen na langdurige, zeer snelle electrische stimulatie onstond kamerfibrilleren. Daarnaast werden betrouwbare epicardiale metingen gecompliceerd door de driedimensionale geometrle van de linker kamer en bleek dat de aritmogene effecten van trage transverale impulsgelelding worden gemaskeerd door snelle impulsgelelding via intramurale- en endocardiale splerlagen.

Een nieuw biologisch model, ontwikkeld om deze problemen op te lossen, wordt gepresenteerd in hoofdstuk drie. Het, volgens de Langendorff techniek geperfundeerde, konijnenhart werd in een verwarmd weefselbakje geplaatst. Door middel van een in de linkerkamer geplaatste cryoprobe werd het totale intraventriculaire septum en 4/5-de deell van de binnenzijde van de linker kamer doodgevroren. Slechts een 1 $\mathrm{mm}$ dikke eplcardlale laag overleefde deze procedure. Na vriezen waren de electrofyslologische eigenschappen van dit overlevende laagje onveranderd: de refractaire perlode en de geleidingssnelheid waren nlet verschillend van de waarden gemeten tijdens controle omstandigheden in het Intacte hart. De epicardiale geleiding werd gemeten met een "mapping" electrode bestaande uit 192 verschillendle electrodes, met een spatiele resolutie van $1 \mathrm{~mm}$. In de intacte ventrikel werd langzame transversale gelelding op een afstand van 3-4 mm van de eplcardiale prikkel plaats onderbroken door snelle intramurale- en endocardiale impulsgeleiding. In de dunne overlevende epicardiale schil echter was de effectleve anisotropie toegenomen omdat langzame transversale geleiding niet meer werd onderbroken door een snelle impulsgelelding in 
diepere lagen. In dit model werd de invloed van hoge concentraties extracellulair kalium, snelle ellectrische stimulatle en extra-systoles op geleiding bestudeerd. Het bleek dat onder alle omstandigheden van verminderde effectiviteit van de impuls geleidingsblok eerst optrad tijdens trage transversale impulsgeleiding. Abnormale impulsgeleiding in deze gebieden kon aanlelding geven tot ritmestoornissen gebaseerd op cirkelgeleiding van de electrische impuls.

De eigenschappen van deze clirkeltachycardleën, opgewekt in het tweedimensionale model van de linker kamer, worden beschreven in hoofdstuk vier.

In hoofdstuk vijf worden de eigenschappen van "anisotrope" reentry vergeleken met cirkeltachycardieën waarbij] de impuls draalt rondom een anatomisch obstakel of rondom een functioneel blokgebied in isotroop weefsel. Voorts worden de cirkeltachycardieën, opgewekt in dit experimentele model, vergeleken met kamertachycardleën die optreden in de genezingsfase van een myocardinfarct.

Uit de experimentele resultaten beschreven in dit proefschrift blijkt dat:

1. De driedimensionale structuur van de hartkamers een efficiente bescherming bledt tegen het ontstaan van cirkeltachycardieën in het gezonde myocard.

2. De toename van weefselanisotropie na een myocardinfarct een belangrlj|ke rol kan spelen bij het optreden van kamerritmestoornissen.

3. Anisotrope reentry een belangrijk mechanisme is voor het ontstaan van kamertachycardieën in de herstelfase van een myocardinfarct.

4. Het door ons ontwikkelde, tweedimensionale, modell van de linker kamer een nuttig hulpmiddel kan zijn blj het onderzoek naar geleldingsstoornlssen en mechanismen van cirkeltachycardieën in het kamermyocard. 
$-144$. 


\section{NAWOORD}

Indien je na een treinreis, van voor Nederlandse begrippen ongekend lange duur. eindelijk in Maastricht aankomt en je na enig zoeken het blomedisch centrum binnenkomt, om je vervolgens voor ongeveer vier jaar in een avontuur met onbekende afloop te storten, weet je niet wat er vast zit aan "Een paar jaar onderzoek lijkt me wel leuk". Ik kijk echter met veel plezler op deze periode terug en ben prof. Allessie en prof. Bonke dan ook dankbaar dat zij mij deze kans gegeven hebben.

De vrijheid binnen het werk en de mogelijkheid om "leuke" dingen te doen, met de zekerheid dat je altijd op Maurits en Vlc terug kon vallen was lets geweldlgs. De wljze waarop Maurits het onderzoek begeleidde was voor sommigen misschien nilet altijd even begrijpelijk, maar als je daar eenmaal aan gewend was geraakt toch geweldig stimulerend. Beste Maurits, hartelijk dank daarvoor. De dlscussies onder het genot van een Javaanse jongen en een grote gele, zal lk niet licht vergeten en zeker missen. Dat Vic na enige tijd rector werd, mocht hem er nlet van weerhouden ons werk critlsch te volgen. Uit de wilze waarop je het manuscript beoordeeld hebt, blijkt dat je betrokkenheid bij de electrofyslologle nlet geleden heeft onder de lusten en lasten van het besturen.

Naast Maurits en Vic waren er nog een aantal mensen dle van essentleel belang zijjn geweest voor het tot stand komen van dit proefschrift.

Prof. Reneman, beste Rob, de manler waarop Jil al gedurende vele Jaren de vakgroep fysiologie leidt, kan alleen maar tot voorbeeld strekken voor ledereen en heeft geleld tot een min of meer hechte groep mensen waarmee het goed samenwerken Is.

Het feit dat mijn cardlologie opleider prof. Bruschke het mogelljk maakte om zonder zorgen voor de toekomst rustlg aan dit onderzoek te kunnen werken speelde zeker een belangrijke rol, daarvoor mljn hartelijke dank.

De recente samenwerking met Frans van Capelle, waarvan de eerste resultaten In hoofdstuk vijf van dit proefschrift zljn beschreven, heeft geleld tot een nieuwe lljn van onderzoek die veelbelovend lijkt te zijn. Het was dan ook een groot genoegen dat je het manuscript wilde beoordelen.

De samenwerking met Prof. Wit op het gebied van de ventriculaire tachycardieën was stimulerend en, beste Andy, het is dan ook een eer voor mil dat je aanwezig kunt zijn op mijn promatie. 
Misschien wel het belangrijkste voor het op tijd klaar komen van dit proefschrift, was de goede sfeer op het laboratorlum waarbj] het niet zelden voorkwam, dat op de meest vreemde momenten iedereen aanwezig was. De tomeloze inzet van Wim Lammers, Wieke Rensma en in het billzonder Charles Kirchhof droegen ten zeerste bij aan de goede onderlinge verstandhouding. Beste Wim, het was gezellig samen paffen in ons rommelhok. Daarnaast was je een uitstekende steun voor schijnbaar onoplosbare computerproblemen. "Natamanna Laka Al Nagah al Souroer wa Fie Al-Ain". Wieke, min of meer mijn voorganger, heeft naast het werk ook nog bijgedragen aan een snelle introductie in Maastricht, waarbi] het geboden gastvrije onderdak en de donderdagavond uitstapjes zorgden voor een goede afleiding en acclimatisering. Charles, het enthousiasme en de inzet waarmee lij werkt zijn onvoorstelbaar en werkten zeker aanstekelljk op de rest van de groep, dat je daarnaast ook nog een groots onderzoeker gaat worden is wel haast zeker. Laten we toch maar proberen om ASCEM van de grond te krijgen. Niet nodig om te zeggen dat het een genoegen is om je als paranymf aan miljn zijde te treffen.Lucas Boersma, beste paranymf, je hebt je min of meer op dezelfde manier aan het onderzoek gebonden en een substantiele bijdrage geleverd aan het tot stand komen van dit proefschrift.

Erlk Musch en Maya Huyberts hebben een bijdrage geleverd aan het tot stand komen van de hoofstukken twee en vijf, daarvoor dank.

Jan Hollen, technisch onmisbaar voor het goede verloop van de experimenten. Daarnaast alt|ljd paraat als er weer eens wat problemen aan de Saab waren. Het was plezlerig om met je samen te werken. Frits Schmltz en Henk Jas waren op de achtergrond altljd aanwezilg om problemen op te lossen of om de nodige bleren achterover te slaan en natuurlijk mede verantwoordelijk voor de goede sfeer op het laboratorium. Met name Henk heeft de uitelndelijke layout van dit boekwerk bepaald, waarbij hil een mate van nauwkeurigheld aan de dag legde, dle verbazingwekkend was voor wie zijn kamer kent.

Het secretariaat, ook in deze tijd nog steeds onmisbaar bij het tijdilg klaar krljgen van manuscripten en verantwoordelijk voor de goede gang van zaken binnen de vakgroep. Met name Luclenne de Boer vervulde daarin een grote rol samen met Karin van Brussel, Jos Heemskerk en Emmy van Roosmalen.

De mensen van de Instrumentele dienst hebben door hun grote technische vaardigheden en mogelljkheden een belangrijke bijgedrage geleverd aan het fabriceren van 
de Langendorff opstelling en het maken van de electroden mallen. Met name Caspar, Huub, Theo en Chris hartelljk dank.

De leden van de beoordelings commissle, Prof. Dr. H.J.J. Wellens, Prof. Dr. H.A.J. Struyker Boudier, Dr. F.J.L. van Capelle, Prof. Dr. A.L. Wit en Prof. Dr. Ir. A. Hasman, hebben met een grondige en kritische beoordeling een bijdrage geleverd aan het ulteindelijke resultaat. $\mathrm{k}$ wil hen daarvoor bedanken.

In een nawoord worden natuurlijk altijd mensen vergeten, Jacques Lambrechts en Rinus Alewijnse bljvoorbeeld, mijn kamer genoten in de eerste jaren, die altijd bereld waren om weer naar een nieuw somber verhaal te luisteren.

Last but not least wil lik graag Nicoline en mijn ouders bedanken. Nicoline voor het geduld wat zij met name in de laatste periode op moest brengen, het "blijna klaar" gedurende meer dan een half jaar stelde je wel wat veel op de proef. Daarnaast heb je altijd meegeholpen met het op de meest onmogelijke momenten klaar maken van weer een set nleuwe figuren of teksten.

Jan en Dlet hebben mij gedurende mijn gehele oplelding tot arts en daarna ook nog altijd alle mogelijkheden gegeven om op hun kosten en met hun steun door te gaan ook al leek het soms wel eens niet zo heel erg snel te gaan daarvoor mijn hartelljke dank.

Tot slot nog een opmerking over het werken op Het laboratorium electrofysiologie, leuke dingen duren altijd te kort en zo hoort het ook, in de toekomst hoop ik het contact met de groep niet helemaal te verliezen. 
$-148-$ 


\section{Curriculum Vitae}

Martin Jan Schalij

1958: $\quad$ Geboren te Haarlem

1970-1976: $\quad$ V.W.O. B, Ichtus College, Drachten en Rijks Scholen Gemeenschap, Harderwi|k

1976-1984: Studie Geneeskunde Rijksuniversiteit Utrecht

Juli 1984: $\quad$ Artsexamen

1984-1988: $\quad$ Tijdelijk wetenschappelijk medewerker bilj de vakgroep Fysiologie, Rilkksuniversiteit Limburg (Hoofd: Prof. Dr. R.S. Reneman)

1988-heden: Opleiling Cardiologie, Academlsch Zlekenhuis Lelden, Rijksuniversiteit Leiden

(Hoofd: Prof. Dr. A.V.G. Bruschke) 